INSTITUTO DE PESQUISAS ENERGÉTICAS E NUCLEARES

AUTARQUIA ASSOCIADA À UNIVERSIDADE DE SÃO PAULO

Desenvolvimento de cerâmicas porosas

à base de Nitreto de Silício

RODRIGO MENDES MESQUITA

Dissertação apresentada como parte dos requisitos para a obtenção do Grau de Mestre em Ciências na Área de Tecnologia Nuclear - Materiais

Orientador: Dr. Luis A. Genova

São Paulo 


\section{DEDICATÓRIA}

À minha avó, que me

apoiou incondicionalmente em todos os momentos, me dando o carinho de uma mãe. 


\section{AGRADECIMENTOS}

Ao Instituto de Pesquisas Energéticas e Nucleares, pela oportunidade de desenvolver este trabalho, pelo rico ambiente acadêmico, e pelo conhecimento adquirido;

Inicialmente a minha família, em especial a minha avó, pois sem seu carinho e apoio meu desenvolvimento acadêmico teria parado;

Ao Dr. Luís Antônio Genova, pela orientação e por me auxiliar no desenvolvimento do tema;

A Dra. Ana Helena Bressiani pelo apoio e pelas diversas contribuições;

Ao meu grande amigo Rodrigo Alves de Souza, pela amizade e companheirismo;

A minha grande amiga Suelanny Carvalho da Silva, pela amizade, carinho e apoio, e por estar sempre por perto quando necessário;

A minha grande amiga Karolina Pereira dos Santos Tonello, pela amizade, e carinho durante todos estes anos;

A minha amada noiva Soraia Mariana de Souza por seu carinho e amor incondicional que me deram forças para continuar prosseguindo com o projeto;

Ao Éliner, Cris, Deby, Tamie, Pedro, René, Celso e Nildemar pelo apoio e amizade;

Ao CNPq, cujo auxílio por meio da bolsa, permitiu que eu continuasse meus estudos 


\title{
Desenvolvimento de cerâmicas porosas à base de Nitreto de Silício
}

\author{
RODRIGO MENDES MESQUITA
}

\begin{abstract}
Resumo
Cerâmicas porosas à base de nitreto de silício vêm sendo amplamente estudadas por possibilitarem a obtenção de corpos que aliam porosidade e resistência mecânica. Isto se deve, principalmente ao característico mecanismo de reforço in-situ que o material apresenta, obtido com o crescimento anisotrópico de grãos de $\mathrm{Si}_{3} \mathrm{~N}_{4}$. Neste estudo foram obtidos corpos de $\mathrm{Si}_{3} \mathrm{~N}_{4}$ com diferentes porosidades (percentual, distribuição de tamanhos, etc.), por três técnicas diferentes: gel-casting de espumas com diferentes gelificantes (albumina, ágar e gelatina), gel-casting com amido e fase sacrificial com amido. As técnicas de obtenção de cerâmicas porosas por gel-casting de espuma, utilizando ágar, gelatina ou albumina como agentes gelificantes gerou muitos resultados, produzindo alterações em termos de estrutura de poros desenvolvida (ampla faixa de porosidade e de tamanho de poros), mas devido às dificuldades encontradas para um rígido controle do processamento (estabilização e reprodutibilidade da estrutura de bolhas) e consequentemente dos corpos obtidos, o tema foi desenvolvido apenas parcialmente. Com a utilização da técnica gel-casting com amido, as amostras produzidas apresentaram maior reprodutibilidade, sendo que a porosidade obtida variou de acordo com o amido empregado: com a utilização do amido de arroz obteve-se a menor porosidade (entre 17,4\% e 20,8\%), enquanto com o amido de batata atingiu-se a maior porosidade (entre $23 \%$ e $36 \%$ ) e com o amido de milho, chegou-se a valores intermediários de porosidade (entre $18,9 \%$ e $28,1 \%$ ). As amostras obtidas foram sinterizadas a $1800{ }^{\circ} \mathrm{C}$ e caracterizadas quanto à porosidade aparente, microestrutura e resistência mecânica por ensaio de compressão, podendo-se relacionar a porosidade e o tipo
\end{abstract}


de amido adicionado com a resistência mecânica. Utilizando-se a técnica da fase sacrificial, adicionou-se à matriz de nitreto de silício diferentes tipos de amido (de arroz, de milho ou de batata), em diferentes percentuais (20, 30 e $40 \%$ em volume), sendo as amostras obtidas sinterizadas sob diferentes temperaturas e tempos. Estas amostras foram caracterizadas de modo semelhante às descritas anteriormente, podendo-se relacionar a porosidade e tratamento térmico com a resistência mecânica. Os resultados obtidos com as amostras com o amido usando as duas técnicas foram comparados, permitindo-se concluir que as amostras obtidas por gel-casting apresentam maior resistência mecânica quando comparadas a amostras com porosidade semelhante, produzidas por fase sacrificial. 


\title{
Development of Porous Silicon Nitride-Based
}

\section{Ceramics}

\author{
Rodrigo Mendes Mesquita
}

\begin{abstract}
Porous silicon nitride based-ceramics have been widely studied by the combination of mechanical strength and porosity. This is due mainly by the characteristic mechanism of in-situ reinforcement obtained with the anisotropic grain growth of $\mathrm{Si}_{3} \mathrm{~N}_{4}$. In this study were obtained bodies of $\mathrm{Si}_{3} \mathrm{~N}_{4}$ with different porosities (amount, pore size distribution, etc.) using three different techniques: gel-casting foams with different gelling agents (albumin, gelatin and agar), gelcasting with starch as gelling agent, and sacrificial phase with starch as fugitive additive. The techniques of obtaining porous ceramics by gel-casting foams, using agar, gelatin or albumin as gelling agent had interesting results and is versatile in terms of the structure of pore developed (broad range of porosity and pore size), but due to difficulties in the processing control (stabilization and reproducibility of the bubbles structure) and thus in the characteristics of the obtained bodies, the issue was only partially developed. With the use of gel-casting technique with starch, the samples produced showed higher reproducibility, and the porosity obtained varied with the starch employed: with the use of rice starch was obtained the lowest porosity (between $17.4 \%$ and $20.8 \%$ ), while with potato starch was reached higher porosity (between 23\% and 36\%) and with corn starch reached to intermediate values of porosity (between $18.9 \%$ and $28.1 \%$ ). The samples were sintered at $1800^{\circ} \mathrm{C}$ and characterized by apparent porosity measurement, microstructure and mechanical strength by compression test, relating the porosity and type of starch with mechanical strength. Another method used to produce porous silicon nitride was the technique of sacrificial phase with different types of starch (rice, maize or potato) added to the matrix of silicon nitride in different amounts (20, 30 and $40 \%$ in volume). The samples obtained were sintered under different temperatures and times, and the obtained samples were characterized in a similar manner to those described above. It was possible to relate to porosity
\end{abstract}


and heat treatment with mechanical strength. The results obtained with the samples produced with the starch using the two techniques were compared allowing concluding that the samples obtained by gel-casting have greater strength when compared to samples with similar porosity produced by sacrificial phase. 


\section{SUMÁRIO}

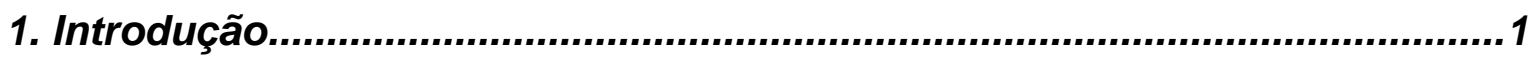

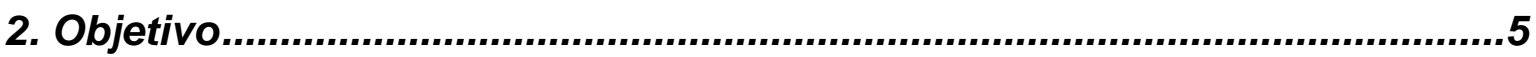

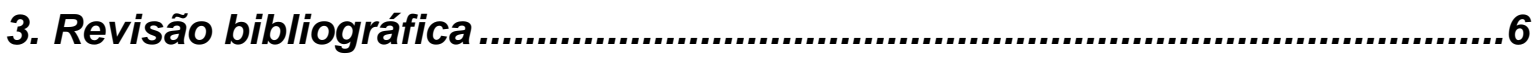

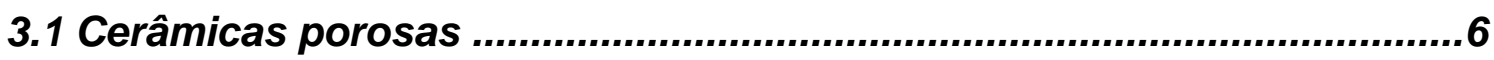

3.2 Métodos de produção de cerâmicas porosas.......................................8

3.3.1 Método da réplica: .........................................................................9

3.3.2 Método da fase sacrificial ..............................................................11

3.3.3 Método do Gel-casting de espumas.............................................12

3.3.3.1 Utilização de albumina como gelificante ....................................17

3.3.3.2 Utilização de amido como gelificante .........................................18

3.4 Propriedades Mecânicas e sua relação com a porosidade .....................21

3.5 Produção de cerâmicas porosas à base de nitreto de silício.................25

4. Materiais e Métodos ....................................................................................30

4.1 Gel-casting utilizando-se amido como gelificante ............................... 31

4.2 Obtenção de corpos porosos pelo método da fase sacrificial

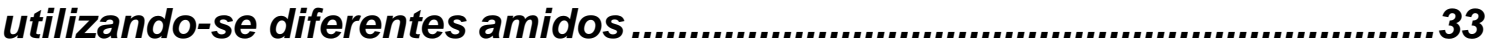

4.3 Gel-casting de espumas utilizando-se albumina, a gelatina ou ágar

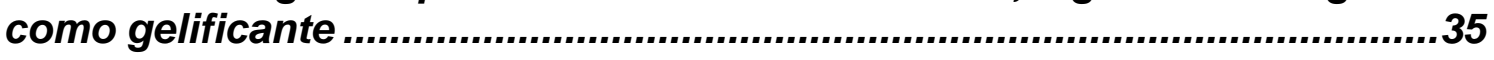

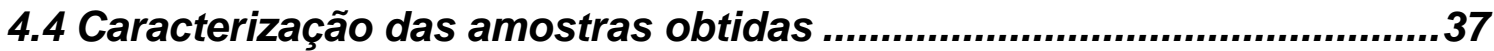

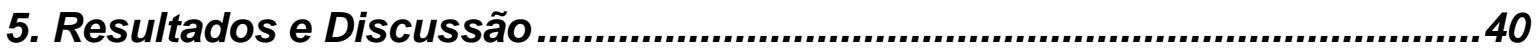

5.1 Produção de amostras pelo método gel-casting .................................40

5.2 Amostras obtidas pelo método gel-casting utilizando-se amido..........47

5.3 Amido como fase sacrificial .................................................................58

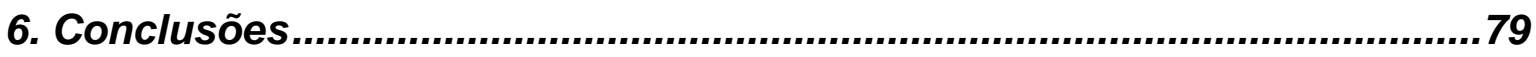

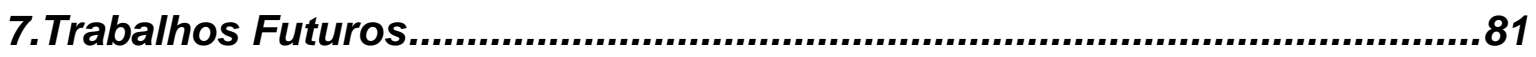

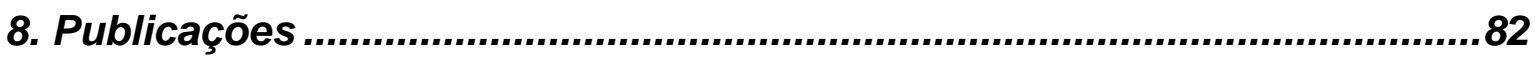

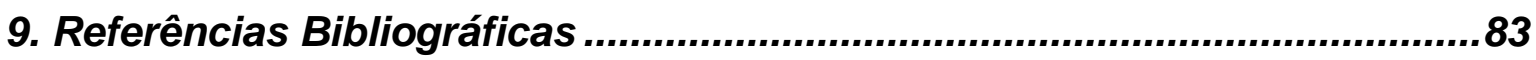




\section{ÍNDICE DE FIGURAS}

Figura 3.1: Diagrama da classificação de materiais porosos proposta por KELLY. [4]

Figura 3.2: Estruturas obtidas pela técnica da réplica, ambas de $\mathrm{Al}_{2} \mathrm{O}_{3}$, (a) a partir da esponja polimérica e (b) e partir do pinheiro. ${ }^{[12]}$

Figura 3.3: Estrutura obtida pelo método da fase sacrificial. Cerâmica de $\beta$-fosfato tricálcico cujos poros foram originados de eliminação de esferas de PMMA........12

Figura 3.4: Estrutura porosa de uma alumina obtida por gel-casting de espumas, sendo, neste caso foi utilizada como agente gelificante albumina. ${ }^{[32]}$ 14

Figura 3.5: Fenômeno do escoamento, F simboliza o sentido do fluxo das bolhas, e a imagem ampliada mostra detalhes das células poliédricas. ${ }^{[6]}$.... 14

Figura 3.6: Representação esquemática do processo de coalescência e do efeito de surfactantes. ${ }^{[6]}$

Figura 3.7: Comparação do efeito de surfactantes e de partículas coloidais na estabilização de espumas. Em (a) é mostrada uma espuma estabilizada com um surfactante após 4 horas de repouso, enquanto em (b) a espuma contendo partículas coloidais se mostra bem mais estabilizada, mesmo por períodos bem mais longos (4 dias). ${ }^{[6]}$ 16

Figura 3.8: Estrutura molecular do amido. ${ }^{[46]}$ 19

Figura 3.9: Exemplo de estrutura de alumina porosa obtida por gel-casting com amido de batata. ${ }^{[45]}$ 20

Figura 3.10: Exemplo de métodos de produção de cerâmicas porosas. ${ }^{[6]}$ 21

Figura 3.11: Desenho mostrando a ruptura de uma célula aberta similar a dos poros abertos. $^{[55]}$

Figura 3.12: Esquema de transformação de fases $\alpha \rightarrow \beta$.do nitreto de silício ${ }^{[11]} \ldots 26$

Figura 3.13: Esquema indicando os principais mecanismos de tenacificação que podem ocorrer em cerâmicas estruturais. ${ }^{[71]}$.

Figura 3.14: Micrografia demonstrando o mecanismo de tenacificação em ação. ${ }^{[71]}$ 
Figura 4.1: Processamento das amostras por gel-casting com amido.

Figura 4.2: Processamento das amostras por fase sacrificial com amido.

Figura 4.3: Processamento das amostras por gel-casting de espumas com albumina.

Figura 5.1: Efeito do tratamento de oxidação superficial do pó nas características reológicas de suspensões aquosas de $\mathrm{Si}_{3} \mathrm{~N}_{4}$.

Figura 5.2: Efeito da oxidação superficial das partículas de $\mathrm{Si}_{3} \mathrm{~N}_{4}$ na viscosidade de suspensões aquosas contendo diferentes teores de sólido.

Figura 5.3: Estruturas porosas obtidas a partir de suspensões contendo LSS/glicerina, por aeração mecânica com diferentes hastes: (a) haste planetária (amostra 1), (b) haste 4 pás (amostra 2).

Figura 5.4: Estruturas porosas obtidas a partir de suspensões contendo albumina, por aeração mecânica com diferentes hastes: (a) haste planetária (amostra 3), (b) haste 4 pás (amostra 4). .................................................................. 44

Figura 5.5: Hastes utilizadas para os teste, 4 pás (a) e planetária (b). .44

Figura 5.6: Distribuição de poros obtida por porosimetria de $\mathrm{Hg}$ para as amostras descritas na tabela 5.1 . 45

Figura 5.7: Estruturas porosas obtidas com diferentes gelificantes; (a) agar, (b) albumina. 46

Figura 5.8: Exemplo de uma estrutura porosa de nitreto de silício da amostra na qual se utiliza ágar como gelificante, mostrando os grãos crescidos anisotropicamente, formando uma estrutura reforçada pelo entrelaçamento destes grãos. 47

Figura 5.9: Distribuição de tamanho de partículas de cada um dos amidos. 48

Figura 5.10: Densidade relativa (a) e porosidade aparente (b) das amostras obtidas por gel-casting, com diferentes amidos e percentuais de sólido na suspensão.

Figura 5.11: Micrografias das amostras produzidas via gel-casting com adição de $30 \%$ em volume de amido de milho: (a) suspensão contendo $50 \%$ de sólido e (b) suspensão contendo $55 \%$ de sólido. 
Figura 5.12: Micrografias das amostras produzidas viam gel-casting com amido de milho com suspensões contendo $50 \%$ de sólido. As diferentes percentagens em volume de amido adicionado, $20 \% \mathrm{em}$ (a), 30\% em (b) e $40 \% \mathrm{em}$ (c) deram origem a cerâmicas com porosidade aparente de 21,4\%, 26,9\% e 28,1\% respectivamente.

Figura 5.13: Micrografia das amostras produzidas via gel-casting utilizando-se como agente gelificante o amido de milho (a) e de batata (b); para estes exemplos, as suspensões contêm $50 \%$ de sólidos e $40 \%$ em volume de amido..55

Figura 5.14: Defeito em amostra produzida via gel-casting com amido de milho; neste caso a suspensão continha $50 \%$ de sólidos e $20 \%$ de amido em volume. .56

Figura 5.15: Relação do módulo de ruptura à compressão versus porosidade das amostras obtidas por gel-casting utilizando diferentes amidos e a partir de suspensões com diferentes percentuais de sólido.

Figura 5.16: Relação entre a retração volumétrica e o percentual de amido adicionado a matriz cerâmica. 61

Figura 5.17: Relação entre densidade a verde e amido adicionado à matriz cerâmica. 63

Figura 5.18: Relação entre perda de massa e adição de amido(\% em peso), para os amidos de arroz (a), milho (b) e batata (c). A linha tracejada nos gráficos indica qual a perda referente apenas ao amido adicionado.

Figura 5.19: Porosidade aparente e densidade aparente versus percentual de amido para amostras porosas de $\mathrm{Si}_{3} \mathrm{~N}_{4}$ obtidas por fase sacrificial, e sinterizadas sob diferentes tratamentos térmicos. Em (a) amido de arroz, em (b) amido de milho e em (c) amido de batata 68

Figura 5.20: Porosidade aparente versus fração volumétrica de amido adicionado para amostras porosas de $\mathrm{Si}_{3} \mathrm{~N}_{4}$ obtidas por fase sacrificial, e sinterizadas sob diferentes tratamentos térmicos.

Figura 5.21: Amostras porosas de $\mathrm{Si}_{3} \mathrm{~N}_{4}$ obtidas com a adição de $20 \%$ (a), $30 \%$ (b) e $40 \%$ (c) de amido de arroz, sinterizadas a $1800^{\circ} \mathrm{C}$ por 1 hora. 70

Figura 5.22: Detalhes da estrutura de poros de amostra obtida com a adição de $30 \%$ de amido de arroz, sinterizada a $1800^{\circ} \mathrm{C}$ por 1 hora. 
Figura 5.23: Difratogramas de raios-x das amostras, porosas de $\mathrm{Si}_{3} \mathrm{~N}_{4}$ sinterizadas sob diferentes condições.

Figura 5.24: Parte do difratograma de raios $X$ indicando os picos relacionados à equação de Yeheskel e Gefen.

Figura 5.25: Módulo de ruptura versus porosidade aparente para amostras processadas com amido de arroz submetidas a diferentes tratamentos térmicos.

Figura 5.26: Módulo de ruptura versus porosidade aparente para amostras processadas com amido de milho submetidas a diferentes tratamentos térmicos.

Figura 5.27: Módulo de ruptura versus porosidade aparente para amostras processadas com amido de batata submetidas a diferentes tratamentos térmicos.

Figura 5.28: Relação do módulo de ruptura versus porosidade das amostras processadas com amidos de arroz, batata e milho e submetidas a diferentes

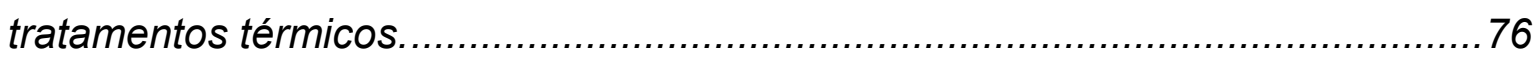

Figura 5.29: Módulo de ruptura versus porosidade aparente para amostras produzidas pelos métodos gel-casting e fase sacrifical, submetidas à sinterização a $1800^{\circ} \mathrm{C}$ por 1 hora. Em (a) amostras obtidas a partir do amido de milho e em (b) a partir do amido de batata. .78 


\section{Introdução}

Os materiais cerâmicos são utilizados em aplicações onde as outras classes de materiais (metais, polímeros e compósitos) não podem ser utilizadas ou apresentam um baixo desempenho. A maioria das aplicações tecnológicas envolve cerâmicas densas, mas há um crescente número de aplicações para as quais se utilizam cerâmicas porosas. As aplicações mais conhecidas para as cerâmicas porosas são como: isolantes térmicos, catalisadores e suportes de catalisadores, filtros e membranas para filtração e separação de partículas, gases e líquidos (incluindo metais fundidos), queimadores de gases e difusores. $O$ campo de utilização destas cerâmicas porosas vem experimentando uma recente e contínua expansão para novos setores tecnologicamente estratégicos, como o de biomateriais, farmacêutico, alimentício, aeroespacial, petroquímico, de engenharia ambiental, etc. ${ }^{[1-7]}$

As cerâmicas porosas podem ser obtidas por diferentes métodos de fabricação, os quais interferem significativamente nas características e propriedades dos produtos obtidos. Dentre os principais métodos que vêm sendo utilizados para a produção de cerâmicas porosas podem ser citados a sinterização parcial, o método da réplica de substratos celulares, o método da fase sacrifical e o método do gel-casting de espuma. Cabe ressaltar que estes métodos podem se complementar uns aos outros ou serem adaptados e/ou adequados de modo a se poder obter estruturas com as mais variadas características, envolvendo diferentes materiais cerâmicos. As características de uma estrutura de poros englobam a porosidade total, a distribuição de tamanho de poros, a conectividade entre os mesmos (poros abertos ou fechados), além da geometria (esféricos, cilíndricos, etc.).

O método da réplica é baseado na impregnação de substratos de estruturas celulares com uma suspensão cerâmica ou solução precursora cerâmica, de maneira a produzir uma estrutura porosa similar à do substrato. Muitas estruturas celulares sintéticas e naturais podem ser usadas como substratos, sendo que o exemplo mais comum é o de espumas poliméricas. As cerâmicas obtidas pelo método da réplica podem apresentar porosidade entre $40 \%$ e $95 \%$, com uma estrutura reticulada e altamente interconectada, com o 
tamanho médio de poros variando entre $200 \mu \mathrm{m}$ a $3 \mathrm{~mm}$. A grande desvantagem dessa técnica é o surgimento de trincas nos filamentos durante a pirólise do substrato, o que compromete suas propriedades mecânicas. ${ }^{[6,12-17]}$

Outro método interessante e bastante utilizado é o da fase sacrificial, que consiste na conformação de corpos a partir de uma mistura contendo uma matriz cerâmica contínua (ou precursores cerâmicos) e uma segunda fase sacrificial dispersa de maneira homogênea. A partir da eliminação desta fase sacrificial (normalmente por pirólise), os espaços ocupados pela mesma se transformam em poros com tamanho e forma similares aos das partículas da fase eliminada. A eliminação desta fase sacrificial é a etapa mais crítica do processo, requerendo normalmente tratamentos por longos períodos. Além disso, o processo de eliminação desta fase sacrificial gera uma quantidade significativa de produtos gasosos que podem ser danosos à saúde e/ou ao meio ambiente. A principal vantagem do método da fase sacrificial, se comparada aos outros métodos, é a possibilidade de controlar a porosidade, distribuição de tamanhos e a forma dos poros no produto final pela escolha adequada da fase sacrificial. Podem ser obtidas porosidades de $20 \%$ a $90 \%$ e poros de $1 \mu \mathrm{m}$ a $700 \mu \mathrm{m} .{ }^{[6,18-26]}$

O método gel-casting de espumas que é uma variação do método gelcasting originalmente desenvolvido para a produção de corpos densos. Partindose de uma suspensão cerâmica estável, contendo monômeros ou polímeros específicos (além de outros componentes, como surfactante, espumante, etc.), produz-se uma espuma por meio da aeração (normalmente por agitação mecânica), que é vertida em molde, passando então por um processo de gelificação (ou polimerização), de modo que o corpo rígido obtido mantenha a estrutura porosa originada pelas bolhas da suspensão aerada. Variáveis de processo que influenciam nas características e propriedades da cerâmica obtida por este método são as características da suspensão inicial, o método de aeração, presença de surfactantes, espumantes ou outros modificadores que permitem o controle do processo e a estabilização da espuma, etc.. ${ }^{[6,11,26-41]}$. A grande desvantagem do método gel-casting de espuma originalmente proposto é que apresenta os mesmos problemas que o método desenvolvido para a produção de cerâmicas densas: os agentes gelificantes são neurotóxicos e exigem que se trabalhe em atmosfera controlada (isenta de oxigênio). 
Devido a estes problemas, grandes esforços vêm sendo feitos no sentido de se desenvolver métodos alternativos de gel-casting, utilizando-se agentes gelificantes atóxicos, que não necessitam de atmosfera controlada e que, além disso, sejam de custo relativamente baixo. Exemplos destes agentes gelificantes que vêm sendo propostos são o ágar, a gelatina, o amido e a albumina. ${ }^{[30-54]}$

Pelo método gel-casting de espumas é possível obter poros na faixa de $35 \mu \mathrm{m}$ a $1,2 \mathrm{~mm}$ e porosidades variando de $40 \%$ até $97 \%$, com filamentos entre os poros isentos de trincas e altamente densificados, o que proporciona altos valores para as propriedades mecânicas das cerâmicas. ${ }^{[6]}$

A relação entre as propriedades mecânicas e a porosidade de

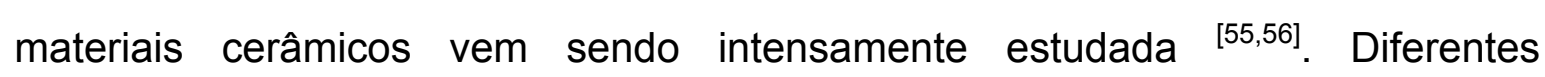
abordagens indicam que a redução da resistência mecânica de materiais porosos pode ser relacionada tanto a fatores macroestruturais (diferentes características da estrutura de poros) como a fatores microestruturais (características da matriz contínua, como densidade, composição, etc.).

Este comprometimento das propriedades mecânicas é um dos principais fatores que limitam a utilização mais ampla das cerâmicas porosas, já que há uma relação inversa entre porosidade e resistência mecânica. Para se contornar esse obstáculo, vêm sendo desenvolvidas novas cerâmicas porosas de alto desempenho, à base de nitreto de silício e seus compósitos. ${ }^{[50,61-64]}$. As cerâmicas à base de nitreto de silício apresentam um interessante conjunto de propriedades (mecânicas, térmicas e químicas) que sugerem um grande potencial para aplicações estruturais, mesmo em altas temperaturas. Além disso, possui como uma de suas principais características, o fenômeno do reforço in-situ, que se dá pelo crescimento anisotrópico dos grãos durante a sinterização, tornandoos alongados e promovendo uma microestrutura reforçada pelo entrelaçamento dos mesmos. Estes grãos alongados, além de interferir positivamente na resistência mecânica do material, promovem o surgimento de mecanismos tenacificadores, podendo-se atingir valores de tenacidade à fratura tão alta como $10 \mathrm{MPa}^{1 / 2}$, quando para a maioria das cerâmicas esse valor não ultrapassa 4 MPa.m ${ }^{1 / 2}$. ${ }^{[52,62-63]}$. Este fenômeno do reforço in-situ, exaustivamente estudado para a produção de cerâmicas densas à base de $\mathrm{Si}_{3} \mathrm{~N}_{4}$, vem sendo explorado nos 
últimos anos visando a obtenção de cerâmicas porosas de alto desempenho mecânico.

Dentre os estudos para a obtenção de cerâmicas porosas à base de nitreto de silício destaca-se o trabalho de Hampshire et al. ${ }^{[52]}$ que utilizou o amido de milho como fase sacrificial para a formação dos poros. Outro grupo que vem investindo grandes esforços na produção e caracterização de cerâmicas porosas à base de $\mathrm{Si}_{3} \mathrm{~N}_{4}$ é coordenado por Tatsuki Ohji ${ }^{[65-69]}$. Dentre os estudos deste grupo, destaca-se a fabricação de corpos de nitreto de silício porosos pela técnica de tape-casting que promove um expressivo alinhamento dos grãos de $\mathrm{Si}_{3} \mathrm{~N}_{4}$, formando uma microestrutura altamente anisotrópica; assim é possível atingir elevados valores de propriedades mecânicas na direção perpendicular aos grãos alinhados ${ }^{[65]}$. Num trabalho recente os grupos de Ohji e Hampshire estudaram em conjunto a influência de diferentes métodos de processamento nas propriedades dos corpos porosos obtidos ${ }^{[70]}$. Neste estudo concluíram que o tamanho do amido utilizado não influencia no valor do módulo de ruptura do material obtido, sendo este valor próximo ao de materiais obtidos por meio da sinterização parcial. No caso de amostras porosas obtidas por sinterização parcial seguida de prensagem a quente, a tensão de ruptura foi maior que a exigida para amostras obtidas por outras técnicas de processamento. 


\section{Objetivo}

O objetivo deste trabalho foi o desenvolvimento de cerâmicas porosas a base de $\beta-\mathrm{Si}_{3} \mathrm{~N}_{4}$ com diferentes características referentes à porosidade, e que apresentem microestrutura isotrópica e propriedades mecânicas elevadas. Como parte deste objetivo principal, partindo-se de uma composição base, foram desenvolvidas e/ou adaptadas diferentes técnicas de processamento (gel-casting e fase sacrificial) que possibilitaram a fabricação destas cerâmicas com diferentes níveis de porosidade (entre 15 e 50\%), variando-se também a distribuição de tamanho de poros. Estas diferentes estruturas porosas obtidas foram relacionadas aos valores de resistência mecânica, de modo a se poder sugerir uma relação entre porosidade e resistência mecânica. 


\section{Revisão bibliográfica}

\subsection{Cerâmicas porosas}

Os materiais cerâmicos apresentam um conjunto de interessantes propriedades e características que os habilitam a serem utilizados em aplicações nas quais as outras classes de materiais (metais e polímeros) não podem ser utilizadas ou tem, de um modo geral, um desempenho abaixo do necessário. Dentre estas propriedades podemos citar a elevada resistência mecânica, a alta dureza, a resistência ao desgaste, o baixo coeficiente de expansão térmica e de condutividade térmica, resistência à oxidação e à corrosão, elevada refratariedade, etc. Apesar da maioria destas aplicações tecnológicas envolverem cerâmicas densas, há um crescente número de aplicações para as quais se utilizam cerâmicas porosas. ${ }^{[1-7]}$

A classificação das cerâmicas porosas não é um tema consensual, pois varia de acordo com o setor ao qual as mesmas são aplicadas. Kelly discute que infelizmente não há uma consistência quanto à classificação das cerâmicas porosas com relação ao tamanho dos poros presentes. Pode-se ter cerâmicas com a distribuição de tamanho de poros dentro de uma ampla faixa de tamanho de poros (de $1 \mathrm{~nm}$ a $1 \mathrm{~cm}$ ), além desta porosidade poder variar desde alguns pontos percentuais até $90 \%$. Por exemplo, pela recomendação da IUPAC (International Union of Pure and Applied Chemistry), poros maiores que $50 \mathrm{~nm}$ são considerados macroporos. Dessa forma a nomenclatura utilizada está intimamente relacionada à aplicação em questão. Aqueles que utilizam a nomenclatura IUPAC certamente trabalham com temas correlatos a catalisadores, membranas e absorventes. Em aplicações onde o tamanho de poros é muito maior que os da classificação da IUPAC, esta deixa de ser válida, pois todos ficam na categoria de materiais macroporosos. Para os objetivos deste projeto, consideramos a porosidade na faixa entre 15 e $75 \%$ em volume, com tamanho de poros variando de $\mu \mathrm{m}$ a $\mathrm{mm}$.

Por outro lado as cerâmicas porosas podem ser classificadas quanto à interconectividade dos poros em duas categorias gerais: as cerâmicas reticuladas, que apresentam estrutura de poros ordenada e simétrica, e as espumas cerâmicas, cujos poros são distribuídos de maneira homogênea na matriz 
cerâmica. Estas diferentes estruturas de poros determinam em grande parte as características (permeabilidade, condutividade térmica, etc.) e possíveis aplicações destes materiais. Logicamente para cada uma destas diferentes estruturas, a distribuição de tamanhos e a fração volumétrica dos poros presentes também interferem fortemente nas características e propriedades do material. $\mathrm{Na}$ Figura 3.1 é apresentada a classificação proposta por Kelly, relacionando as diferentes aplicações com tamanho, volume e interconectividade de poros. ${ }^{[4]}$

Em recente publicação, Rödel et.al, ${ }^{[8]}$ indicam que cada vez mais as cerâmicas porosas deverão expandir sua importância tecnológica, já que serão utilizadas em diversas novas aplicações. Entre estas novas aplicações, os autores citam:

- Como componentes de células a combustível de alta temperatura,

- Como membranas de filtração para a produção de água limpa e potável,

- Membranas de separação para o uso em catalisadores automotivos mais eficientes,

- Como cerâmicas estruturais, e mesmo sendo materiais mais leves, atingirão propriedades mecânicas próximas às das cerâmicas densas,

$\mathrm{Na}$ área de biomateriais, principalmente como suportes para o crescimento de tecidos e cultura de células. 


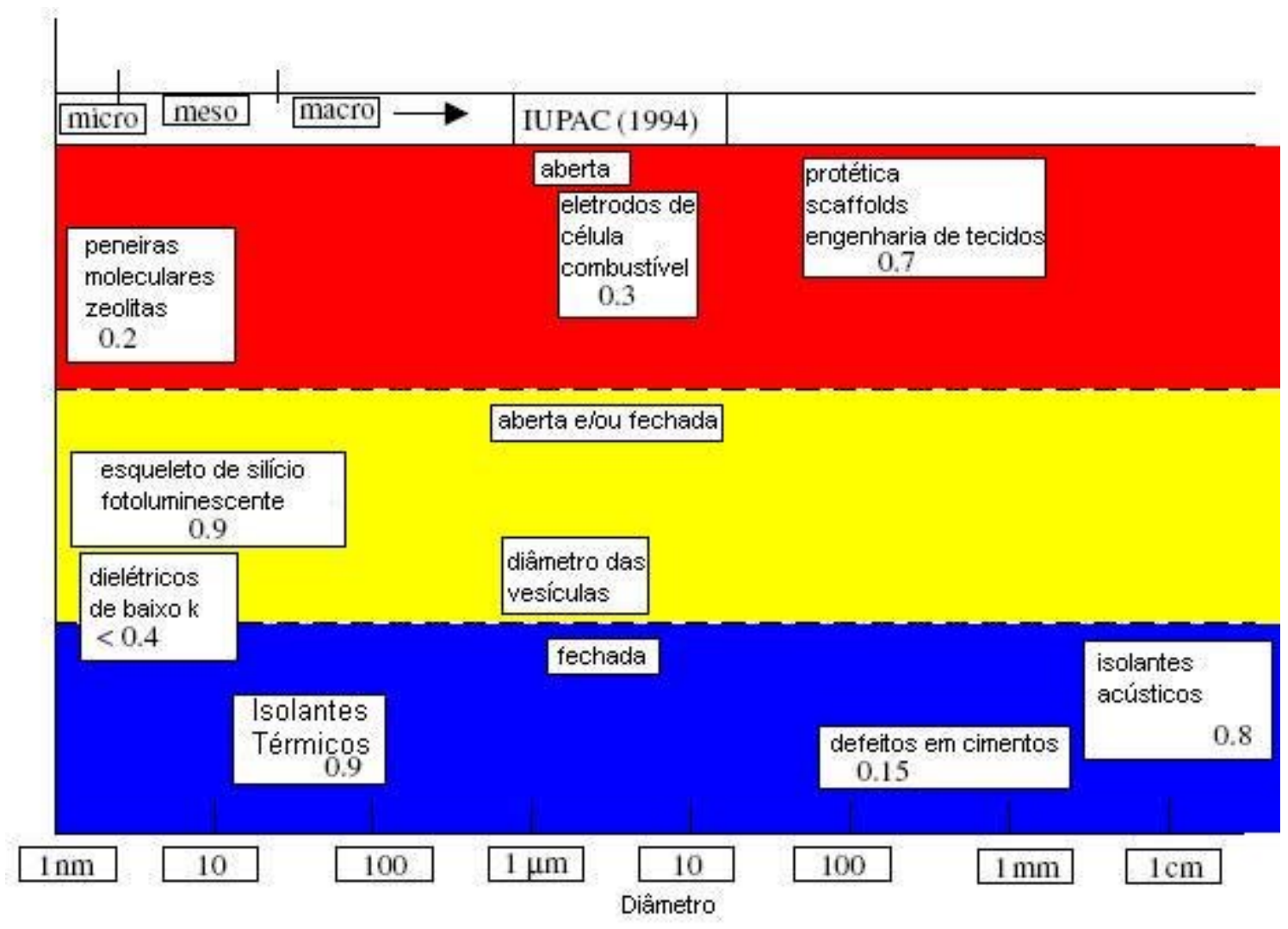

Figura 3.1: Diagrama da classificação de materiais porosos proposta por KELLY. [4]

\subsection{Métodos de produção de cerâmicas porosas}

Cerâmicas porosas podem ser obtidas por diferentes métodos, sendo que alguns destes são adaptações de métodos clássicos de conformação de materiais cerâmicos densos. ${ }^{[1-7]}$ A escolha do método mais adequado está relacionada, além da geometria da peça a ser produzida, às características da estrutura de poros que se deseja. Os métodos empregados para a produção de cerâmicas com poros na escala nanométrica não serão descritos aqui, sendo então detalhados apenas os principais métodos para a produção de corpos com porosidade na escala micrométrica a milimétrica, que descreveremos como cerâmicas macroporosas.

Para a produção destas cerâmicas macroporosas existem diferentes métodos, sendo cada qual mais adequado à produção de determinadas estruturas de poros, e dessa forma determinando as propriedades do produto final. ${ }^{[5-7]}$ 
Um dos métodos para produção mais simples é o da sinterização parcial, onde a porosidade é controlada pelos parâmetros de sinterização do material, como por exemplo o empacotamento das partículas, a presença de aditivos, a temperatura e tempo de sinterização etc. ${ }^{[3,5]}$

O método da prensagem isostática a quente também é utilizado para produção de cerâmicas porosas; nesse caso os corpos de prova já conformados são introduzidos na prensa sem serem selados, permitindo assim que o gás sob alta pressão penetre nos poros, impedindo que os mesmos se fechem durante a sinterização. A porosidade resultante e o tamanho dos poros do corpo tratado na prensa isostática a quente é muito similar a do corpo a verde original. ${ }^{[5]}$

Existem outros métodos descritos na literatura e alguns largamente utilizados na indústria como a prototipagem rápida, o método da réplica, da fase sacrificial e gel-casting de espumas. A seguir serão descritos detalhadamente os métodos mais utilizados. ${ }^{[7]}$

\subsubsection{Método da réplica:}

Este método desenvolvido no início dos anos 60 por Schwartzwalder e Somers ${ }^{[6]}$ é baseado na impregnação de substratos de estruturas celulares com uma suspensão cerâmica ou solução precursora de maneira a produzir uma estrutura porosa similar à do substrato. Muitas estruturas celulares sintéticas e naturais podem ser usadas como gabarito para fabricar cerâmicas porosas por meio deste método, sendo que o exemplo mais comum é o de esponjas poliméricas. Na Figura 3.2 vemos um exemplo de uma cerâmica produzida com uso de esponjas poliméricas e outra obtida a partir da madeira de pinheiro ${ }^{[12]}$.

No caso da produção de cerâmicas porosas a partir de uma estrutura natural como a madeira, procede-se inicialmente a um processo de pirólise da mesma para a eliminação de fases orgânicas, restando no final uma estrutura de carbono. A partir desta estrutura pode-se, por infiltração de metais ou gases, promover reações que levem à formação de diferentes fases cerâmicas, sejam covalentes ou iônicas. ${ }^{[6,12]}$ As cerâmicas porosas obtidas pelo método da réplica apresentam porosidade entre $40 \%$ e $95 \%$ com uma estrutura reticulada e altamente interconectada, com o tamanho médio de poros podendo variar entre 
$200 \mu \mathrm{m}$ e $3 \mathrm{~mm}$, o que faz com que estas cerâmicas sejam adequadas para aplicações que necessitem de alta permeabilidade. ${ }^{[6,12-17]}$
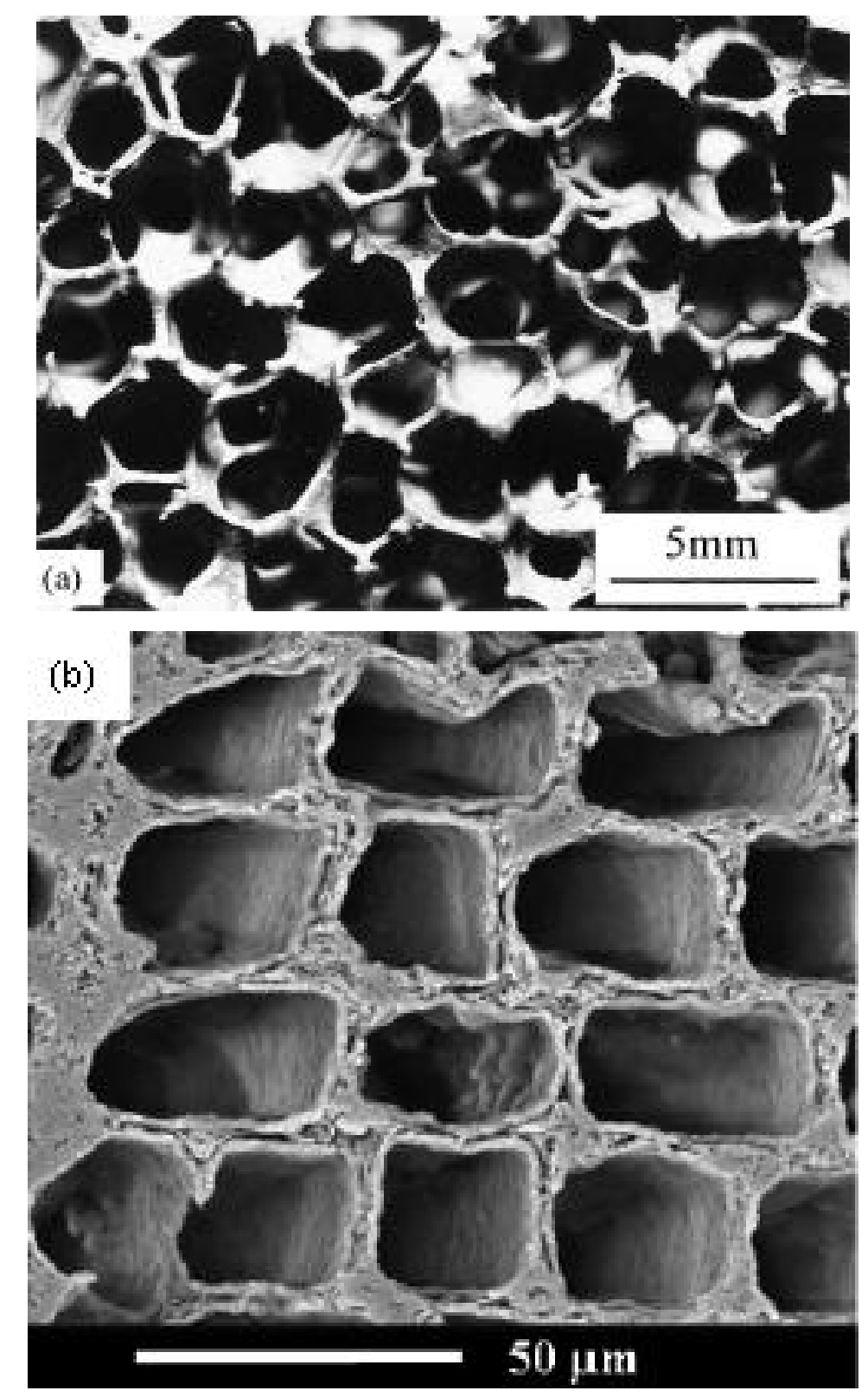

Figura 3.2: Estruturas obtidas pela técnica da réplica, ambas de $\mathrm{Al}_{2} \mathrm{O}_{3}$, (a) a partir da esponja polimérica e (b) e partir do pinheiro. ${ }^{[12]}$

Um dos problemas que pode ocorrer com a utilização deste método da réplica é o surgimento de trincas nos filamentos durante a pirólise da esponja, o que pode comprometer as propriedades mecânicas da cerâmica. Visando evitar esse problema foram propostas algumas soluções, como melhorar a molhabilidade da suspensão no substrato a ser impregnado, fazer mais de uma 
impregnação para o preenchimento das trincas dos filamentos, adição de fibras na suspensão cerâmica, desgaseificação da mesma, etc. ${ }^{[6,12-17]}$

Quando se utiliza como base uma estrutura natural, as propriedades mecânicas são comumente melhores, pois a estrutura mantém sua forma original e é transformada por meio de processos físico-químicos em um material cerâmico, gerando uma estrutura sem falhas e sem vazios dentro dos filetes. ${ }^{[6,12]}$

\subsubsection{Método da fase sacrificial}

O método da fase sacrificial consiste na conformação de corpos a partir de uma mistura contendo uma matriz cerâmica contínua (ou precursores cerâmicos) e uma segunda fase sacrificial dispersa homogeneamente. Com a eliminação desta fase sacrificial (geralmente por tratamento térmico), os espaços ocupados pela mesma se transformam em poros com tamanho e forma similares às partículas que os originaram. ${ }^{[6,18-26]}$

Uma grande variedade de materiais pode ser usada como formadores de poros, como serragem, amidos, polietileno, PMMA, parafina, etc. ${ }^{[6]}$

Quando da eliminação da fase sacrificial por tratamento térmico, o material é submetido a processo de aquecimento bastante lento, com patamares em temperaturas intermediárias para que não ocorra a formação de defeitos que venham a comprometer as propriedades mecânicas do produto final. Além disso, durante a pirólise pode ser gerada uma quantidade considerável de produtos gasosos, prejudiciais à saúde e/ou ao meio ambiente, o que exige que estes produtos da pirólise sejam tratados antes de serem lançados na atmosfera. $\mathrm{Na}$ Figura 3.3 é apresentada uma estrutura obtida por este método; Neste caso adicionou-se a uma suspensão de $\beta$-fosfato tricálcico, esferas de PMMA (poli metil meta-acrilato) que após a pirólise deixaram poros nos espaços que ocupavam. ${ }^{[18]}$

A maior vantagem do método da fase sacrificial, se comparada aos outros métodos, é a possibilidade de controlar a porosidade, distribuição de tamanhos e a forma dos poros no produto final pela escolha adequada da fase a ser eliminada na pirólise. Um levantamento da literatura permite afirmar que podem ser obtidas cerâmicas com porosidades de $20 \%$ a $90 \%$ e poros variando de $1 \mu \mathrm{m}$ a $700 \mu \mathrm{m} .{ }^{[6,18,22,26]}$ 


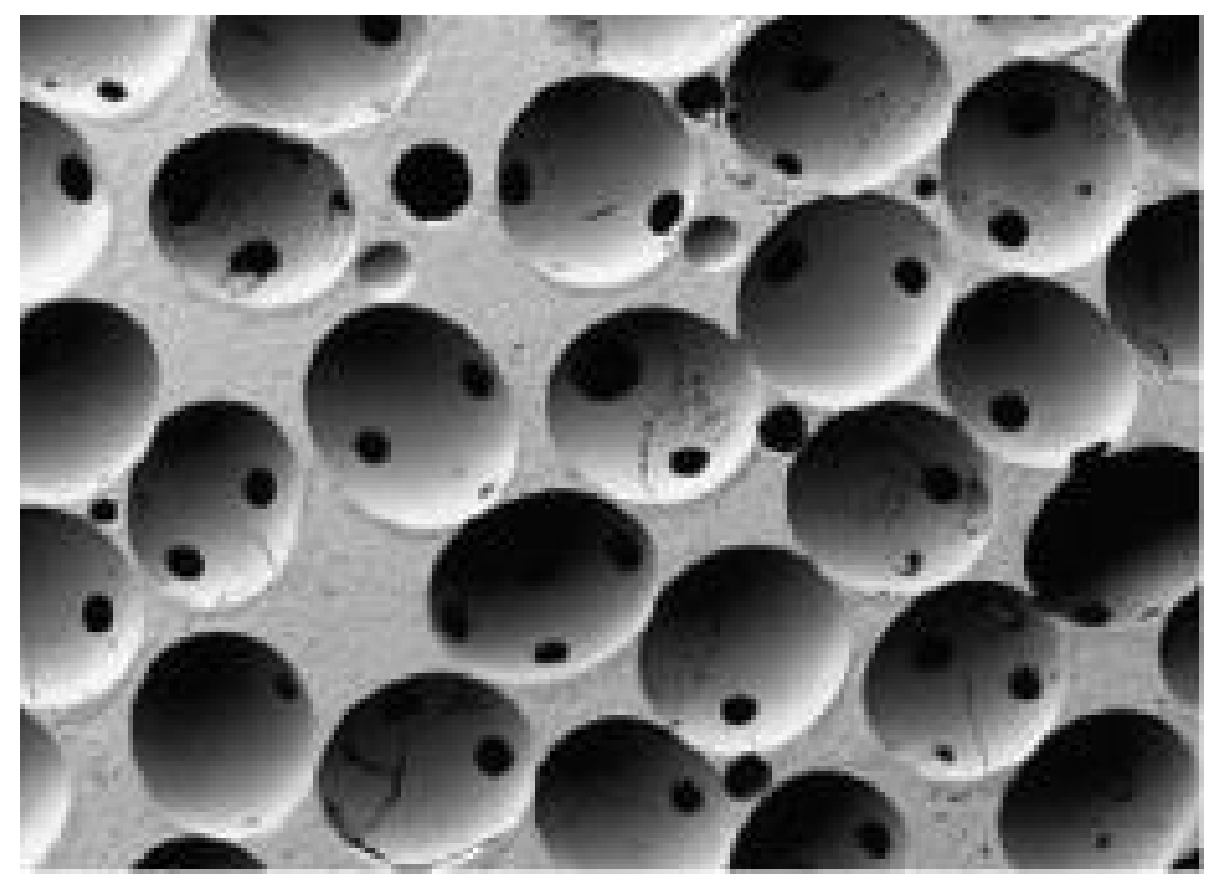

Figura 3.3: Estrutura obtida pelo método da fase sacrificial. Cerâmica de $\beta$-fosfato tricálcico cujos poros foram originados de eliminação de esferas de PMMA.

Como neste método o produto final corresponde a um negativo da fase sacrificial, não ocorrem trincas nos filamentos como na técnica da réplica, fazendo com que essas cerâmicas porosas tenham melhores propriedades mecânicas que as produzidas por réplica. ${ }^{[6]}$

\subsubsection{Método do Gel-casting de espumas}

O método "gel-casting" foi originalmente desenvolvido para produção de corpos densos de geometria complexa. Uma suspensão cerâmica estável, contendo monômeros ou polímeros específicos, é vertida em um molde, passando então por um processo de gelificação (ou polimerização), de modo a obter um corpo rígido. A peça conformada é submetida a sucessivas etapas de secagem com posterior tratamento térmico para eliminação de orgânicos e sinterização. Variáveis de processo como as características da suspensão inicial (umidade, viscosidade, etc.), influenciam nas características dos corpos obtidos. $^{[6,11,27-44]}$.

A partir do método original de gel-casting foi proposta uma adaptação (gel-casting de espumas) para a produção de cerâmicas porosas. ${ }^{[27]}$. Por este método, uma suspensão cerâmica contendo o agente gelificante passa por um 
processo de aeração (normalmente por agitação mecânica), sendo que a espuma obtida é vertida em um molde, passando então por processo de gelificação (ou polimerização) similar ao método original, de modo que o corpo rígido obtido mantenha a estrutura de bolhas formada pela aeração da suspensão. A peça conformada é submetida a sucessivas etapas de secagem com posterior tratamento térmico para eliminação de orgânicos e sinterização. Variáveis de processo como as características da suspensão inicial (umidade, viscosidade, etc.), método de aeração, presença de surfactantes, espumantes ou outros modificadores permitem que se possa controlar o processo de modo a se obter diferentes estruturas porosas, seja quanto ao percentual de poros, à distribuição de tamanho e forma dos mesmos, ou ainda quanto às características físicas da fase cerâmica entre os poros. Este controle do processo permite que se interfira nas características do corpo poroso como sua resistência mecânica, permeabilidade, condutividade térmica, etc. O método de conformação por gelcasting original apresenta o inconveniente de utilizar monômeros que podem ser neurotóxicos, e que, além disso, polimerizam in-situ, e exigem que a operação ocorra em atmosfera controlada (sem a presença de $\mathrm{O}_{2}$ ). ${ }^{[6,27-29]} \mathrm{Na}$ Figura 3.4 é mostrada uma estrutura obtida por esse método. ${ }^{[32]}$

Um fator muito importante no processo gel-casting de espumas é a estabilidade das bolhas formadas, pois estas são termodinamicamente instáveis devido à grande área de superfície na interface entre o gás e o líquido. Assim no intuito de diminuir a área de superfície nesta interface três fenômenos podem ocorrer: escoamento, coalescência e desproporção ("Ostwald rippening"). ${ }^{[6]}$

O escoamento consiste na separação física (pelo efeito da gravidade) entre as bolhas e a fase líquida, com as bolhas se concentrando no topo do recipiente. Estas bolhas, ao se concentrarem, deformam-se e se tornam células poliédricas, com filmes finos entre as mesmas; na junção de 3 células aparece uma região conhecida como platô,(Figura 3.5). ${ }^{[6]}$ 


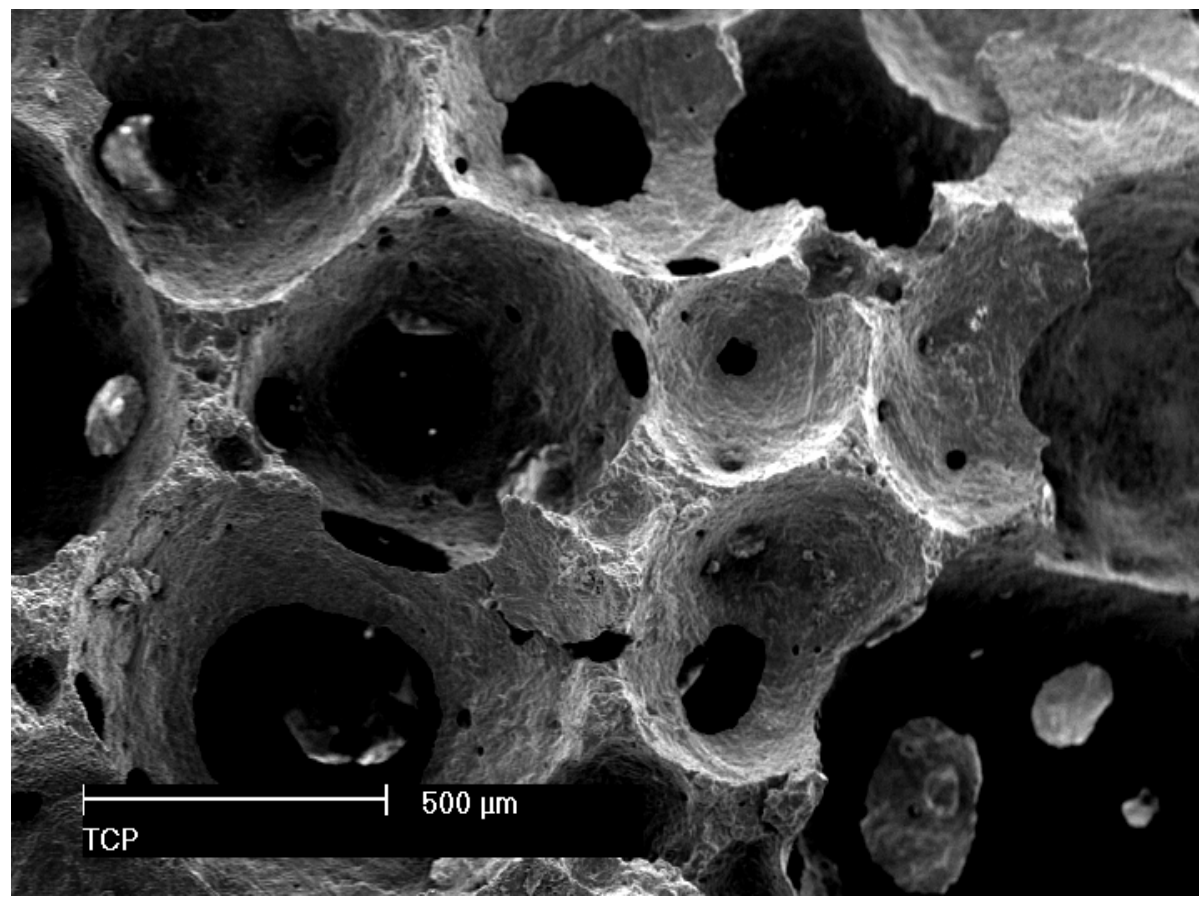

Figura 3.4: Estrutura porosa de uma alumina obtida por gel-casting de espumas, sendo, neste caso foi utilizada como agente gelificante albumina. ${ }^{[32]}$

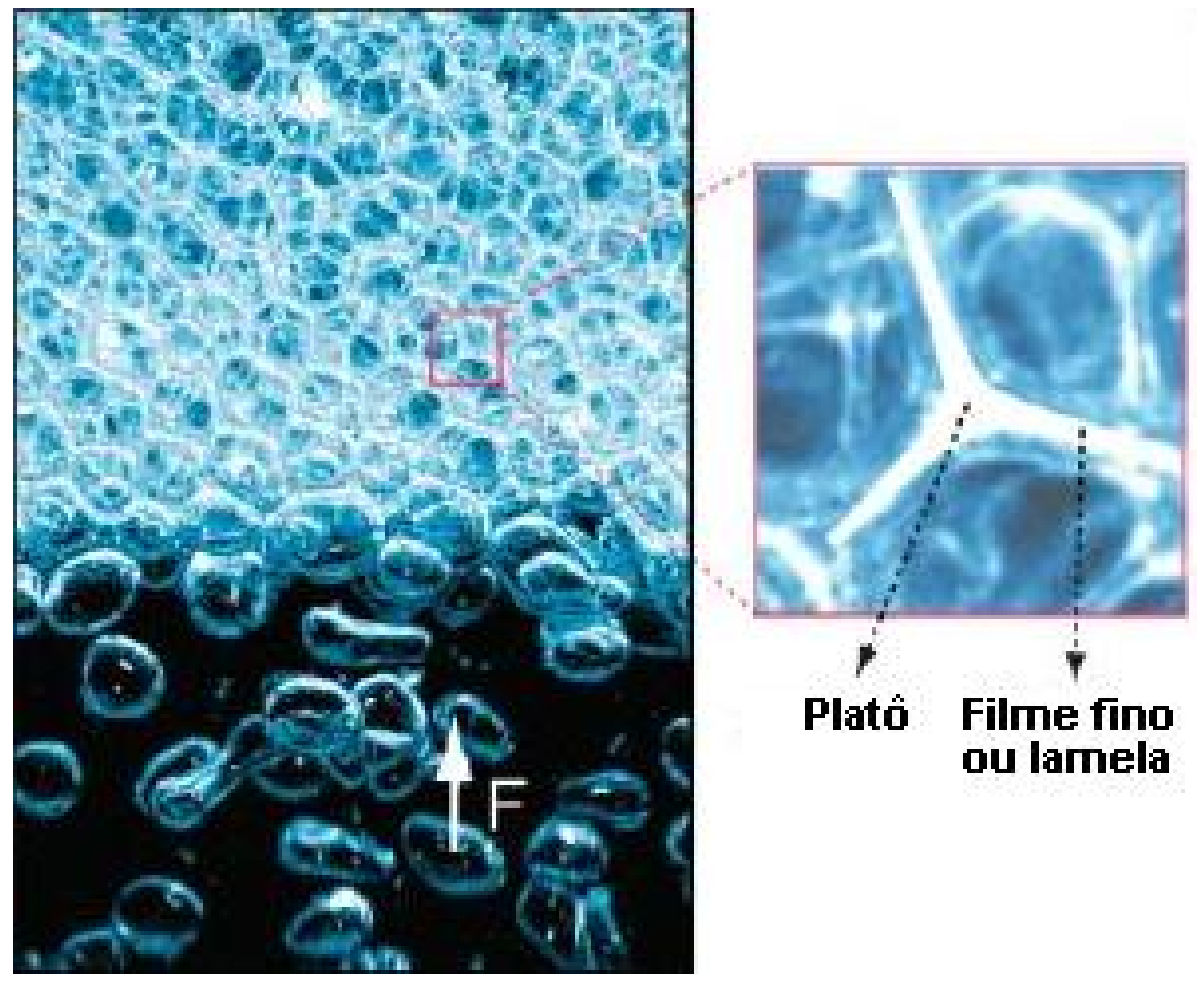

Figura 3.5: Fenômeno do escoamento, F simboliza o sentido do fluxo das bolhas, e a imagem ampliada mostra detalhes das células poliédricas. ${ }^{[6]}$ 
A coalescência ocorre quando o filme formado durante o escoamento não é estável, provocando a associação de células vizinhas. A estabilidade do filme é definida pelas forças de atração e repulsão entre as bolhas. A força motriz deste processo são as forças atrativas de Van der Waals, que empurram as bolhas umas contra as outras, colapsando o filme entre as mesmas. A única maneira de se evitar esse colapso é prover as bolhas de forças de repulsão estérica e/ou eletrostática que superem as forças de van der Waals. Isto é feito por meio de moléculas surfactantes ou partículas na interface gás-líquido. $\mathrm{Na}$ Figura 3.6 é mostrado esquematicamente este processo. ${ }^{[6]}$

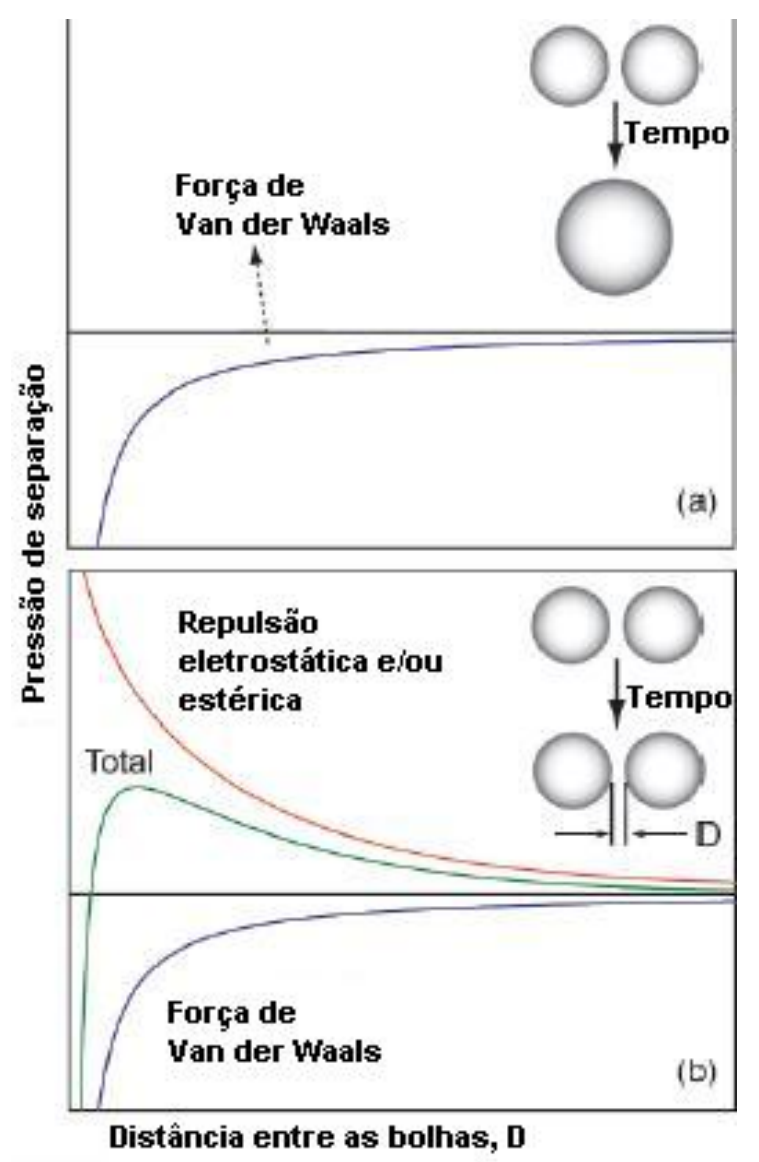

Figura 3.6: Representação esquemática do processo de coalescência e do efeito de surfactantes. ${ }^{[6]}$

Por fim tem-se o mecanismo de desproporção ou "Otswald rippening" que é controlado pela diferença da pressão laplaciana entre bolhas de tamanho diferentes; esta diferença de pressão faz com que o ar difunda das bolhas 
menores para as maiores, que dessa forma crescem, absorvendo as menores. Este processo pode ser minimizado por meio da utilização de surfactantes (ou de partículas coloidais, discutido a seguir), que reduzem a difusão de gás entre as bolhas, aumentando a estabilidade de uma espuma de minutos para horas.

Recentemente foi proposta a utilização de partículas coloidais, em substituição aos surfactantes para a estabilização das espumas. Estas partículas são adsorvidas irreversivelmente na interface gás-líquido adquirindo um aspecto de uma rede, estabilizando as bolhas. Na Figura 3.7 pode-se comparar o efeito da adição de surfactante e de partículas coloidais na estabilização de uma espuma, constatando-se a maior eficiência para o caso da adição das partículas. ${ }^{[6]}$
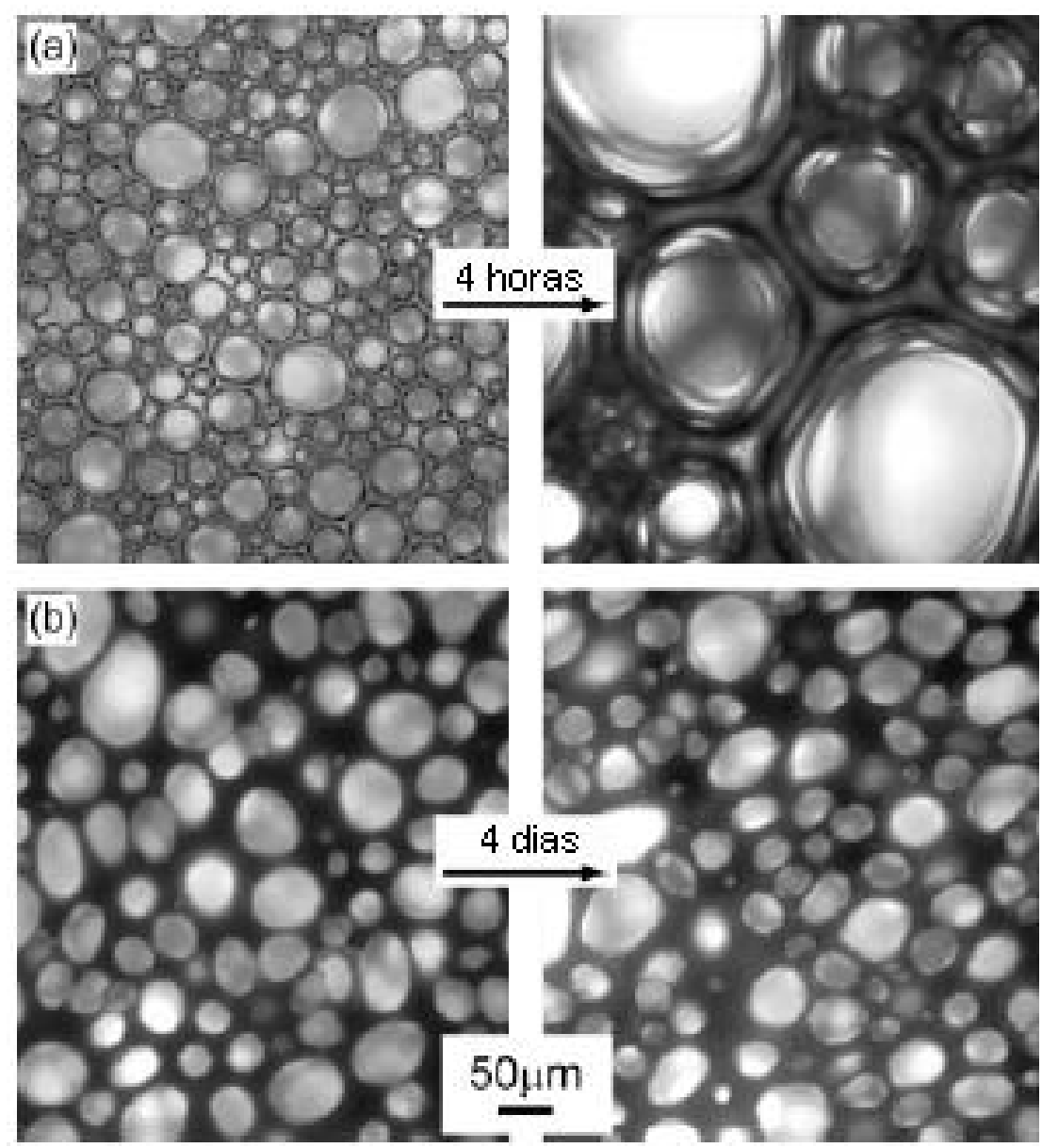

Figura 3.7: Comparação do efeito de surfactantes e de partículas coloidais na estabilização de espumas. Em (a) é mostrada uma espuma estabilizada com um surfactante após 4 horas de repouso, enquanto em (b) a espuma contendo partículas coloidais se mostra bem mais estabilizada, mesmo por períodos bem mais longos (4 dias). ${ }^{6]}$ 
A estabilidade das espumas, por esse novo método, é obtida pela adsorção irreversível das partículas coloidais na interface gás-líquido, atuam impedindo a coalescência entre bolhas vizinhas e também a desproporção, formando uma barreira à difusão gasosa, e à variação volumétrica das bolhas ${ }^{[6]}$

Pelo método gel-casting de espumas é possível obter poros na faixa de $35 \mu \mathrm{m}$ a $1,2 \mathrm{~mm}$ e porosidades variando de $40 \%$ até $97 \%{ }^{[6]}$. Os poros obtidos são esféricos e podem ser tanto fechados quanto abertos dependendo dos parâmetros de processo. Poros abertos são obtidos quando as partículas do pó cerâmico segregam na região de platô gerando janelas nas paredes e interconectando os poros; já poros fechados são obtidos quando o pó cerâmico se distribui uniformemente na superfície da bolha. ${ }^{[6]}$

O método gel-casting de espumas normalmente gera filamentos densos e sem trincas no produto sinterizado, o que aumenta as propriedades mecânicas das cerâmicas em comparação às obtidas pelo método da réplica. Para porosidades acima de $90 \%$ as paredes se tornam tão finas que as propriedades ficam abaixo do previsto teoricamente para uma cerâmica porosa de células abertas. Para menores valores de porosidade, ocorre a melhoria nas propriedades mecânicas a ponto de ultrapassar o previsto para células fechadas. ${ }^{[6]}$ Este tópico onde se relaciona porosidade com a propriedade mecânica será discutido na seção 3.4 .

Como dito anteriormente o método de produção via gel-casting convencional apresenta restrições quanto à saúde do operador e ao meio ambiente, além de restrições operacionais (exigência de atmosfera controlada). Diante disso, diferentes métodos alternativos vêm sendo desenvolvidos, utilizando-se agentes gelificantes atóxicos, e que não necessitam de atmosfera controlada. Além disso, busca-se empregar gelificantes de custo relativamente baixo. Exemplos de agentes gelificantes que cumprem os requisitos acima são o ágar, a gelatina, o amido e a albumina. ${ }^{[31-44]}$

\subsubsection{Utilização de albumina como gelificante}

A albumina, como outras proteínas, é um composto molecular condensado de aminoácidos. Devido à sua estrutura globular, a albumina é adsorvida na interface gás/água, gerando sítios hidrofóbicos que reduzem a 
tensão superficial dessa interface, estabilizando dessa forma a espuma formada. Quando aquecida entre 70 e $90{ }^{\circ} \mathrm{C}$, a albumina sofre um processo de desnaturação, saindo do seu estado ordenado sem romper as ligações covalentes. As cadeias estendidas se ligam umas às outras por meio de pontes de hidrogênio, formando assim uma estrutura entrelaçada (gel), termicamente irreversível. $^{[30,32,40,41]}$

Diversos estudos indicam a albumina como uma alternativa bastante promissora e interessante para ser utilizada como agente gelificante na produção de espumas cerâmicas pelo método gel-casting. Além de ser um agente gelificante, a albumina é um eficiente espumante para as suspensões cerâmicas, tendo a vantagem, em relação a espumantes iônicos, de poder ser acrescida à suspensão sem interferir na estabilização da mesma. Os mesmos estudos mostram que é possível, a partir da utilização da albumina como gelificante para o processo de gel-casting de espuma, produzir cerâmicas com até $95 \%$ de porosidade. ${ }^{[31,33,41]}$

\subsubsection{Utilização de amido como gelificante}

O amido, por suas características específicas, pode ser utilizado na obtenção de cerâmicas porosas, tanto como fase sacrificial quanto como agente gelificante no método gel-casting. Pode ser extraído de diferentes vegetais (como o milho, a mandioca, o arroz, a batata, etc.), sendo que suas características e propriedades variam significativamente, dependendo da sua origem. Por exemplo, o tamanho médio das partículas do amido pode variar entre 2 e $170 \mu \mathrm{m}$ (Tabela 3.1), assim como sua forma (arredondada ou anisométrico). Quando em contato com a água e aquecido acima de determinada temperatura, que também varia conforme a sua origem, o amido tem as suas ligações intermoleculares enfraquecidas, ocorrendo a absorção de água de maneira irreversível pelas partículas, com o conseqüente inchamento das mesmas, que podem atingir até $20 \%$ (de expansão). As partículas de amido são formadas por misturas de 2 tipos de polissacarídeos, um linear (amilose) e um altamente ramificado (amilopectina), sendo a amilose a responsável pela gelificação do amido em suspensões aquosas. As unidades de glicose, que compõem as cadeias poliméricas deixam exposta uma grande quantidade de grupos hidroxila, fazendo com que as 
partículas de amido sejam fortemente hidrofílicas. Na Figura 3.8 é mostrada a estrutura do amido. ${ }^{[45-54]}$.

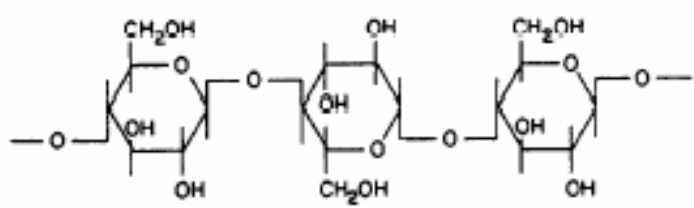

Figura 3.8: Estrutura molecular do amido. ${ }^{[46]}$

Tabela 3.1: Diferentes tipos de amidos e suas características ${ }^{[53]}$ :

\begin{tabular}{|c|c|c|c|c|c|}
\hline Amido & $\begin{array}{c}\text { Amilose } \\
(\%)\end{array}$ & $\begin{array}{c}\text { Amilopectina } \\
(\%)\end{array}$ & $\begin{array}{c}\text { Taxa de } \\
\text { inchamento } \\
\text { granular }\end{array}$ & $\begin{array}{c}\text { Início de } \\
\text { gelificação } \\
\left({ }^{\circ} \mathrm{C}\right)\end{array}$ & $\begin{array}{c}\text { Término de } \\
\text { gelificação } \\
\left({ }^{\circ} \mathrm{C}\right)\end{array}$ \\
\hline Batata & $20-21$ & $79-80$ & Rápida & $50-56$ & 68 \\
\hline Trigo & $25-30$ & $70-75$ & Lenta & 58 & 64 \\
\hline Mandioca & $16-17$ & $83-84$ & Rápida & 49 & 65 \\
\hline Milho & $25-28$ & $72-75$ & Lenta & 62 & $72-80$ \\
\hline Arroz & $17-30$ & $70-83$ & Lenta & $58-69$ & $79-86$ \\
\hline
\end{tabular}

Como dito anteriormente existem duas maneiras de se utilizar o amido para a produção de corpos cerâmicos porosos: como material de sacrifício, ou seja, é adicionado à mistura cerâmica (em suspensão ou mistura sólida) e após a conformação do corpo cerâmico, este é submetido a tratamento térmico para eliminação dos orgânicos, e a conseqüente formação de poros nas posições que estes ocupavam. A outra maneira é a sua utilização como agente gelificante no processo gel-casting, aproveitando-se ainda da expansão volumétrica que experimenta quando aquecido em contato com a água: a suspensão cerâmica contendo amido é vertida em molde (com ou sem agitação anterior para a 
formação de espuma) e aquecida adequadamente de maneira que o amido absorva água e gelifique, enrijecendo a suspensão; seguem-se as etapas de desmoldagem, secagem, eliminação de orgânicos e sinterização dos corpos produzidos. Na Figura 3.9 é mostrada a microestrutura de uma cerâmica produzida por este método. ${ }^{\text {[45-54] }}$

Na Figura 3.10 se encontram resumidos os métodos que discutidos neste tópico de produção de cerâmicas macroporosas.

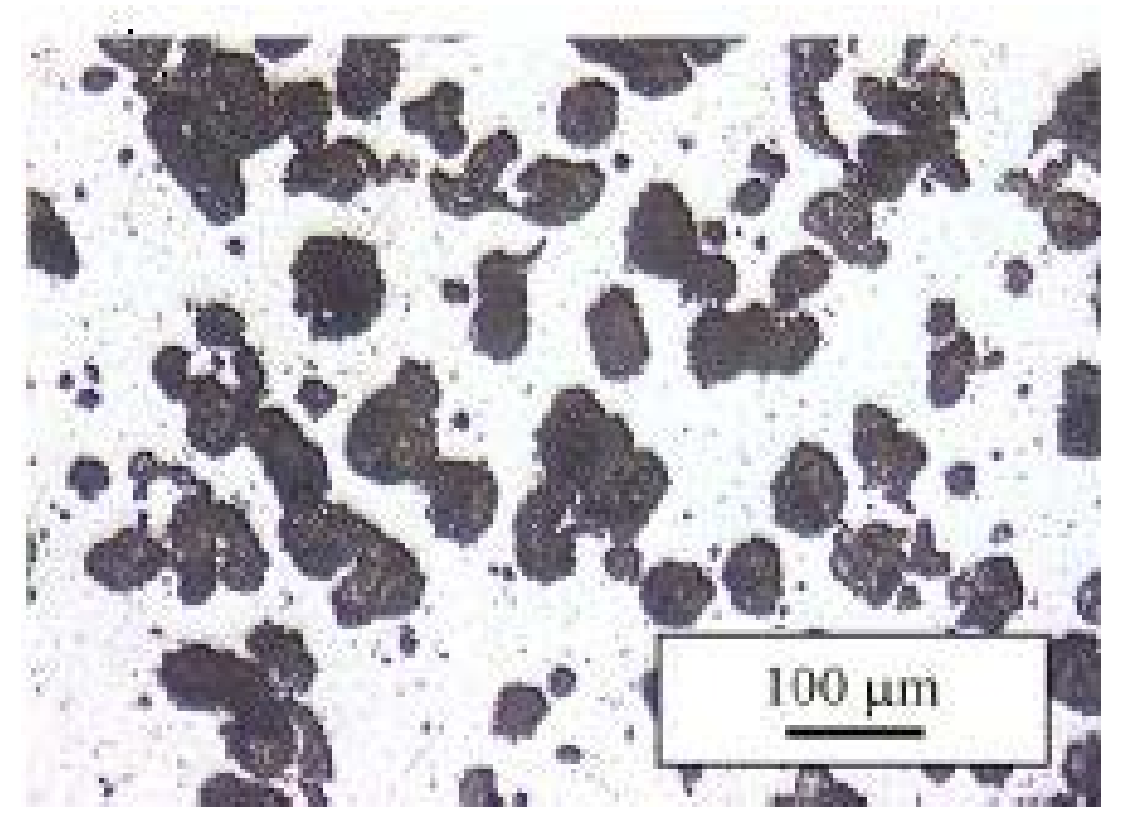

Figura 3.9: Exemplo de estrutura de alumina porosa obtida por gel-casting com amido de batata. ${ }^{[45]}$ 


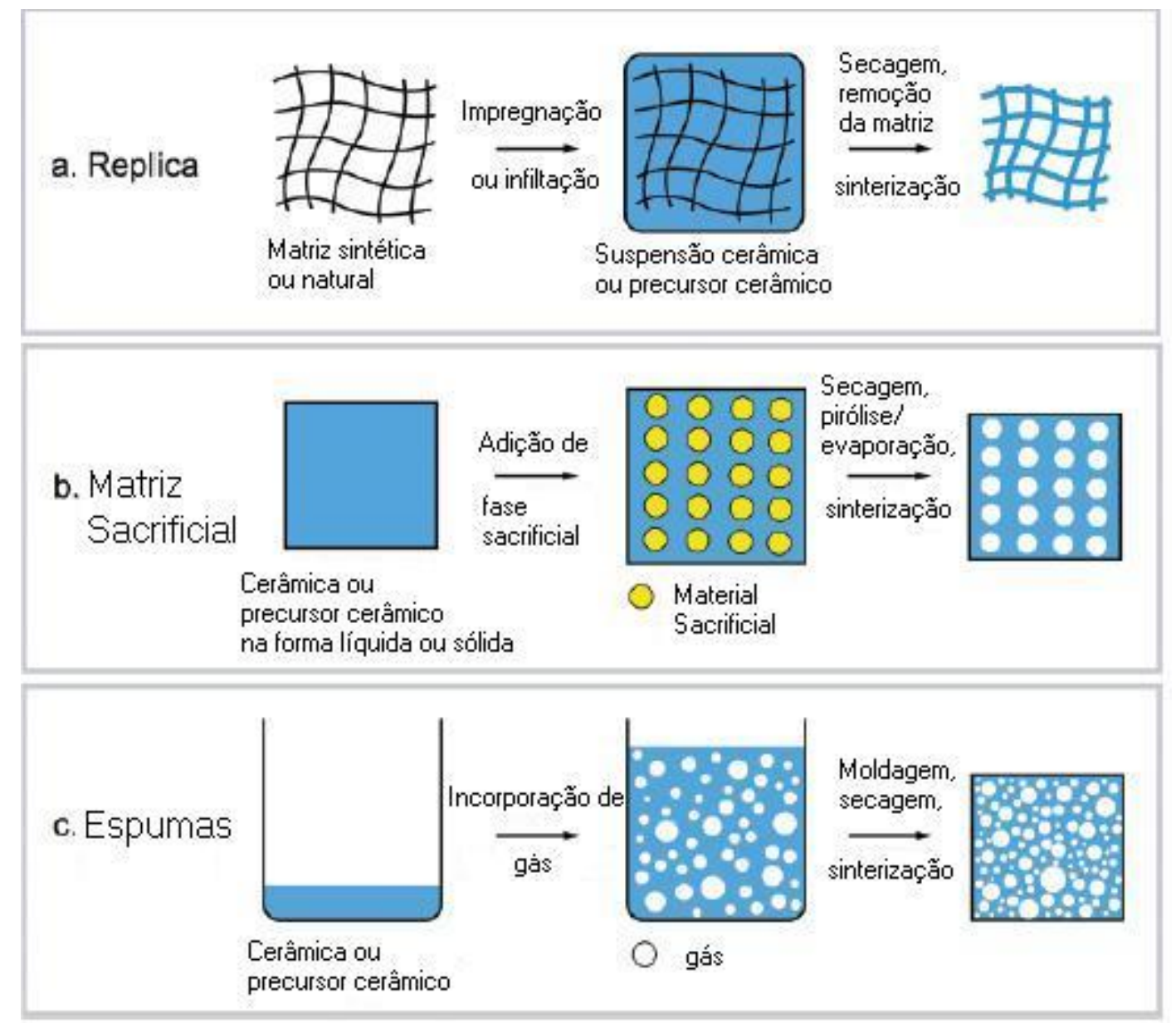

Figura 3.10: Exemplo de métodos de produção de cerâmicas porosas. ${ }^{[6]}$

\subsection{Propriedades Mecânicas e sua relação com a porosidade}

É um fato conhecido que a porosidade provoca uma diminuição nos valores das propriedades mecânicas dos materiais de um modo geral.

Existem as mais diversas abordagens para o estudo das propriedades mecânicas de cerâmicas porosas, sendo que um dos principais critérios para a definição de um modelo a ser empregado é a porosidade, pois cada modelo trabalha dentro de faixas específicas de porosidade.

No caso das espumas cerâmicas, de porosidade acima de $70 \%$ em volume, as propriedades mecânicas dependem das características macroestruturais (densidade relativa, interconectividade e forma dos poros) e microestruturais relacionadas com o material que constitui as paredes dos poros (densidade, o módulo elástico, resistência mecânica e fluência). Segundo ASHBY as espumas apresentam, quando submetidas à compressão/tração, um 
comportamento mecânico que pode ser dividido em 3 estágios diferentes: linear elástico, platô e densificação. ${ }^{[55]}$

Inicialmente ocorre a deformação elástica das paredes e filamentos dos poros da espuma. O módulo elástico nessa região pode ser calculado pela equação 3.4.1, que é válida apenas para os casos de poros interconectados:

$$
\frac{E}{E_{p}}=C_{1}\left(\frac{\rho}{\rho_{0}}\right)^{2}
$$

E= módulo elástico da espuma

$E_{p}=$ módulo elástico do material da parede da espuma

$\rho=$ densidade da espuma

$\rho_{0}=$ densidade do material das paredes

$\mathrm{C}_{1}=$ constante de valor próximo a 1 .

Para o caso da espuma ser constituído por poros fechados, o Módulo Elástico se torna dependente da fração volumétrica de material $(\phi)$ nas faces do poro, ou seja, da espessura das paredes que constituem o poro. Neste caso o Módulo Elástico é descrito pela equação 3.4.2: ${ }^{[55]}$

$$
\frac{E}{E_{p}}=C_{1} \phi^{2}\left(\frac{\rho}{\rho_{0}}\right)^{2}+C_{2}(1-\phi)\left(\frac{\rho}{\rho_{0}}\right)
$$

onde $\mathrm{C}_{1}$ e $\mathrm{C}_{2}$ são constantes com valor de aproximadamente 1.

O segundo estágio do comportamento de uma espuma cerâmica sob compressão, ou seja, a região de platô da curva tensão versus deformação, iniciase quando ocorre a fratura do material, o que leva a uma queda da tensão. Neste estágio observam-se sucessivos aumentos e quedas na tensão devido à quebra gradual dos filamentos que constituem a espuma. O módulo de ruptura sob compressão de espumas cerâmicas está associado com à tensão que provoca a fratura inicial do material, como mostrado na equação 3.4.3:[55] 


$$
\frac{\sigma}{\sigma_{0}}=C_{3}\left(\frac{\rho}{\rho_{0}}\right)^{\frac{3}{2}}
$$

$\sigma=$ módulo de ruptura da espuma

$\sigma_{0}=$ módulo de ruptura do material das paredes

$\rho / \rho_{0}=$ densidade relativa da espuma

$\mathrm{C}_{3}=$ constante com valor de 0,2

Na figura 3.11 é mostrado um desenho esquemático da ruptura da célula por compressão. ${ }^{[5]}$

Ainda para o estágio do platô, mas para cerâmicas com os poros fechados, deve-se ainda levar em conta a fração volumétrica $(\phi)$ do material das paredes, o que reflete na adequação da equação anterior que se transforma na equação 3.4.4: ${ }^{[55]}$

$$
\frac{\sigma}{\sigma_{0}}=C_{3} *\left(\phi \frac{\rho}{\rho_{0}}\right)^{\frac{3}{2}}+\left[C_{3} *(1+\phi) *\left(\frac{\rho}{\rho_{0}}\right)\right]
$$

No terceiro estágio do processo de ruptura, a espuma começa a "densificar" gerando um aumento na tensão. ${ }^{[55]}$

Outra abordagem proposta por Mackenzie relaciona o módulo elástico das cerâmicas com a porosidade. Segundo o autor o módulo elástico de um corpo isotrópico e homogêneo (não importando se as células são abertas ou fechadas), varia com a porosidade de acordo com a equação $3.4 .5:^{[56]}$ 


$$
E(p)=E_{0}\left(1-1,9 p+0,9 p^{2}\right)
$$

$\mathrm{E}_{0}=$ Módulo Elástico do material denso

$p=$ fração volumétrica dos poros

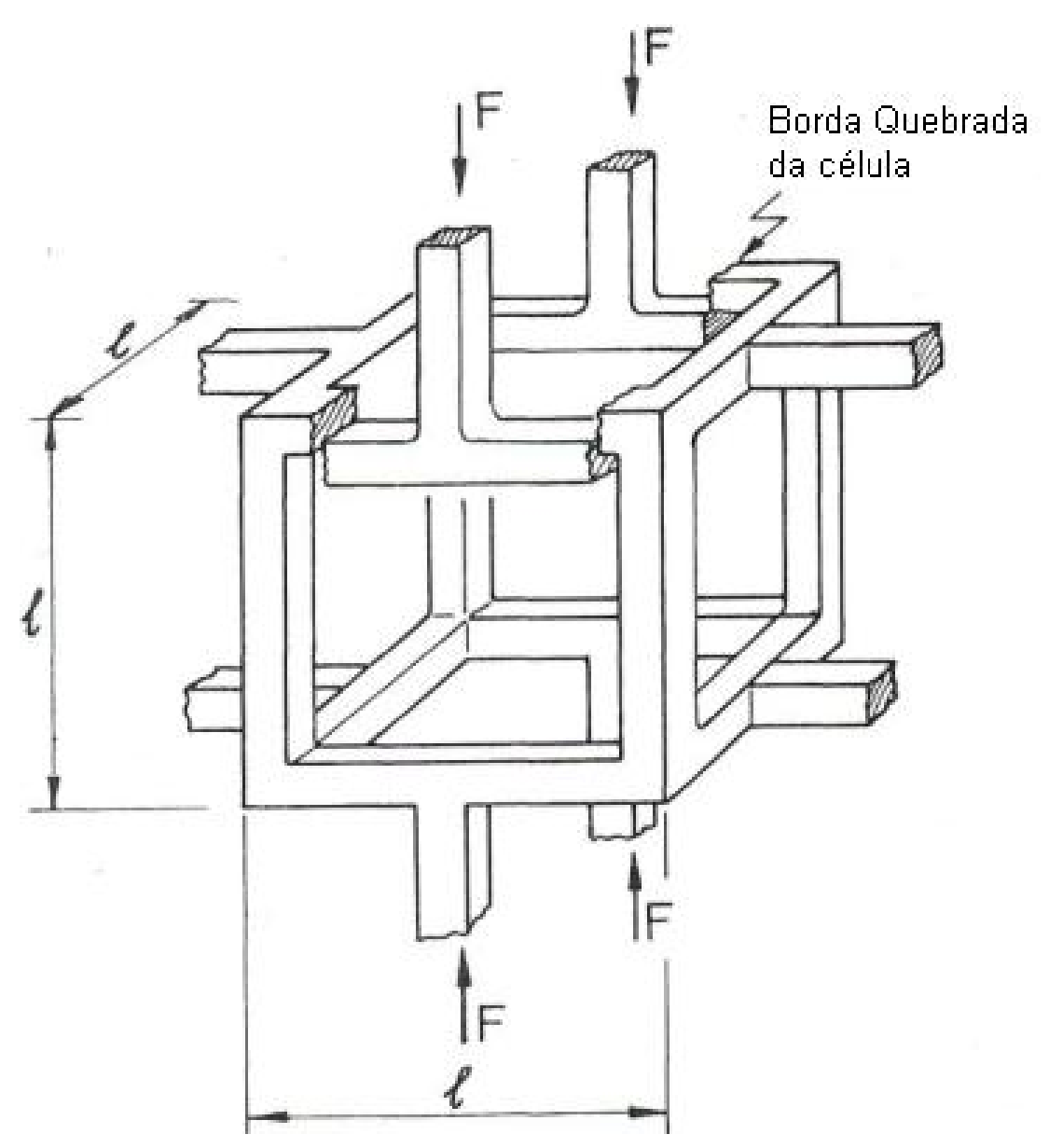

Figura 3.11: Desenho mostrando a ruptura de uma célula aberta similar a dos poros abertos. ${ }^{[55]}$

Em um estudo recentemente publicado por Pabst et al, são propostas equações que se baseiam na relação entre o Módulo Elástico relativo e o Módulo Elástico Intrínseco (do material) $E_{0}$; neste estudo as principais equações já propostas, para modelar o comportamento mecânico de cerâmicas porosas foram 
classificadas e exaustivamente analisadas confrontando-se as mesmas com resultados experimentais. ${ }^{[56]}$

Neste estudo Pabst et al., apresentam a equação (3.4.6) como a que melhor se ajusta aos dados coletados experimentalmente. Esta equação inclui um fator de ajuste, denominado porosidade crítica $\left(\Phi_{\mathrm{C}}\right)$, que leva em consideração o fenômeno da percolação, sendo sugerido pelos autores como sendo 0,684. ${ }^{[56]}$

$$
E_{r}=(1-\phi) *\left(1-\frac{\phi}{\phi_{c}}\right)
$$

onde $E_{r}$ é o Módulo Elasticidade relativo e $\Phi$ é a porosidade total e $\Phi_{C}$ é a porosidade crítica.

\subsection{Produção de cerâmicas porosas à base de nitreto de silício}

Uma das principais limitações para a utilização mais ampla das cerâmicas porosas é a sua baixa resistência mecânica, já que há uma relação inversa entre porosidade e resistência mecânica. Para se contornar esse obstáculo, vêm sendo desenvolvidas novas cerâmicas porosas de alto desempenho, à base de nitreto de silício e seus compósitos, que podem apresentar melhor desempenho mecânico em relação às cerâmicas atualmente em uso (cordierita, mulita, alumina, carbeto de silício). ${ }^{[52,64-67]}$

O nitreto de silício possui duas diferentes fases cristalinas estáveis, ambas com similares estruturas cristalinas hexagonais: $0 \quad \alpha-\mathrm{Si}_{3} \mathrm{~N}_{4}$ com simetria trigonal e o $\beta$ - $\mathrm{Si}_{3} \mathrm{~N}_{4}$ com simetria hexagonal. $\mathrm{O}$ nitreto de silício por ser uma cerâmica covalente, apresenta baixo coeficiente de difusão, e com isso apresenta dificuldade de densificar via estado sólido. Normalmente são introduzidos aditivos de sinterização (óxidos como $\mathrm{Al}_{2} \mathrm{O}_{3}, \mathrm{Y}_{2} \mathrm{O}_{3}, \mathrm{MgO}$ etc.) que reagem com a camada de sílica na superfície do nitreto, formando de uma fase líquida. Esta fase líquida dissolve continuamente as partículas de $\alpha-\mathrm{Si}_{3} \mathrm{~N}_{4}$, e com a supersaturação da mesma, ocorre a precipitação de grãos $\beta-\mathrm{Si}_{3} \mathrm{~N}_{4}$. Com o resfriamento, surge uma microestrutura composta basicamente de grãos de $\mathrm{Si}_{3} \mathrm{~N}_{4}\left(\beta-\mathrm{Si}_{3} \mathrm{~N}_{4}\right.$ podendo ocorrer $\alpha-\mathrm{Si}_{3} \mathrm{~N}_{4}$ residual) e uma fase intergranular amorfa (podendo ocorrer a cristalização 
parcial desta). Os grãos de $\beta-\mathrm{Si}_{3} \mathrm{~N}_{4}$ crescem anisotropicamente na presença de fase líquida, na forma de prismas hexagonais, formando grãos alongados, de alta razão de aspecto, ocorrendo então o fenômeno do reforço in-situ da microestrutura do nitreto de silício. Na Figura 3.12 apresenta-se de modo esquemático a evolução microestrutural do $\mathrm{Si}_{3} \mathrm{~N}_{4}$ durante a sinterização.

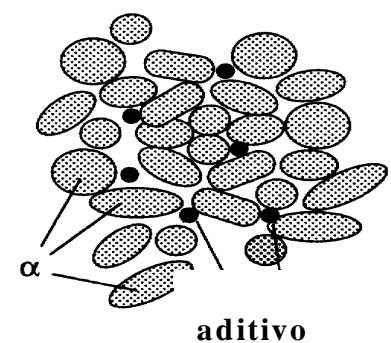

Pó de partida

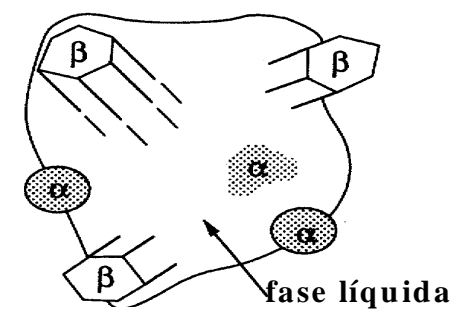

Transformação $\alpha \rightarrow \beta$

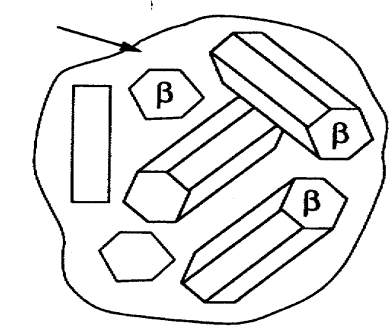

$\mathrm{Si}_{3} \mathrm{~N}_{4}$ Denso
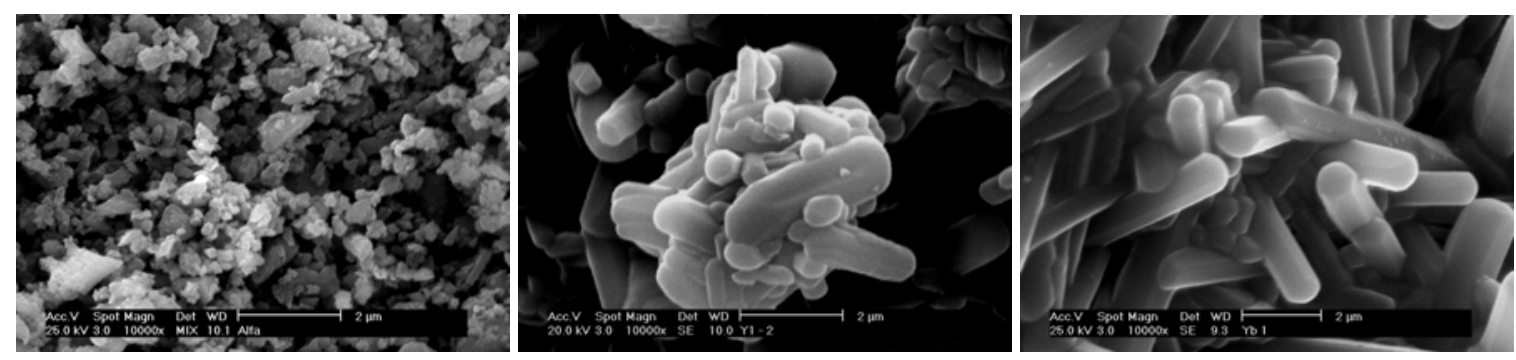

Figura 3.12: Esquema de transformação de fases $\alpha \rightarrow \beta$.do nitreto de silício ${ }^{[71]}$.

O nitreto de silício possui um conjunto ímpar de propriedades (mecânicas, térmicas e químicas) e, além disso, possui como uma de suas principais características, o fenômeno do reforço in-situ, que se dá pelo crescimento anisotrópico dos grãos durante a sinterização, tornando-os alongados e promovendo uma microestrutura reforçada pelo entrelaçamento dos mesmos. Estes grãos alongados, além de interferir positivamente na resistência mecânica do material, promovem o surgimento de mecanismos tenacificadores, podendo-se atingir valores de tenacidade à fratura tão altos como $10 \mathrm{MPa} \cdot \mathrm{m}^{1 / 2}$, quando para a maioria das cerâmicas esse valor não ultrapassa $4 \mathrm{MPa} \cdot \mathrm{m}^{1 / 2}$. Este fenômeno é mostrado nas Figuras 3.13 e 3.14. ${ }^{[52,64-67]}$

Esta particularidade microestrutural do nitreto de silício, que já vem sendo bastante explorada para a obtenção de peças densas de alto desempenho mecânico, pode também ser altamente benéfica para o desenvolvimento de cerâmicas porosas com superior resistência mecânica, fazendo com que 
diferentes grupos de pesquisadores se dediquem à exploração deste tema.

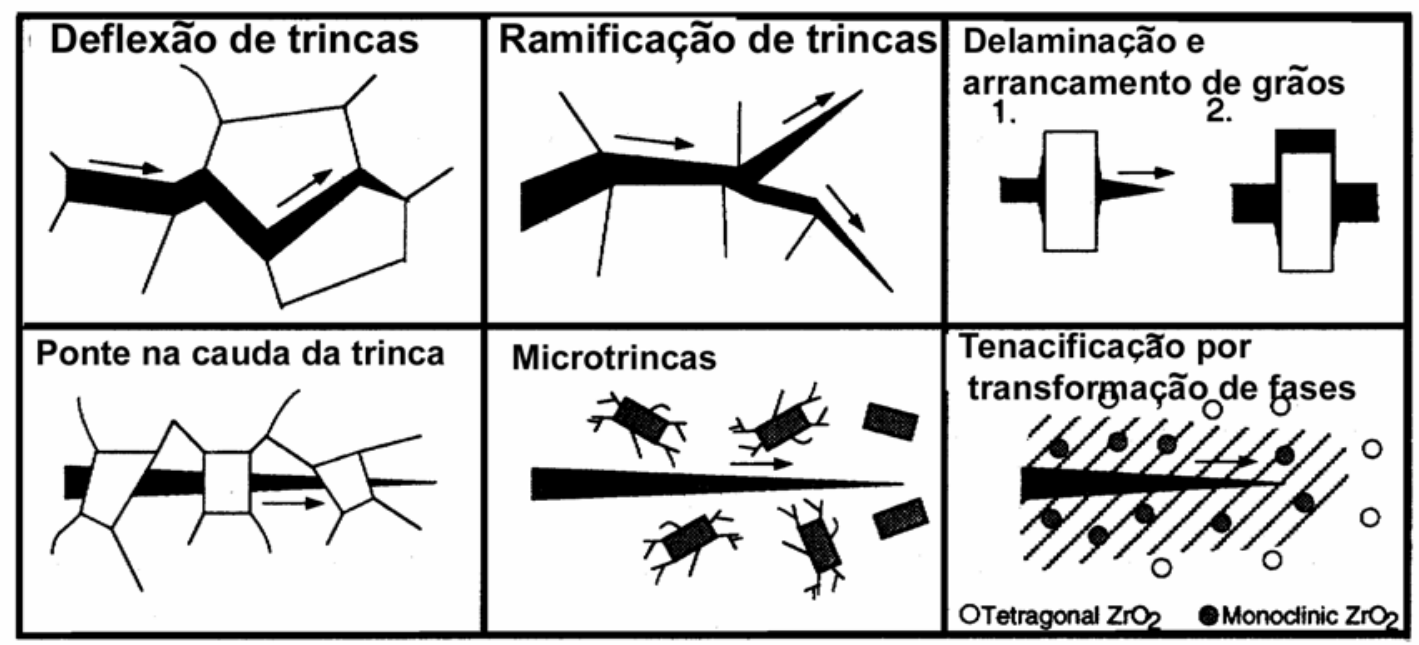

Figura 3.13: Esquema indicando os principais mecanismos de tenacificação que podem ocorrer em cerâmicas estruturais. ${ }^{[71]}$

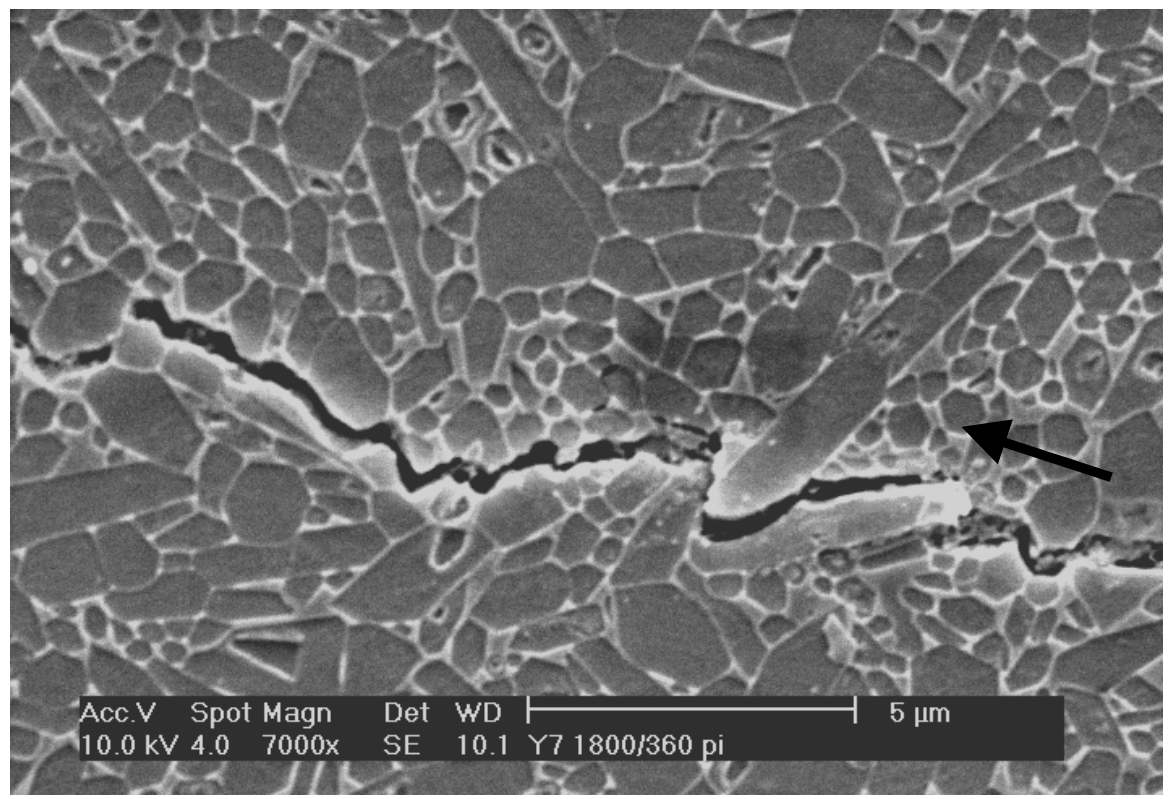

Figura 3.14: Micrografia demonstrando o mecanismo de tenacificação em ação. ${ }^{[71]}$

Dentre os estudos para a obtenção de cerâmicas porosas à base de nitreto de silício destaca-se o trabalho de Hampshire et al. ${ }^{[52]}$ que utilizaram amido de milho como fase sacrificial para a produção deste material. Neste a 
influência do teor de amido na porosidade e conseqüentemente foi analisado. Para uma porosidade de $20 \%$ o valor de módulo de ruptura varia de 150 a 300 MPa.

Outro grupo que vem sistematicamente estudando a produção e caracterização de cerâmicas porosas à base de $\mathrm{Si}_{3} \mathrm{~N}_{4}$ é o grupo coordenado por Tatsuki Ohji. Dentre os estudos deste grupo, destaca-se a fabricação de corpos de nitreto de silício porosos pela técnica de tape-casting que promove, com a sinterização, um expressivo alinhamento dos grãos de $\mathrm{Si}_{3} \mathrm{~N}_{4}$, formando uma microestrutura altamente anisotrópica; os autores do estudo demonstram que é possível atingir elevados valores de propriedades mecânicas (resistência à fratura de $1080 \mathrm{MPa}$ ) na direção perpendicular aos grãos alinhados. ${ }^{[65]} \mathrm{Em}$ outro estudo, partindo de um pó de nitreto de silício de baixa pureza obtiveram corpos com porosidade variando de $43,8 \%$ a $47 \%$, módulo de elasticidade de $62 \mathrm{GPa}-75$ GPa e resistência mecânica de $110 \mathrm{MPa}$ a $170 \mathrm{MPa} .{ }^{[66]}$. Em um outro trabalho, utilizando fibras de resina de fenol-formaldeído como fase sacrificial, produziram corpos de $\mathrm{Si}_{3} \mathrm{~N}_{4}$ com $42 \%$ de porosidade, sendo os poros na forma de canais de $10 \mu \mathrm{m}$ de diâmetro. ${ }^{[67]}$.Partindo de suspensões aquosas de $\mathrm{Si}_{3} \mathrm{~N}_{4}$ e utilizando a técnica de conformação e secagem por freeze-drying, estes mesmos autores obtiveram corpos com porosidade variando entre 49 e $69 \%$, com os poros na forma de canais alinhados. ${ }^{[68]}$

Este mesmo grupo ainda explorou a possibilidade de se obter corpos porosos de $\mathrm{Si}_{3} \mathrm{~N}_{4}$ aliando sinterização parcial e prensagem a quente, obtendo valores expressivos de resistência mecânica (780 MPa) ${ }^{[69]}$

Por fim, em uma publicação recente, os grupos de Ohji e Hampshire estudaram em conjunto a influência de diferentes métodos de processamento nas propriedades dos corpos de $\mathrm{Si}_{3} \mathrm{~N}_{4}$ porosos obtidos. Concluíram que para o caso da utilização do amido como fase sacrificial, o tamanho deste não deve influenciar no módulo de ruptura do material. Concluíram ainda que amostras produzidas por sinterização parcial seguida por prensagem a quente, e com porosidade de até $25 \%$, são as que apresentam, até o momento maiores valores de resistência mecânica, se comparadas às obtidas por outras técnicas reportadas. ${ }^{[70]}$ 
Diversos estudos indicam que a estabilização da suspensão é um importante fator que interfere nas propriedades mecânicas dos corpos de $\mathrm{Si}_{3} \mathrm{~N}_{4}$ porosos, quando estes são obtidos a partir suspensões aquosas de nitreto de silício. ${ }^{[55-62]}$ Uma eficiente maneira de estabilizar o nitreto de silício em meio aquoso é através do uso do poliacrilato de amônia $\left(\mathrm{NH}_{4} \mathrm{PA}\right)$ como defloculante; no entanto este defloculante é efetivo para a estabilização de óxidos, de modo que duas alternativas são propostas na literatura: o recobrimento da superfície das partículas de nitreto com hidróxido de alumínio, ou a calcinação do pó de nitreto para que ocorra oxidação superficial das partículas, formando uma camada de $\mathrm{SiO}_{2}$. A calcinação a $600^{\circ} \mathrm{C}$, aumenta a carga positiva na superfície dos aditivos de sinterização $\left(\mathrm{Al}_{2} \mathrm{O}_{3}\right.$ e $\left.\mathrm{Y}_{2} \mathrm{O}_{3}\right)$ e a quantidade de grupos silanóis em detrimento dos grupos aminas, mudando o ponto isoelétrico para região ácida e favorecendo a estabilização as valores de $\mathrm{pH}$ próximos a 8 . As suspensões obtidas com nitreto calcinado com concentrações relativamente altas de sólidos (60\% em volume) possuem comportamento pseudo-plástico, com baixa viscosidade. ${ }^{[57-64]}$ 


\section{Materiais e Métodos}

Para todo o estudo fixou-se uma composição padrão consistindo de $92 \%$ de $\alpha-\mathrm{Si}_{3} \mathrm{~N}_{4}, 6 \%$ de $\mathrm{Y}_{2} \mathrm{O}_{3}$ e $2 \%$ de $\mathrm{Al}_{2} \mathrm{O}_{3}$ (percentuais em peso). A mistura dos componentes foi moída em moinho de alta energia, tipo Atritor, por 4 horas a 300 rpm, utilizando-se esferas e recipiente de $\mathrm{Si}_{3} \mathrm{~N}_{4}$, e álcool isopropílico como meio líquido. Após a moagem, a suspensão foi seca em rotoevaporador e desaglomerada. Abaixo são apresentadas as características físicas e químicas das matérias-primas utilizadas. ${ }^{[71,72] \text { : }}$

Nitreto de sílicio:

- M11- H.C. Starck

- $\mathrm{D}_{50}=0,66 \mu \mathrm{m}$

- Área específica $=14,5 \mathrm{~m}^{2} / \mathrm{g}$

- $\alpha-\mathrm{Si}_{3} \mathrm{~N}_{4}=$ acima de $93 \%$

Tabela 4.1: Análise química do $\mathrm{Si}_{3} \mathrm{~N}_{4} \mathrm{M} 11-\mathrm{H}$. C. Starck ${ }^{[71]}$

\begin{tabular}{cc}
\hline Elemento & Concentração \\
\hline $\mathrm{N}$ & $38,99 \%$ \\
$\mathrm{C}$ & $0,17 \%$ \\
$\mathrm{O}$ & $1,68 \%$ \\
$\mathrm{Fe}$ & $13 \mathrm{ppm}$ \\
$\mathrm{Al}$ & $380 \mathrm{ppm}$ \\
$\mathrm{Ca}$ & $35 \mathrm{ppm}$ \\
\hline
\end{tabular}


Alumina $\left(\mathrm{Al}_{2} \mathrm{O}_{3}\right)$ :

- A-16 - Alcoa

- $D_{50}=0,32 \mu \mathrm{m}$

- $\quad 99,7 \%$ de pureza

Óxido de Ítrio $\left(\mathrm{Y}_{2} \mathrm{O}_{3}\right)$ :

- Aldrich Chemical Company, Inc:

- $\mathrm{D}_{50}=0,60 \mu \mathrm{m}$

- $99,9 \%$ de pureza

Foram realizados estudos com o intuito de avaliar o efeito do tratamento térmico a $600^{\circ} \mathrm{C} / 1 \mathrm{~h}$ (oxidação das partículas de $\mathrm{Si}_{3} \mathrm{~N}_{4}$ ) nas características reológicas de suspensões aquosas de nitreto de silício. Após estes estudos definiu-se por utilizar este tratamento prévio para todas as conformações a partir de suspensões aquosas, já que dessa forma estas se mostraram mais fáceis de serem, estabilizadas.

\subsection{Gel-casting utilizando-se amido como gelificante}

Para este estudo foram usados amidos de 3 diferentes procedências, amido de batata, de milho e de arroz. Foram preparadas suspensões aquosas contendo 50 e $55 \%$ em peso de sólido, sendo adicionado às mesmas 10,3, 16,4 e $23,4 \%$ em peso de amido (com relação à massa de $\mathrm{Si}_{3} \mathrm{~N}_{4}$ ) que corresponde a 20 , 30 e $40 \%$ em volume. As composições estudadas são apresentadas na Tabela 4.2. A mistura foi feita em moinho atritor por 30 minutos sob uma rotação baixa (150 rpm) de modo a minimizar possível cominuição das partículas já moídas anteriormente. As suspensões contendo amido foram vertidas em moldes cilíndricos e aquecidas em banho termostático em temperaturas típicas de gelificação para cada amido específico: a $65{ }^{\circ} \mathrm{C}$ para a suspensão contendo amido de batata, $75^{\circ} \mathrm{C}$ para a suspensão contendo amido de milho e $82,5^{\circ} \mathrm{C}$ para a suspensão contendo amido de arroz. Todos os corpos foram mantidos na temperatura de gelificação por 2horas. Após isso os corpos foram desmoldados, secos, e tratados termicamente, por meio de um processo lento de secagem $(24 \mathrm{~h}$ 
ao ar a temperatura ambiente, seguido de $24 \mathrm{~h}$ a $60^{\circ} \mathrm{C}$ em estufa e por fim $24 \mathrm{~h}$ a $\left.12{ }^{\circ} \mathrm{C}\right)$. Após a secagem ocorreu a fase de eliminação dos orgânicos por tratamento térmico, aquecendo-se lentamente os corpos de prova a uma taxa de $1{ }^{\circ} \mathrm{C} / \mathrm{min}$, com patamares de 60 minutos a 200,300 e $400{ }^{\circ} \mathrm{C}$, seguido de resfriamento. Por fim os corpos de prova foram sinterizados em forno com elemento resistivo de grafite (Astro furnace), a $1800{ }^{\circ} \mathrm{C}$ por 60 minutos, sob atmosfera de 0,2 $\mathrm{MPa}$ de $\mathrm{N}_{2}$, com taxa de aquecimento de $15^{\circ} \mathrm{C} / \mathrm{min}$., e resfriamento com o desligamento do forno. Na Figura 4.1 é mostrado um fluxograma esquemático do processo.

Tabela 4.2: Composições estudadas para produção de amostras via gel-casting com amido.

\begin{tabular}{|c|c|c|c|}
\hline Amostra & Amido & $\begin{array}{c}\text { Total de sólidos } \\
(\%)\end{array}$ & Amido (\%vol) \\
\hline $5520 A$ & Arroz & 55 & 20 \\
\hline $5530 A$ & Arroz & 55 & 30 \\
\hline 5020A & Arroz & 50 & 20 \\
\hline $5030 A$ & Arroz & 50 & 30 \\
\hline $5040 A$ & Arroz & 50 & 40 \\
\hline $5520 B$ & Batata & 55 & 20 \\
\hline $5530 \mathrm{~B}$ & Batata & 55 & 30 \\
\hline $5020 B$ & Batata & 50 & 20 \\
\hline $5030 \mathrm{~B}$ & Batata & 50 & 30 \\
\hline $5040 B$ & Batata & 50 & 40 \\
\hline $5520 M$ & Milho & 55 & 20 \\
\hline $5530 \mathrm{M}$ & Milho & 55 & 30 \\
\hline 5020M & Milho & 50 & 20 \\
\hline $5030 M$ & Milho & 50 & 30 \\
\hline 5040M & Milho & 50 & 40 \\
\hline
\end{tabular}




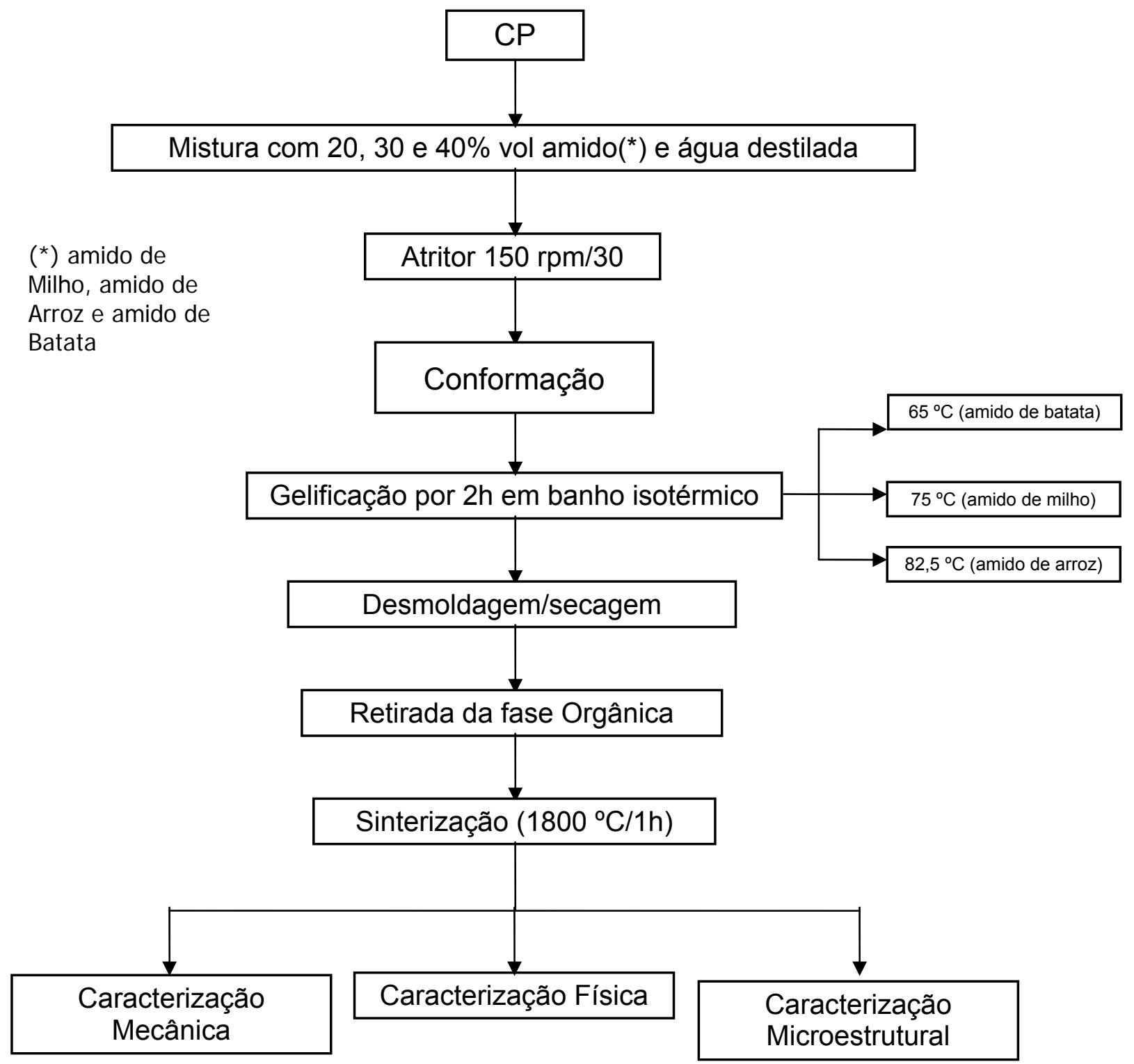

Figura 4.1: Processamento das amostras por gel-casting com amido.

\subsection{Obtenção de corpos porosos pelo método da fase sacrificial utilizando-se diferentes amidos}

Para este estudo foram utilizados os mesmos amidos citados anteriormente, que foram adicionados à suspensão aquosa de $\mathrm{Si}_{3} \mathrm{~N}_{4}$ em proporções tais que ao final correspondesse a 20,30 e $40 \%$ em volume da mistura seca. As composições estudadas são apresentadas na Tabela 4.3. A adição dos amidos se deu em moinho tipo atritor por 30 minutos a 150 RPM. As suspensões foram secas em estufa a $70^{\circ} \mathrm{C}$ por 48 horas, sendo os pós obtidos, desaglomerados em almofariz de alumina e homogeneizados em misturador Túrbula por 90 minutos. Os pós foram então prensados uniaxialmente em 
pastilhas $\phi 14 \mathrm{~mm}$, sob pressão de $32 \mathrm{MPa}$, sendo estas sinterizadas sob 5 diferentes condições $\left(1600{ }^{\circ} \mathrm{C}, 1800^{\circ} \mathrm{C}\right.$ e $1850^{\circ} \mathrm{C}$ por 1 hora, $1700{ }^{\circ} \mathrm{C}$ por 30 minutos e 3 horas), em atmosfera de nitrogênio. Na Figura 4.2 é mostrado um fluxograma esquemático do processo de produção via fase sacrificial.

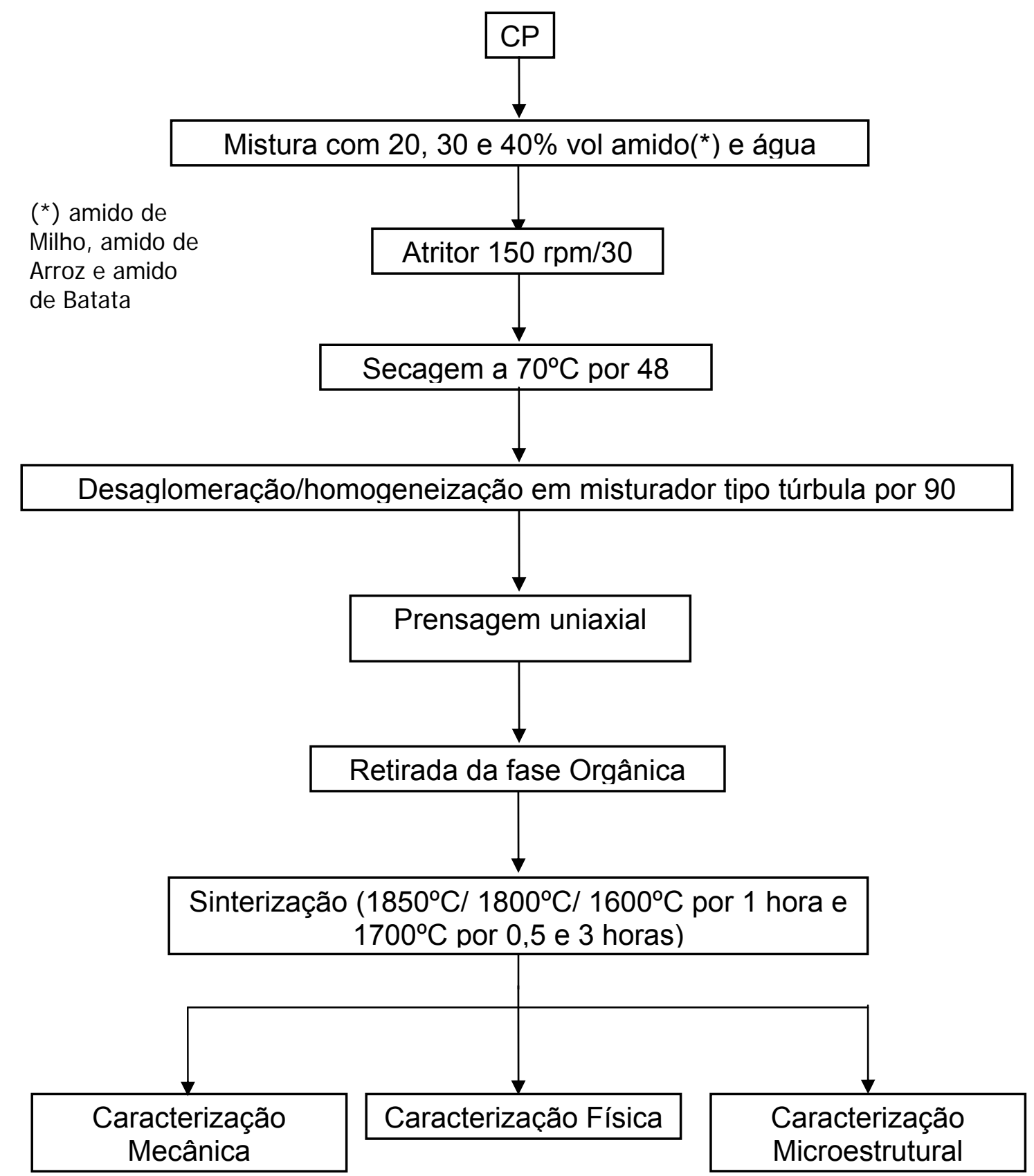

Figura 4.2: Processamento das amostras por fase sacrificial com amido. 
Tabela 4.3: Composições estudadas.

\begin{tabular}{ccc}
\hline Amostra & Amido & Amido (\%vol) \\
\hline A20 & Arroz & 20 \\
A30 & Arroz & 30 \\
A40 & Arroz & 40 \\
B20 & Batata & 20 \\
B30 & Batata & 30 \\
B40 & Batata & 40 \\
M20 & Milho & 20 \\
M30 & Milho & 30 \\
M40 & Milho & 40 \\
\hline
\end{tabular}

\subsection{Gel-casting de espumas utilizando-se albumina, a gelatina ou ágar como gelificante}

Foram realizados estudos preliminares para avaliação de outros agentes de gelificação como a gelatina, ágar ou albumina. Para o caso da utilização da albumina, as suspensões contendo $3 \%$ em peso do agente gelificante (em relação ao peso do $\mathrm{Si}_{3} \mathrm{~N}_{4}$ ) foram preparadas a temperatura ambiente, passando por um processo de aeração por diferentes métodos (mistura em batedeira doméstica, com o auxílio de agitador sob diferentes rotações e diferentes tipos de hastes, etc.), e com a adição de diferentes agentes espumantes. Após a etapa de aeração, as suspensões foram vertidas em diferentes moldes e aquecidas a temperaturas acima de $90{ }^{\circ} \mathrm{C}$, para que ocorresse o processo de gelificação. Esta etapa de gelificação é bastante crítica, pois se deve evitar que ocorra simultaneamente a secagem não uniforme dos corpos. Neste sentido foram testados diferentes métodos de aquecimento, inclusive com a utilização de autoclave. Os corpos obtidos passaram então por processo de secagem lenta, eliminação dos orgânicos e sinterização de maneira similar ao descrito para o amido.

Com relação à utilização de gelatina ou ágar como agentes gelificantes, as suspensões foram preparadas em temperaturas adequadas para a dissolução destes (acima de $60{ }^{\circ} \mathrm{C}$ para a gelatina e acima de $80^{\circ} \mathrm{C}$ para o agar), 
passando por processos de aeração similar ao descrito anteriormente, sendo vertidas então nos moldes e resfriadas para a gelificação. Posteriormente passaram pelas etapas de secagem lenta, eliminação de orgânicos e sinterização como descrito anteriormente. Um exemplo de fluxograma do processo (no exemplo para albumina) é mostrado na Figura 4.3.

Os estudos com estes gelificantes não prosseguiram como aqueles referentes ao uso do amido, pois não se conseguiu, até então, um controle rígido do processo que permitisse a reprodutibilidade dos resultados, particularmente no que se refere à etapa de aeração e estabilização da espuma formada. Estes estudos serão retomados oportunamente, já que este método de obtenção de cerâmicas porosas por gel-casting se mostra bastante versátil, permitindo a obtenção de uma ampla variedade de estruturas de poros. 


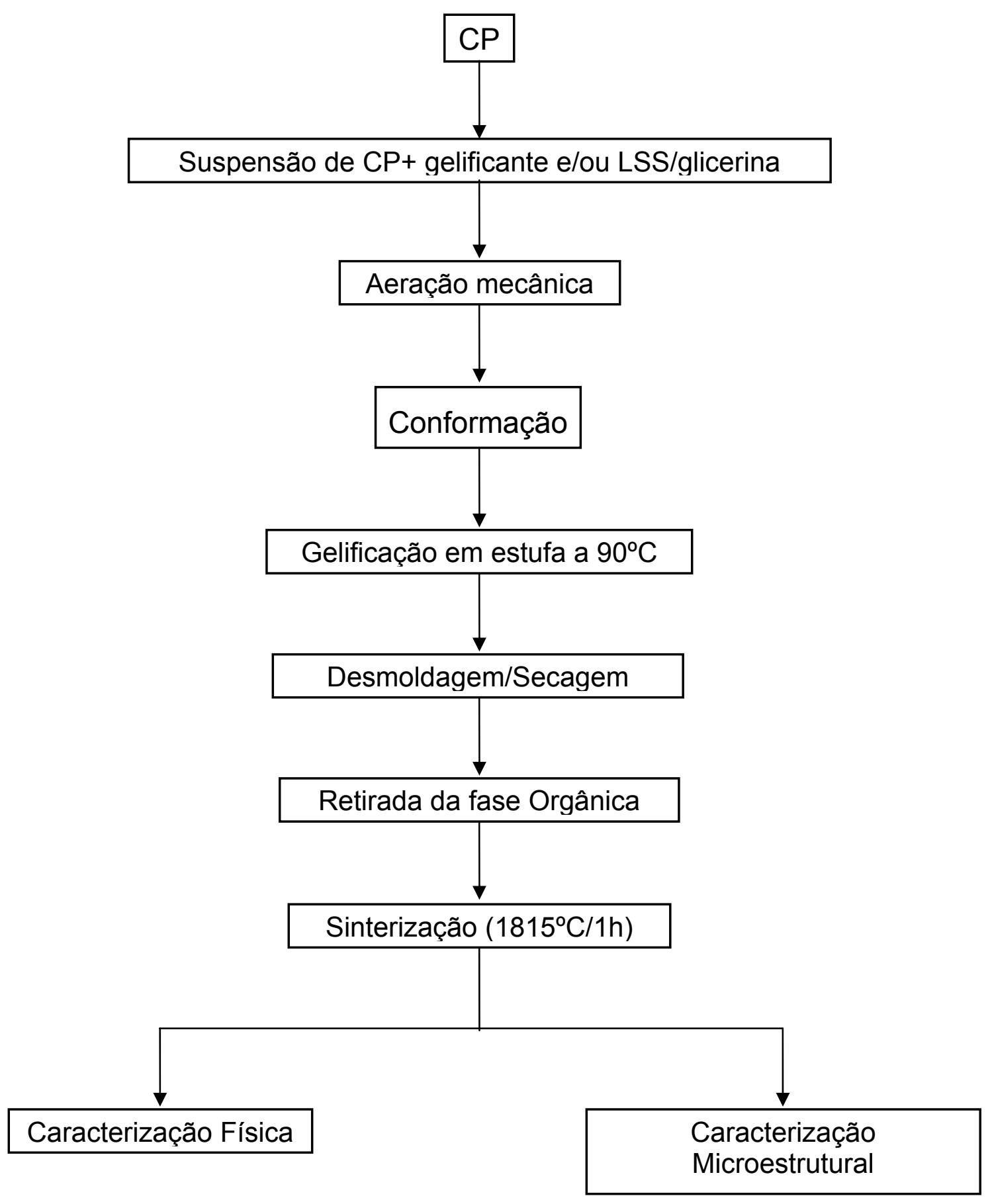

Figura 4.3: Processamento das amostras por gel-casting de espumas com albumina.

\subsection{Caracterização das amostras obtidas}

As suspensões foram caracterizadas utilizando-se um reômetro Brookfield LVD-III com a velocidade variando de 0 a $60 \mathrm{rpm}$.

A distribuição do tamanho de partículas do amido for analisada utilizando-se o método de espalhamento de laser com o equipamento (CILAS 1064). 
Todas as amostras produzidas pelos métodos que utilizaram o amido, descritos anteriormente, foram caracterizadas quanto à densidade e porosidade aparentes (método de Archimedes):

$$
\begin{aligned}
& \text { Densidade }_{\text {aparente }}=\frac{\text { Massa }_{\text {seca }}}{\text { Massa }_{\text {úmida }}-\text { Massa }_{\text {imersa }}} \\
& \text { Porosidade }_{\text {aparente }}=\frac{\text { Massa }_{\text {úmida }}-\text { Massa }_{\text {sec } a}}{\text { Massa }_{\text {úmida }}-\text { Massa }_{\text {imersa }}}
\end{aligned}
$$

A porosimetria de mercúrio foi feita com o uso do porosímetro Autopore III.

A resistência mecânica foi obtida por meio de ensaio de compressão, utilizando-se uma máquina de ensaio universal Instron 4400R com célula de carga de 10 toneladas e o avanço de $0,5 \mathrm{~mm}$ por minuto, sendo ensaiadas, em média 5 amostras de cada condição. As amostras cilíndricas possuíam aproximadamente altura de $10 \mathrm{~mm}$ e diâmetro de $12 \mathrm{~mm}$, sendo que tiveram suas faces retificadas com rebolo diamantado $(45 \mu \mathrm{m})$ antes de serem ensaiadas.

As amostras para a análise microestrutural foram embutidas com resina, sob vácuo, para que esta se infiltrasse nos poros, tornado assim possível o tratamento ceramográfico. As amostras foram desbastadas e posteriormente polidas em uma politriz MOTOPOL 2000 com suspensões de diamante de $30 \mu \mathrm{m}$, $15 \mu \mathrm{m}, 6 \mu \mathrm{m}$ e $1 \mu \mathrm{m}$. As amostras foram recobertas com ouro e depois analisadas no MEV. Por meio das imagens obtidas buscou-se verificar a existência de diferentes níveis de porosidade e tamanho de poro.

As amostras sinterizadas foram analisadas por difração de raios- $X$ utilizando uma varredura de $2 \theta$ de 10 a $60^{\circ}$ e velocidade contínua de 2 graus/minuto. $O$ percentual relativo das fases $\alpha-S_{3} N_{4}$ e $\beta-S i_{3} N_{4}$, em relação à quantidade total de fases $\alpha-S_{3} N_{4}+\beta-S_{3} N_{4}$, foi calculado utilizando as equações a seguir, propostas por Yeheskel e Gefen ${ }^{[73]}$, que relacionam as intensidades de difração de picos específicos.

O percentual relativo de $\alpha-\mathrm{Si}_{3} \mathrm{~N}_{4}$ é dado por:

$$
C_{\frac{\alpha}{(\alpha+\beta)}}=\frac{I_{\alpha(210)}+I_{\alpha(201)}}{I_{\alpha(210)}+I_{\alpha(201)}+I_{\beta(200)}+I_{\beta(210)}} x 100
$$


e consequentemente, o percentual de $\beta-\mathrm{Si}_{3} \mathrm{~N}_{4}$,

$$
C_{\frac{\beta}{(\alpha+\beta)}}=\left(1-C_{\frac{\alpha}{(\alpha+\beta)}}\right) X 100
$$




\section{Resultados e Discussão}

\subsection{Produção de amostras pelo método gel-casting}

$\mathrm{Na}$ figura 5.1 são apresentadas curvas de viscosidade com relação à velocidade de rotação onde são comparados os comportamentos de suspensões aquosas produzidas com pós de $\mathrm{Si}_{3} \mathrm{~N}_{4}$ oxidados superficialmente e não oxidados. Constata-se que os pós oxidados contribuem para uma significativa redução da viscosidade da suspensão; isso ocorre porque o comportamento das partículas de nitreto de silício se torna similar ao do óxido de silício, já que estão envoltas por uma camada superficial de $\mathrm{SiO}_{2}$ formada durante o tratamento térmico a $600{ }^{\circ} \mathrm{C}$. Como conseqüência desta redução na viscosidade, é possível, com os pós oxidados, produzir cerâmicas porosas pelo método "gel-casting de espumas" a partir de suspensões com uma maior faixa de teor de sólido, comparado com as suspensões processadas com pós não oxidados. Com os pós oxidados pode-se processar suspensões aquosas com elevados teores de sólido (acima de 75\%), enquanto para o caso da utilização de pós não oxidados, suspensões contendo acima de $50 \%$ de sólidos apresentaram viscosidade tão alta que inviabilizou a produção de cerâmicas porosas por gel-casting de espuma.

$\mathrm{Na}$ Figura 5.2 são apresentadas curvas de viscosidade versus velocidade de rotação para suspensões produzidas com os dois tipos de pós, contendo diferentes teores de sólido. O teor de sólido é um fator extremamente importante, pois afeta significativamente a etapa de secagem dos corpos obtidos após a gelificação. 


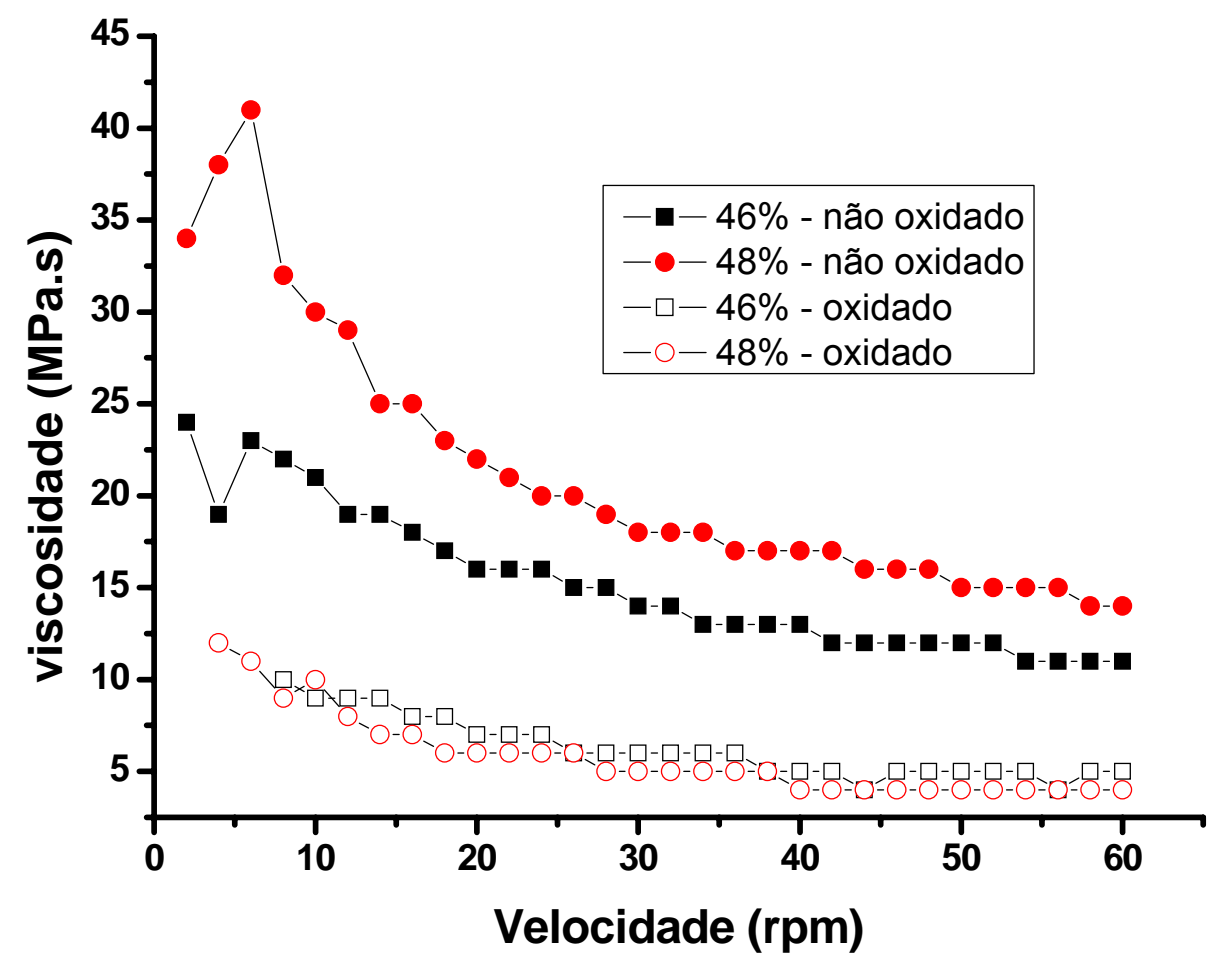

Figura 5.1: Efeito do tratamento de oxidação superficial do pó nas características reológicas de suspensões aquosas de $\mathrm{Si}_{3} \mathrm{~N}_{4}$.

No início do trabalho foram testados diversos parâmetros do processo de gel-casting, que geraram resultados interessantes, mas que devido à falta de reprodutibilidade do processo, foram interrompidos para serem retomados posteriormente. Na Tabela 5.1 e Figuras 5.3 a 5.4 são apresentados alguns destes resultados, quando foram testados diferentes tipos de haste (mostradas na Figura 5.5) para a aeração da suspensão, assim como da presença de compostos que atuam como surfactantes e/ou espumantes (por exemplo, a mistura comercial lauril sulfato de sódio-LSS /glicerina) 


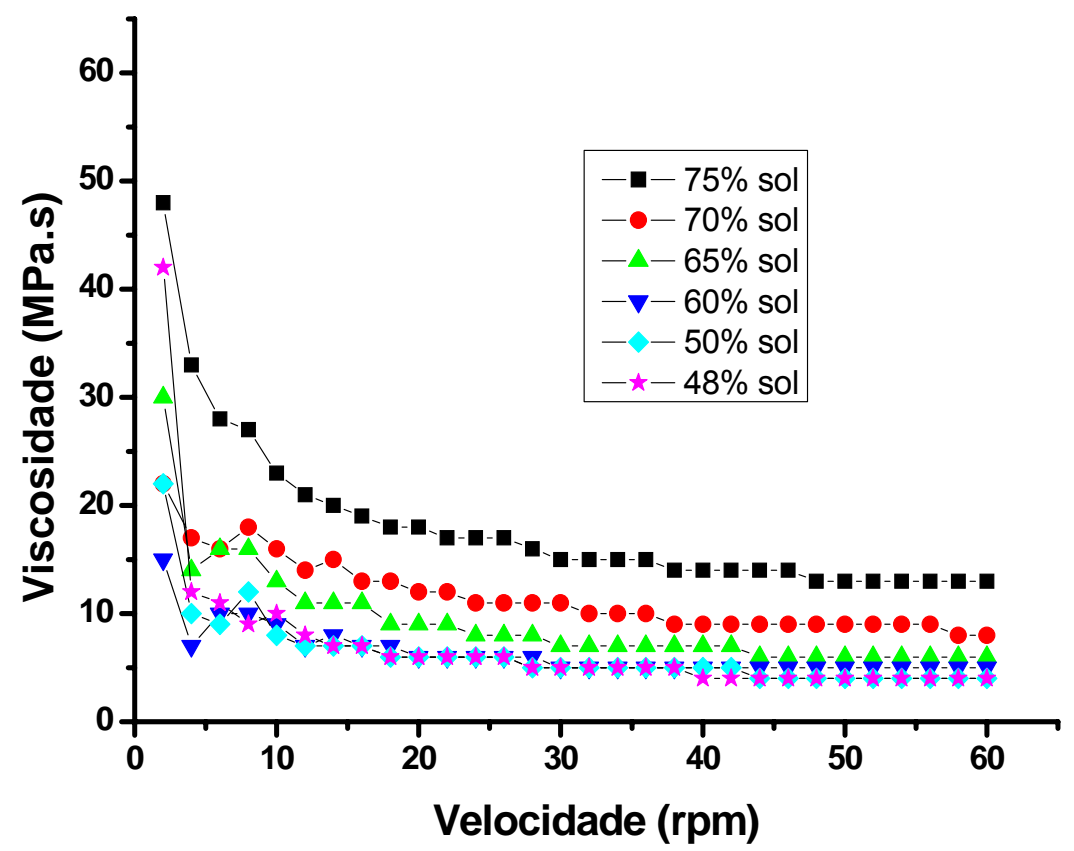

(a) a partir de pós oxidados

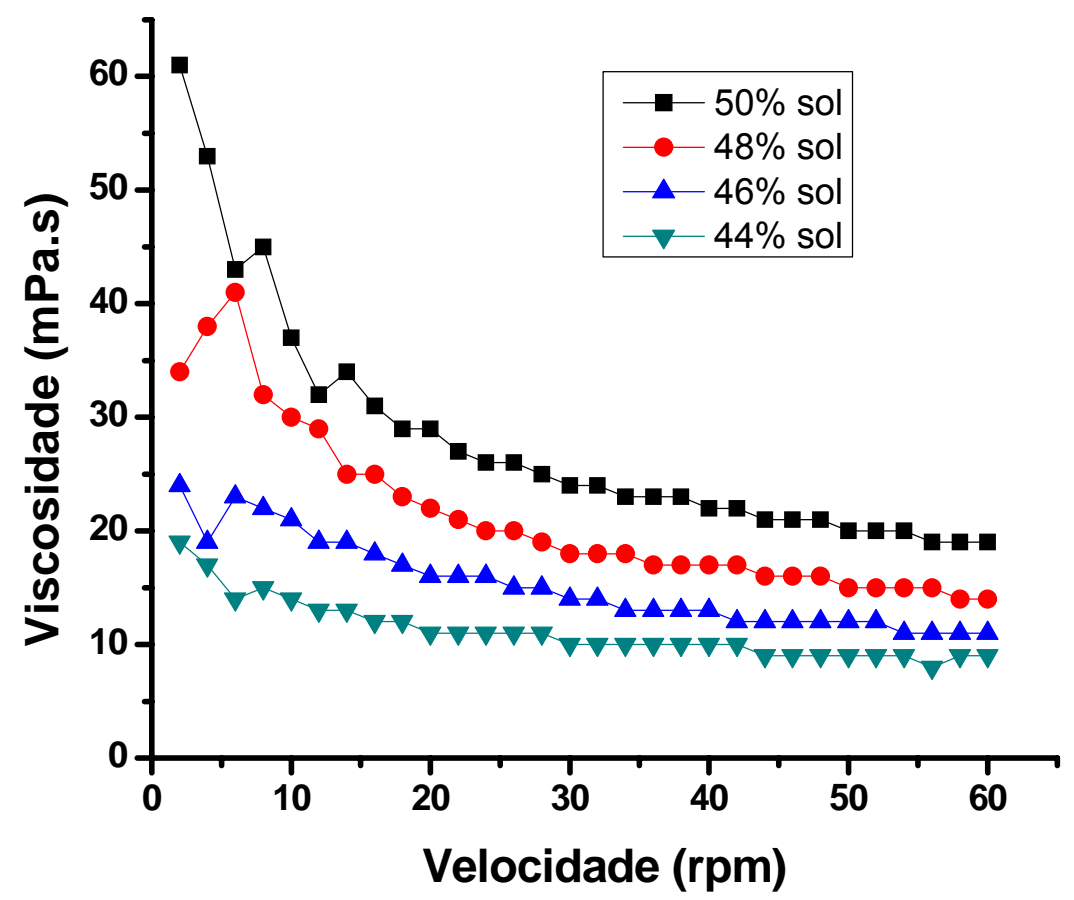

(b) a partir de pós não oxidados

Figura 5.2: Efeito da oxidação superficial das partículas de $\mathrm{Si}_{3} \mathrm{~N}_{4}$ na viscosidade de suspensões aquosas contendo diferentes teores de sólido. 
Tabela 5.1: Efeito do tipo de haste e do agente espumante nas características das cerâmicas porosas obtidas por gel-casting com albumina.

\begin{tabular}{cccccc}
\hline Amostra & haste & LSS/glicerina & $\begin{array}{c}\text { Densidade } \\
\text { relativa (\%) }\end{array}$ & $\begin{array}{c}\text { Porosidade } \\
\text { aparente (\%) }\end{array}$ & $\begin{array}{c}\text { Porosidade (\%) } \\
\text { porosímetro Hg }\end{array}$ \\
\hline 1 & planetária & Sim & $44,0 \pm 6,0$ & $44,0 \pm 9,0$ & 49,5 \\
2 & 4 pás & Sim & $51,0 \pm 2,0$ & $37,0 \pm 2,0$ & 46,5 \\
3 & planetária & Não & $38,0 \pm 9,0$ & $49,0 \pm 6,0$ & 53,5 \\
4 & 4 pás & Não & $50,0 \pm 4,0$ & $39,0 \pm 4,0$ & 40,2 \\
\hline
\end{tabular}

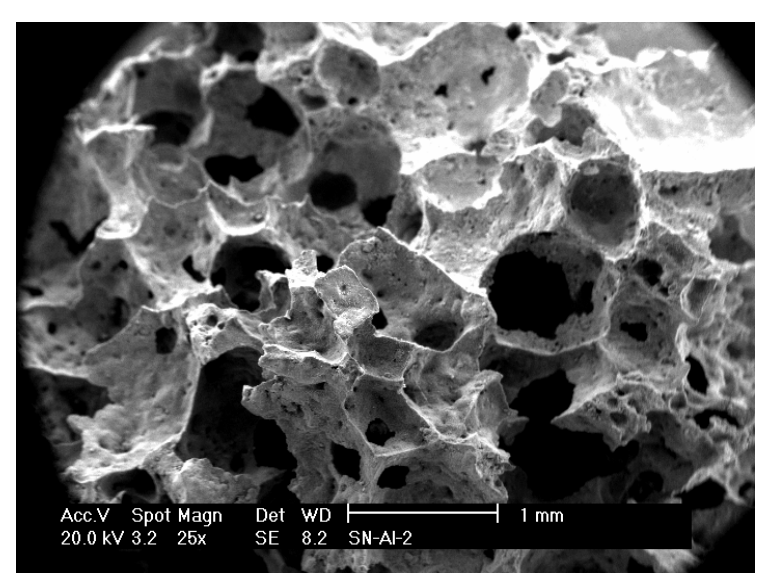

(a)

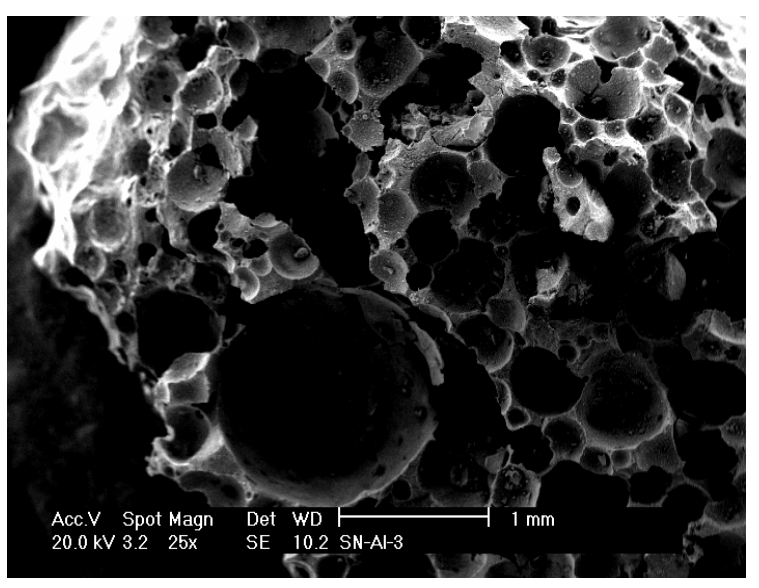

(b)

Figura 5.3: Estruturas porosas obtidas a partir de suspensões contendo LSS/glicerina, por aeração mecânica com diferentes hastes: (a) haste planetária (amostra 1), (b) haste 4 pás (amostra 2). 


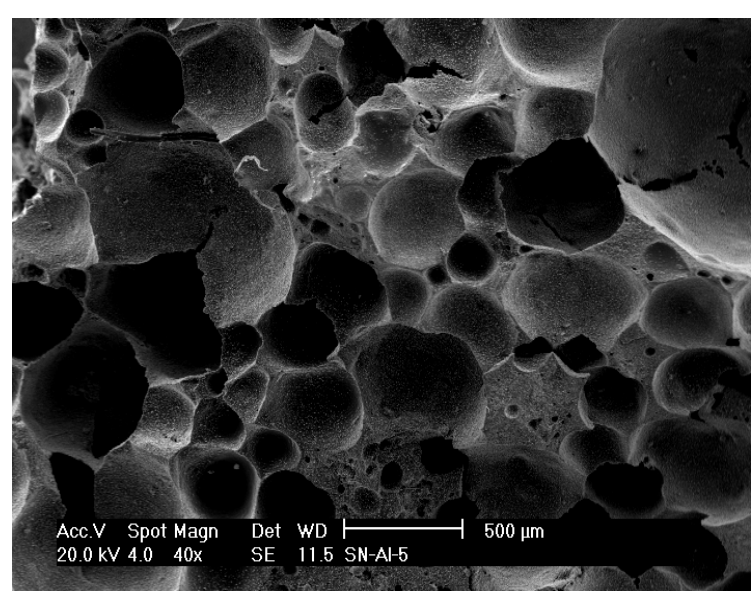

(a)

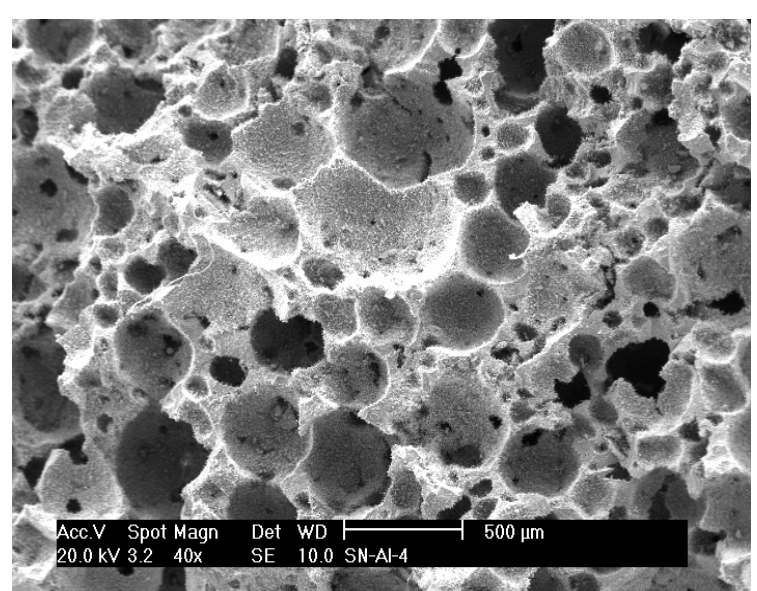

(b)

Figura 5.4: Estruturas porosas obtidas a partir de suspensões contendo albumina, por aeração mecânica com diferentes hastes: (a) haste planetária (amostra 3), (b) haste 4 pás (amostra 4).

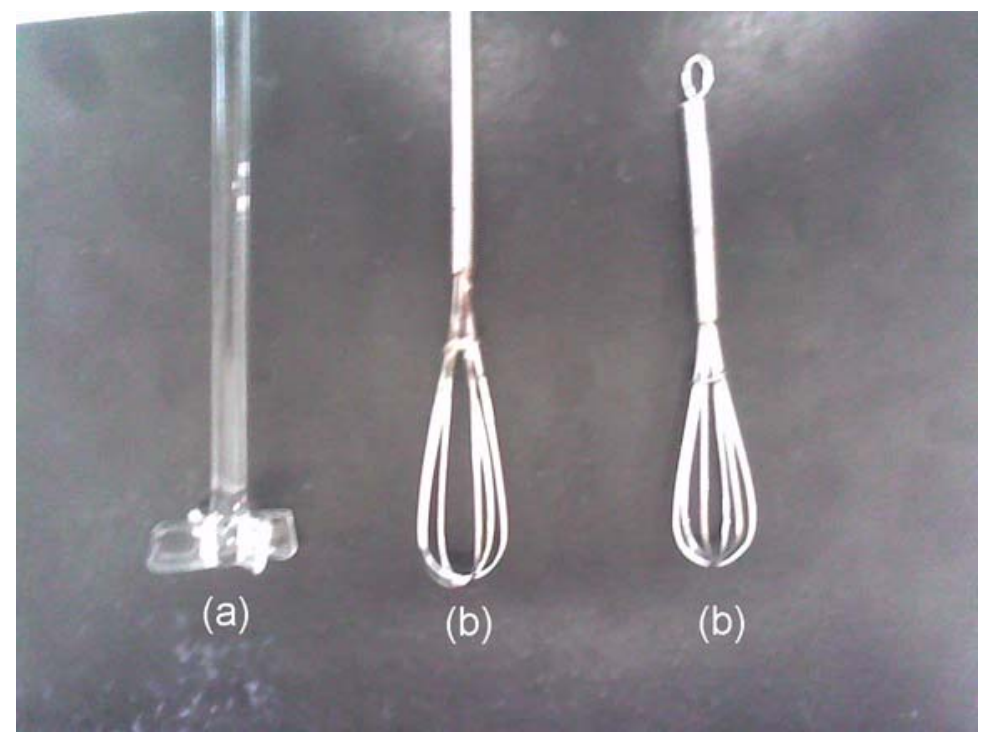

Figura 5.5: Hastes utilizadas para os teste, 4 pás (a) e planetária (b).

Algumas amostras também foram analisadas por meio de porosimetria de mercúrio, sendo apresentado na Figura 5.6, alguns destes resultados. Pelos resultados obtidos com a porosimetria de $\mathrm{Hg}$ observa-se uma distribuição bimodal de tamanho de poros para as amostras 1,2 e 3 , sendo que a amostra 4 apresentou maior tamanho de poros e uma distribuição de tamanhos mais estreita, sem a presença de poros submicrométricos. Apesar disso não se pode 
tirar conclusões definitivas quanto a isto devido à pouca reprodutibilidade do processo, já citada anteriormente.

Uma das etapas críticas do processo de gel-casting utilizando-se albumina é a de gelificação, pois com o aquecimento em estufa em temperaturas acima de $60^{\circ} \mathrm{C}$ (foram testadas diferentes temperaturas) ocorre a perda de água na superfície dos corpos de prova, provocando a formação de defeitos como trincas e deformação do corpo. Foram testadas diferentes alternativas para este tratamento de gelificação, como aquecimento em banho isotérmico, em panela de pressão doméstica e em autoclave. Apesar de o tratamento de gelificação em autoclave ter se mostrado promissor (utilizando-se ciclos de autoclavagem de líquidos), estas técnicas deverão ser mais bem exploradas posteriormente.
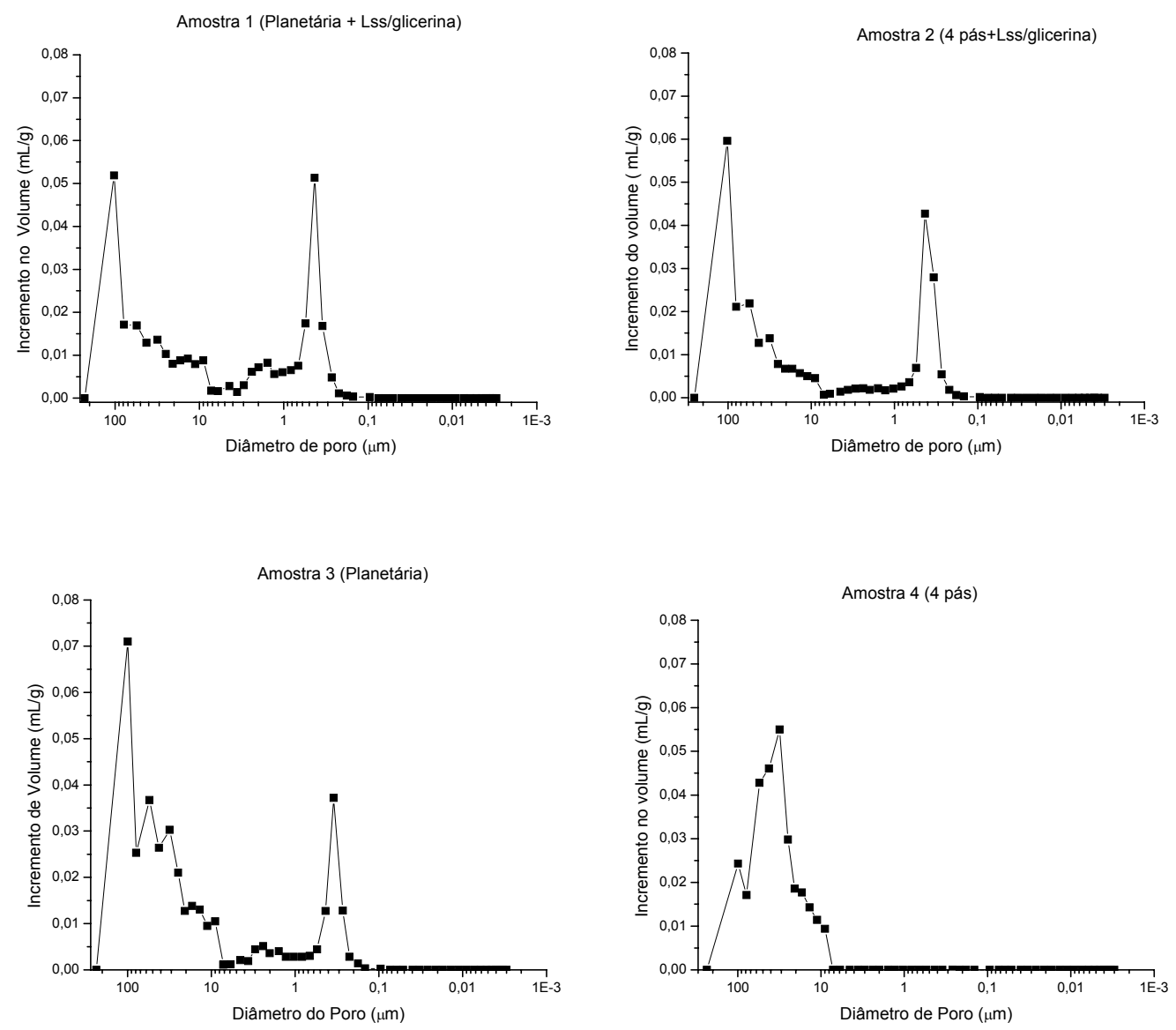

Figura 5.6: Distribuição de poros obtida por porosimetria de $\mathrm{Hg}$ para as amostras descritas na tabela 5.1 . 
Os resultados obtidos com a utilização de ágar ou gelatina como agentes gelificantes são bastante preliminares, pois não se conseguiu, até o momento, superar dificuldades inerentes ao processo de estabilização de espumas e gelificação. Na Figura 5.7 podem-se comparar dois exemplos de estruturas: a obtida com ágar e a obtida com albumina. Neste caso a amostra obtida com a utilização do ágar apresentou estrutura com menor tamanho de poros, comparada à amostra contendo albumina. No entanto não se pode afirmar que este efeito seja devido ao agente gelificante, já que diversos fatores (rotação da haste, percentual de espumante etc.) podem ter influenciado para a definição desta estrutura de poros.

Na Figura 5.8 são mostrados detalhes de uma estrutura porosa de $\beta$ $\mathrm{Si}_{3} \mathrm{~N}_{4}$ obtida neste estudo. Fica bastante evidente a formação de uma estrutura entrelaçada de grãos alongados de $\beta$-Si3N4, que deverá promover uma significativa melhoria nas propriedades mecânicas do material.

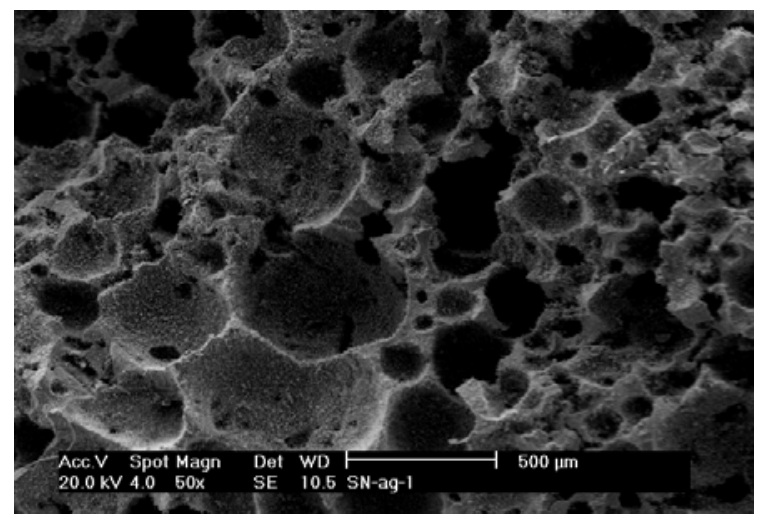

(a)

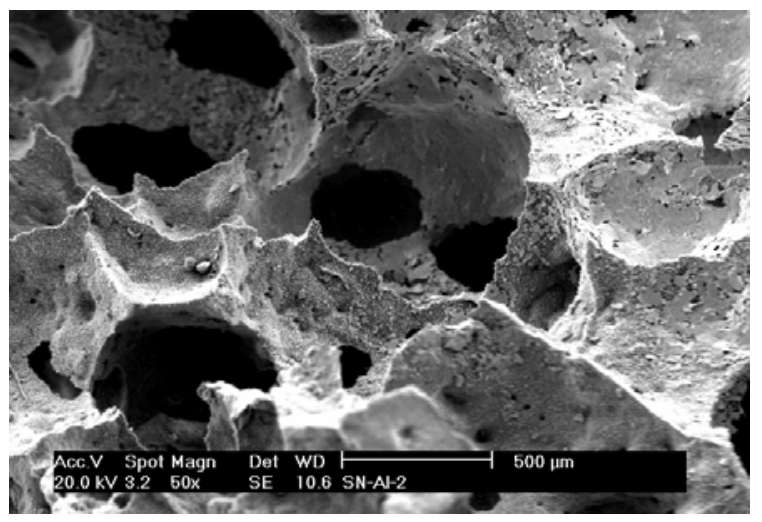

(b)

Figura 5.7: Estruturas porosas obtidas com diferentes gelificantes; (a) agar, (b) albumina. 

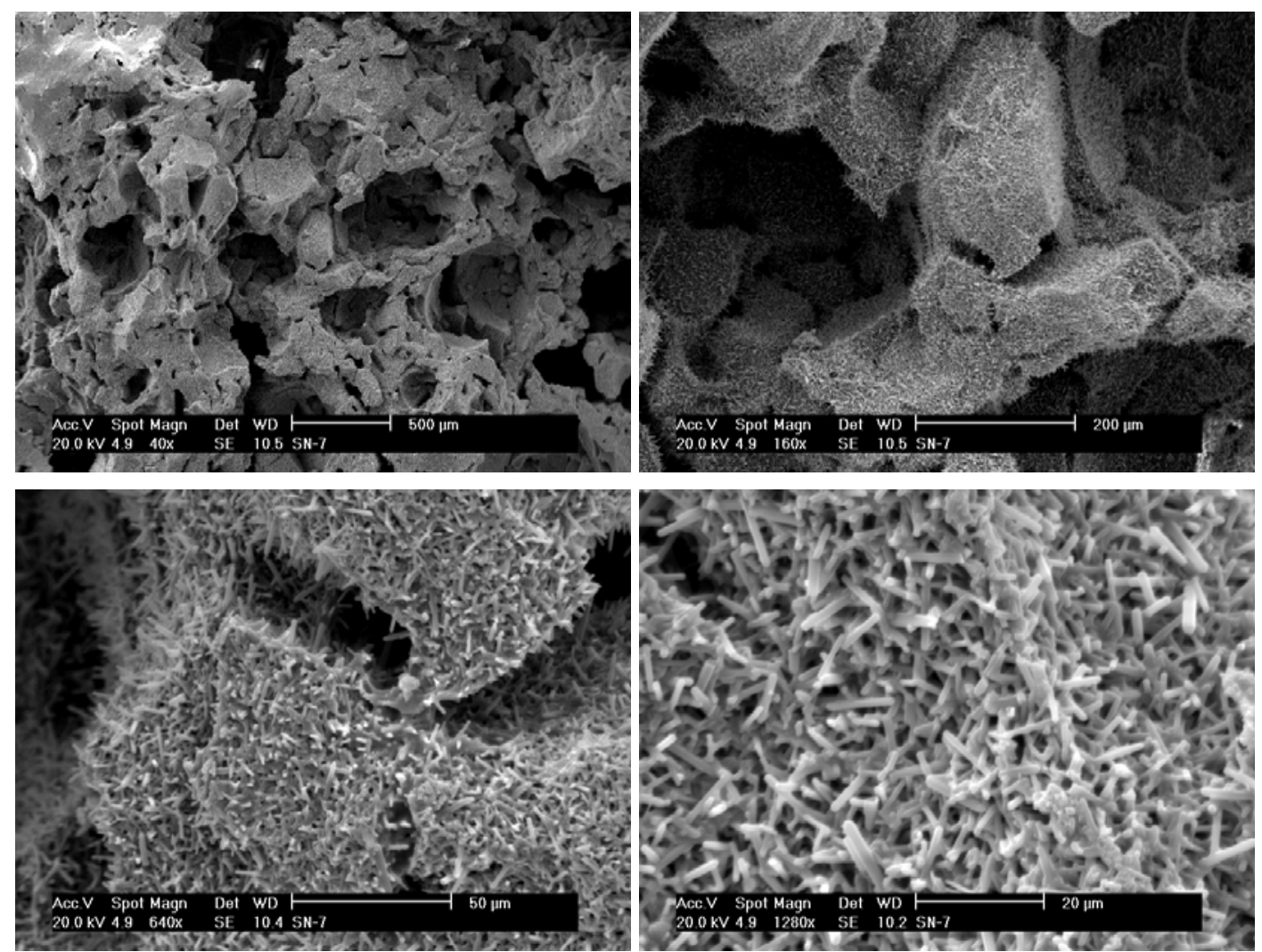

Figura 5.8: Exemplo de uma estrutura porosa de nitreto de silício da amostra na qual se utiliza ágar como gelificante, mostrando os grãos crescidos anisotropicamente, formando uma estrutura reforçada pelo entrelaçamento destes grãos.

\subsection{Amostras obtidas pelo método gel-casting utilizando-se amido}

Na figura 5.9, são mostradas as curvas de distribuição de tamanho de partículas para cada um dos amidos utilizados neste estudo. É possível verificar que cada amido tem uma distribuição de tamanho específica, permitindo a seleção do amido de acordo com o tamanho próximo aos poros do produto final. 


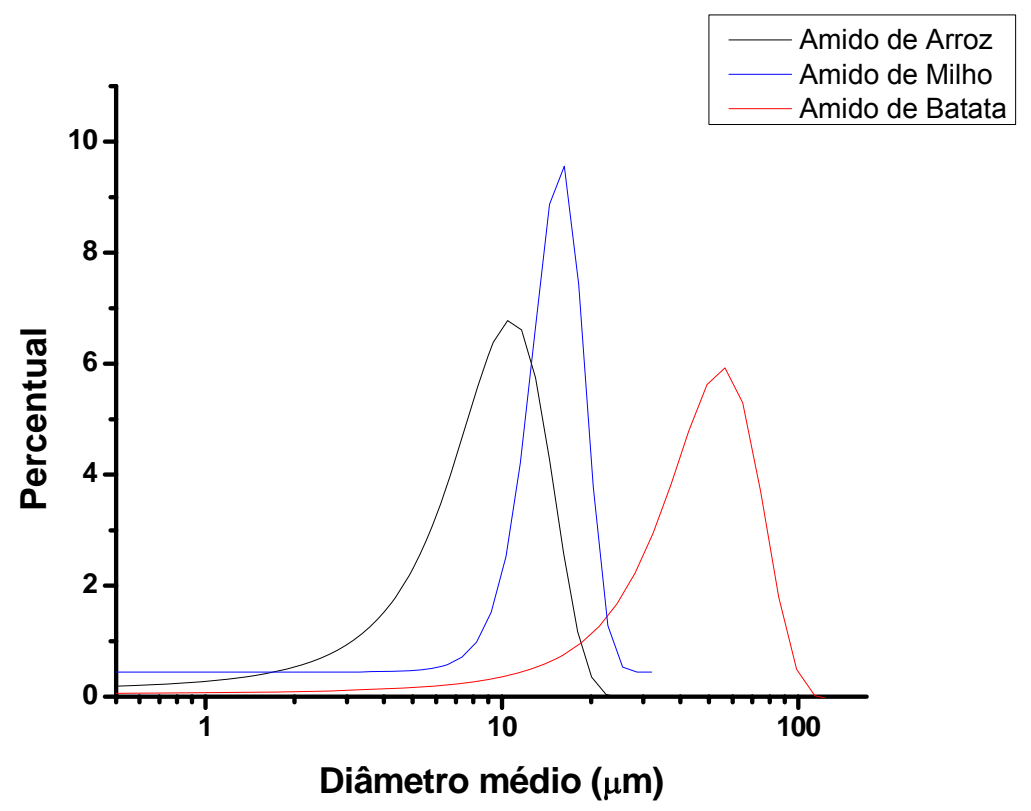

Figura 5.9: Distribuição de tamanho de partículas de cada um dos amidos.

Pela análise por espalhamento de laser (CILAS 1064) obteve-se o tamanho médio das partículas de cada amido, como já esperado o amido de batata é o de o maior tamanho médio $(44,5 \mu \mathrm{m})$, o de milho $(12,0 \mu \mathrm{m})$ e o de arroz $(8,3 \mu \mathrm{m})$.

Na tabela 5.2 e na Figura 5.10 são apresentados os valores médios (referentes a três amostras) de densidade aparente e porosidade aparente (pelo método de Archimedes) das amostras obtidas pela técnica de gel-casting, utilizando-se amido como agente gelificante, e sinterizadas a $1800^{\circ} \mathrm{C}$ por 1 hora. Foram produzidas amostras a partir de duas suspensões com diferentes teores de sólido (50\% e $55 \%$ ), e com a adição de 20,30 ou $40 \%$ (em volume) de amido. Para a composição contendo $55 \%$ de sólido, a adição de $40 \%$ de amido provocou um aumento muito grande na viscosidade da suspensão, inviabilizando a produção de corpos de prova. 
Tabela 5.2: Densidade e porosidade das amostras produzidas via gel-casting com amido.

\begin{tabular}{|c|c|c|c|}
\hline Amido & Amostra & Densidade relativa (\%) & Porosidade Aparente(\%) \\
\hline \multirow{5}{*}{ Amido de Arroz } & $5020 \mathrm{~A}$ & $82,6 \pm 1,5$ & $17,4 \pm 1,5$ \\
\hline & $5030 \mathrm{~A}$ & $81,9 \pm 1,6$ & $18,1 \pm 1,6$ \\
\hline & $5040 A$ & $79,4 \pm 5,0$ & $20,6 \pm 5,0$ \\
\hline & $5520 A$ & $80,4 \pm 1,1$ & $19,6 \pm 1,1$ \\
\hline & $5530 \mathrm{~A}$ & $79,2 \pm 1,9$ & $20,8 \pm 1,9$ \\
\hline \multirow{5}{*}{ Amido de Milho } & $5020 \mathrm{M}$ & $78,6 \pm 1,4$ & $21,5 \pm 1,4$ \\
\hline & $5030 \mathrm{M}$ & $73,1 \pm 4,1$ & $26,9 \pm 4,1$ \\
\hline & $5040 \mathrm{M}$ & $71,9 \pm 1,4$ & $28,1 \pm 1,4$ \\
\hline & $5520 \mathrm{M}$ & $81,1 \pm 6,8$ & $18,9 \pm 6,8$ \\
\hline & $5530 \mathrm{M}$ & $76,3 \pm 5,3$ & $23,7 \pm 5,3$ \\
\hline \multirow{5}{*}{ Amido de Batata } & 5020B & $77,0 \pm 4,0$ & $23,0 \pm 4,0$ \\
\hline & $5030 \mathrm{~B}$ & $74,0 \pm 1,0$ & $26,0 \pm 1,0$ \\
\hline & $5040 B$ & $64,0 \pm 8,0$ & $36,0 \pm 8,0$ \\
\hline & $5520 B$ & $76,0 \pm 0,0$ & $24,0 \pm 0,0$ \\
\hline & $5530 \mathrm{~B}$ & $64,0 \pm 5,0$ & $36,0 \pm 5,0$ \\
\hline
\end{tabular}




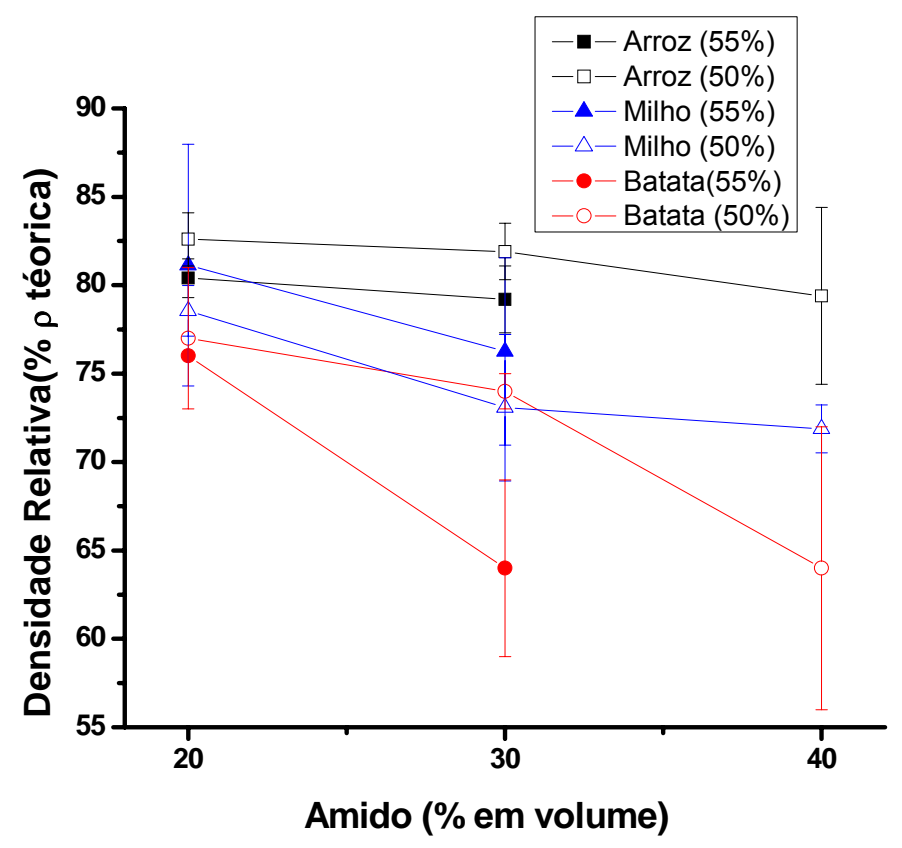

(a)

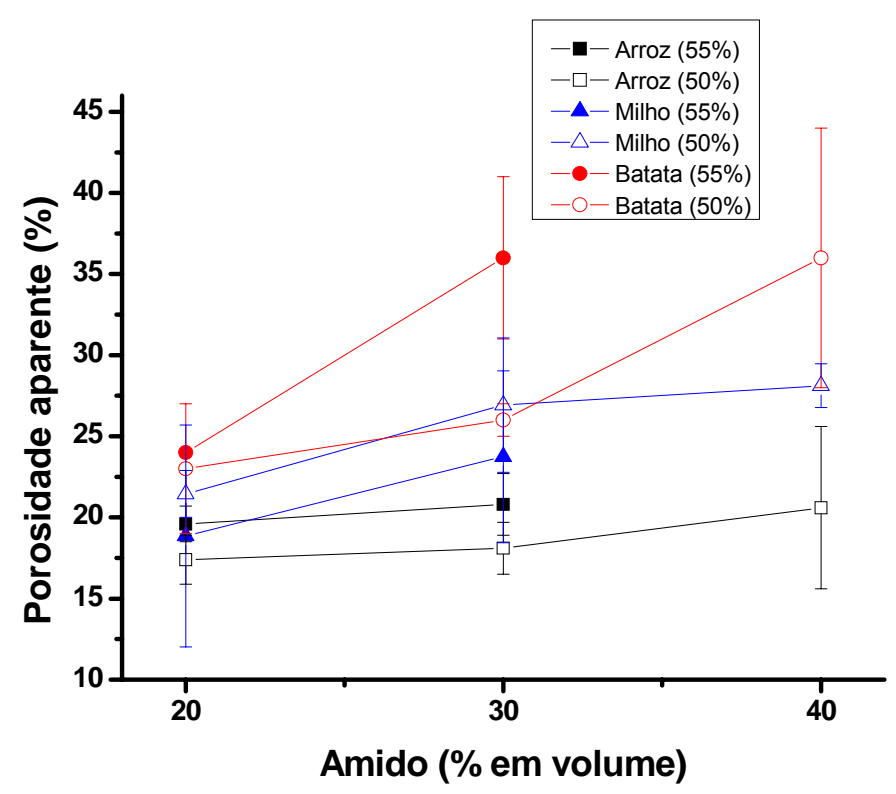

(b)

Figura 5.10: Densidade relativa (a) e porosidade aparente (b) das amostras obtidas por gel-casting, com diferentes amidos e percentuais de sólido na suspensão. 
Observa-se uma relação direta entre a porosidade obtida e o teor de amido adicionado à suspensão. Quanto à variação do teor de sólido na suspensão, deve-se esperar que as suspensões contendo maior teor de líquido originem corpos com maior porosidade; no entanto, a porosidade dos corpos obtidos a partir de suspensões contendo amido de arroz e de batata, apresentou comportamento inverso. Na Figura 5.11 são comparadas amostras obtidas a partir de suspensões contendo diferentes concentrações de sólido com a adição do amido de milho. Apesar de não se ter feito uma análise quantitativa das microestruturas, pode-se afirmar que há coerência com os valores de porosidade aparente obtidos pelo método de Archimedes.

Constatou-se também uma relação entre a porosidade e o tamanho de partículas do amido, pois ao se comparar amostras originadas de suspensões contendo a mesma quantidade de amido, observa-se que aquelas originadas a partir de amidos de maior tamanho apresentam maior porosidade. Uma explicação possível para isso é que poros pequenos podem ser eliminados durante a sinterização, e dessa forma amostras originadas de amidos menores podem ter um maior percentual de poros eliminados. Além disso, para o caso da utilização do amido de batata, constataram-se problemas nas etapas de processamento que serão discutidas a seguir, mas que podem ter interferido na formação de defeitos que são interpretados como parte da porosidade quando calculada pelo método de Archimedes. 


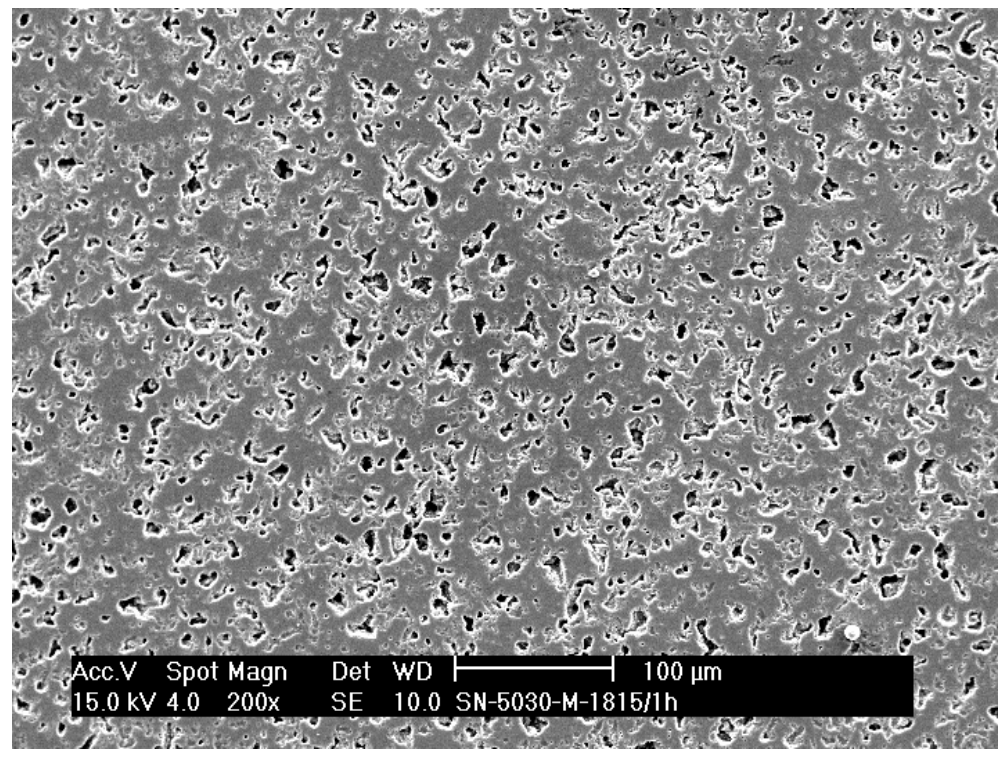

(a)

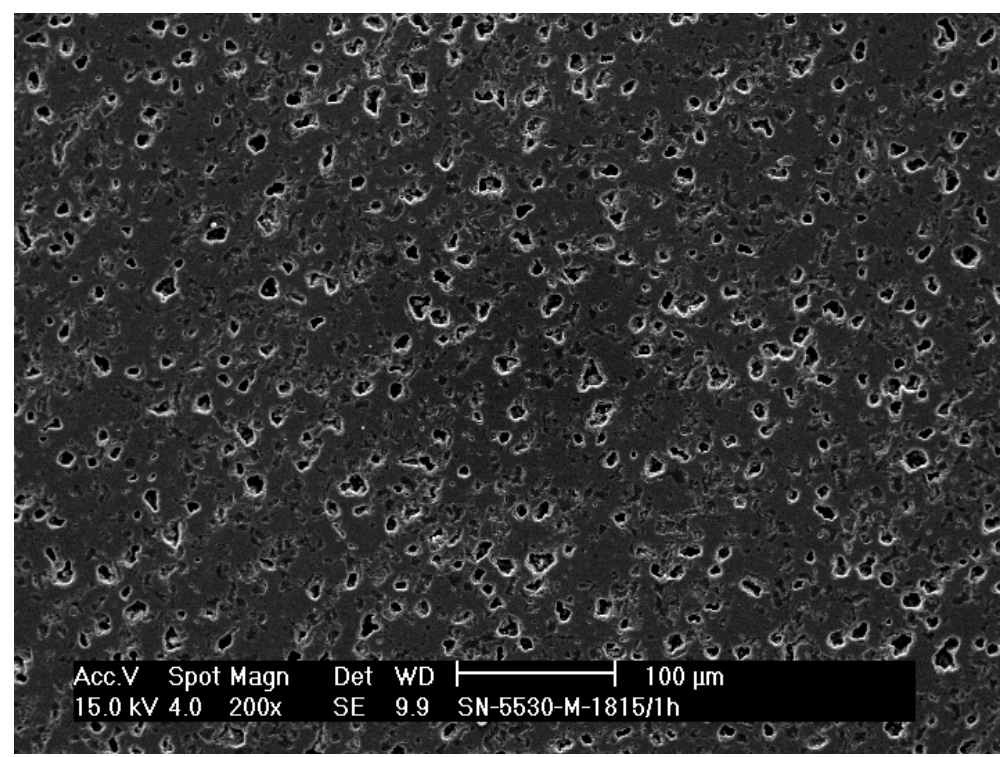

(b)

Figura 5.11: Micrografias das amostras produzidas via gel-casting com adição de $30 \%$ em volume de amido de milho: (a) suspensão contendo $50 \%$ de sólido e (b) suspensão contendo $55 \%$ de sólido.

Na Figura 5.12 são apresentadas micrografias de amostras obtidas a partir de suspensões contendo diferentes teores de amido de milho com $50 \%$ de sólidos. Estas micrografias estão coerentes com os resultados de porosidade aparente calculados e apresentados na tabela 5.2.

$\mathrm{Na}$ figura 5.13 são comparadas amostras oriundas de diferentes amidos. Nota-se que a microestrutura obtida a partir da suspensão contendo 
amido de batata se mostra mais irregular, com uma população de defeitos bem mais acentuada. Isto se deve aos problemas encontrados durante 0 processamento das suspensões contendo amido de batata, que apresentaram maior dificuldade para atingirem uma homogeneização durante a mistura, além de atingirem viscosidades bem maiores que as obtidas com os demais amidos, provocando dificuldades também durante a etapa de preenchimento dos moldes. Estes defeitos também afetarão as propriedades mecânicas das cerâmicas, como será discutido a seguir.

O processo de obtenção de cerâmicas porosas por gel-casting, utilizando-se o amido como agente gelificante mostrou-se viável e bastante interessante, permitindo que se obtivessem cerâmicas com estrutura de poros bastante homogênea. No entanto pode-se observar que não são raros os defeitos na microestrutura, particularmente, para este estudo, quando da utilização do amido de batata. Na figura 5.14 é apresentado um defeito com dimensão aproximada de $100 \mu \mathrm{m}$, que pode ter sido originado a partir de um aglomerado de amido (neste caso o amido de milho), ou mesmo de uma bolha de ar aprisionada. Este tipo de defeito certamente pode comprometer o desempenho mecânico do material, indicando que o processo de fabricação necessita ainda de um melhor controle. 


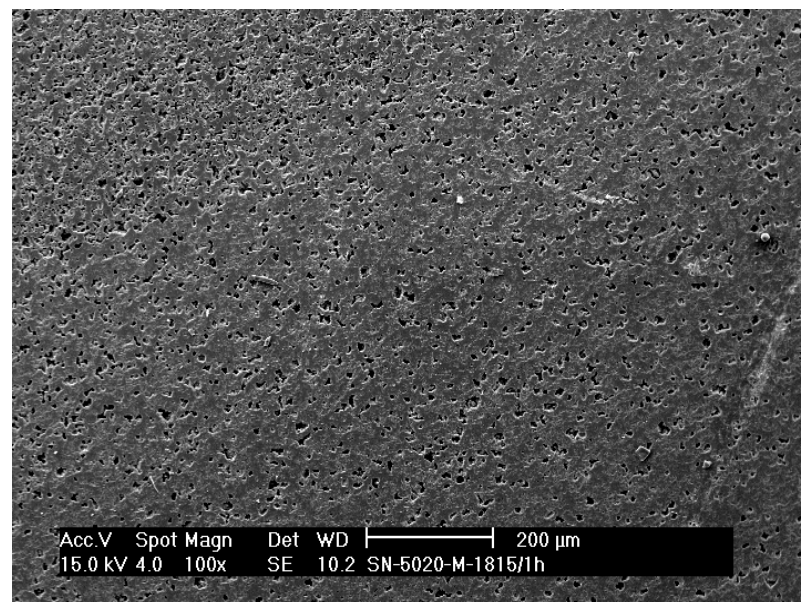

(a)

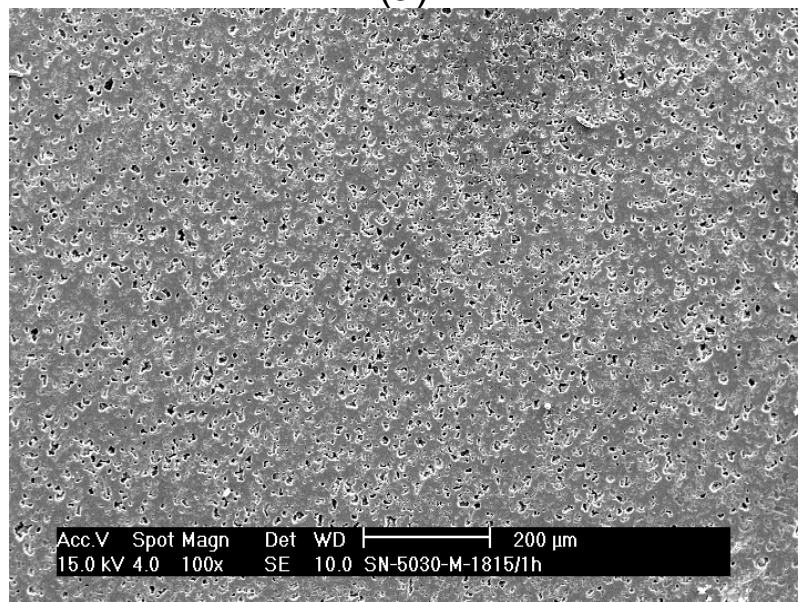

(b)

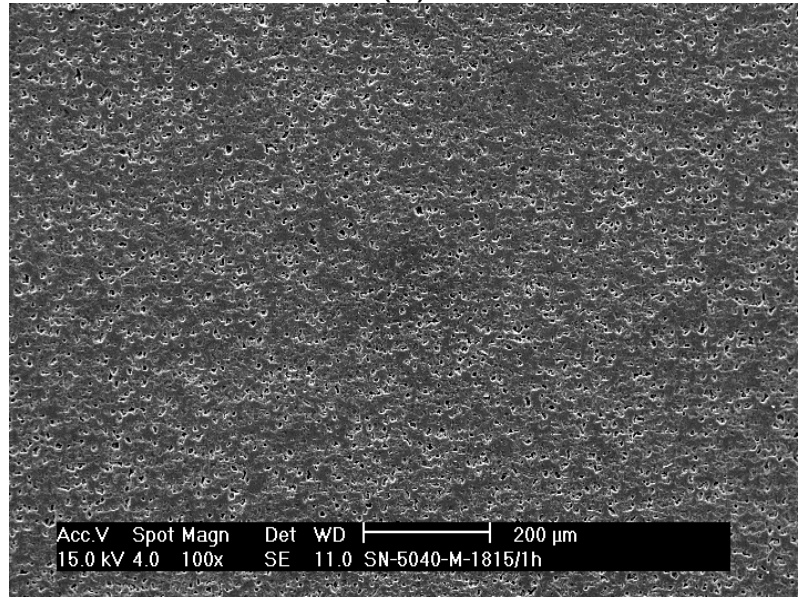

(c)

Figura 5.12: Micrografias das amostras produzidas viam gel-casting com amido de milho com suspensões contendo $50 \%$ de sólido. As diferentes percentagens em volume de amido adicionado, $20 \% \mathrm{em}$ (a), 30\% em (b) e $40 \%$ em (c) deram origem a cerâmicas com porosidade aparente de 21,4\%, 26,9\% e 28,1\% respectivamente. 


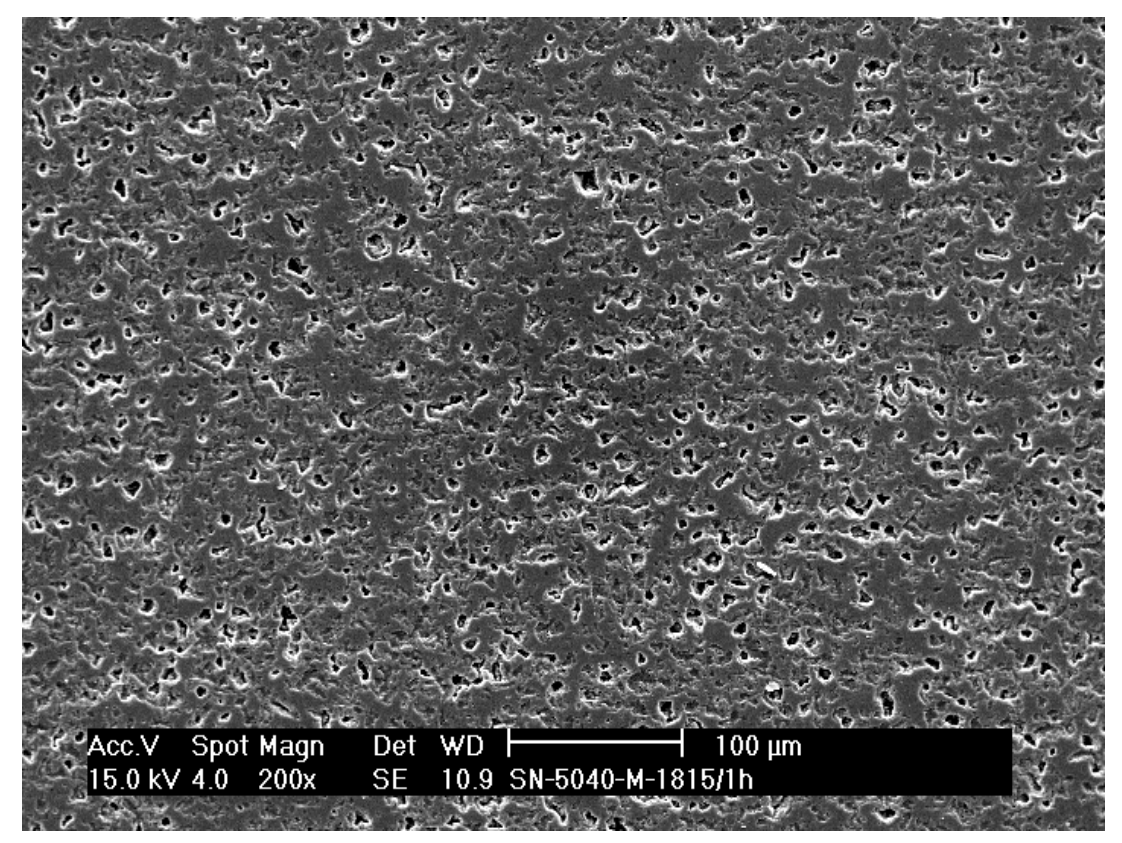

(a)

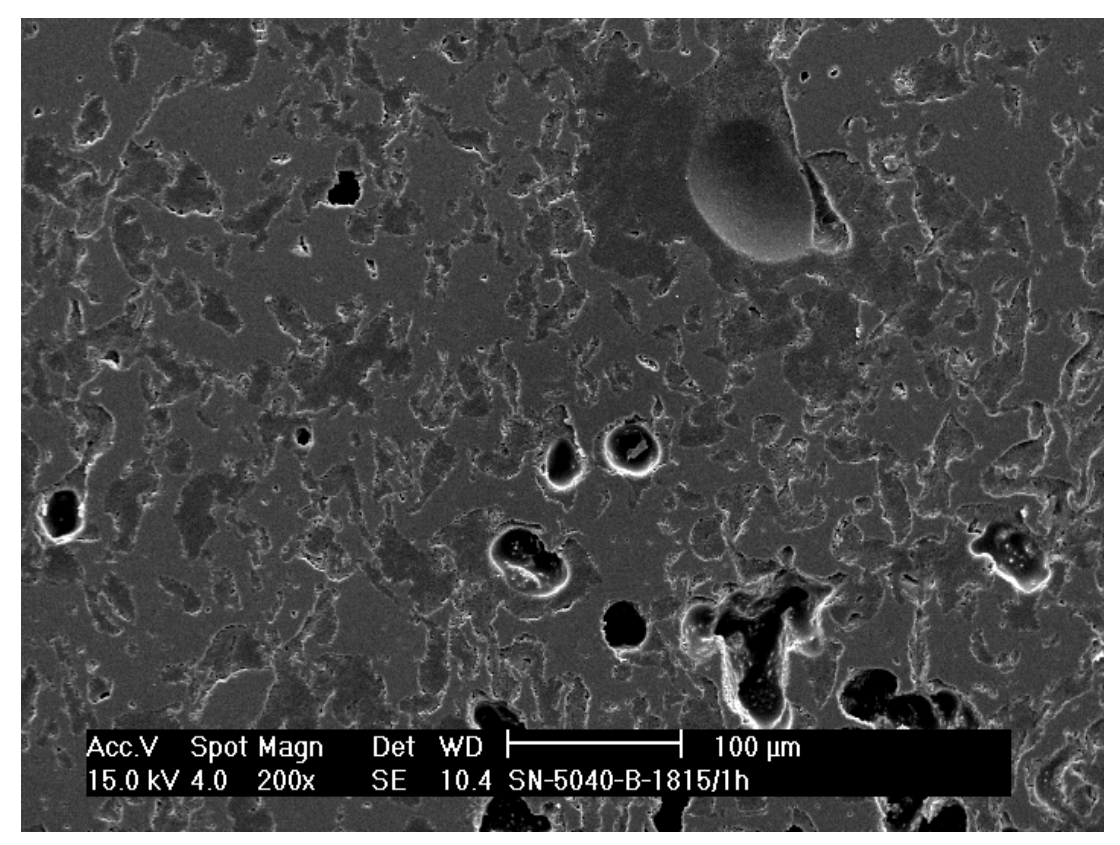

(b)

Figura 5.13: Micrografia das amostras produzidas via gel-casting utilizando-se como agente gelificante o amido de milho (a) e de batata (b); para estes exemplos, as suspensões contêm $50 \%$ de sólidos e $40 \%$ em volume de amido. 


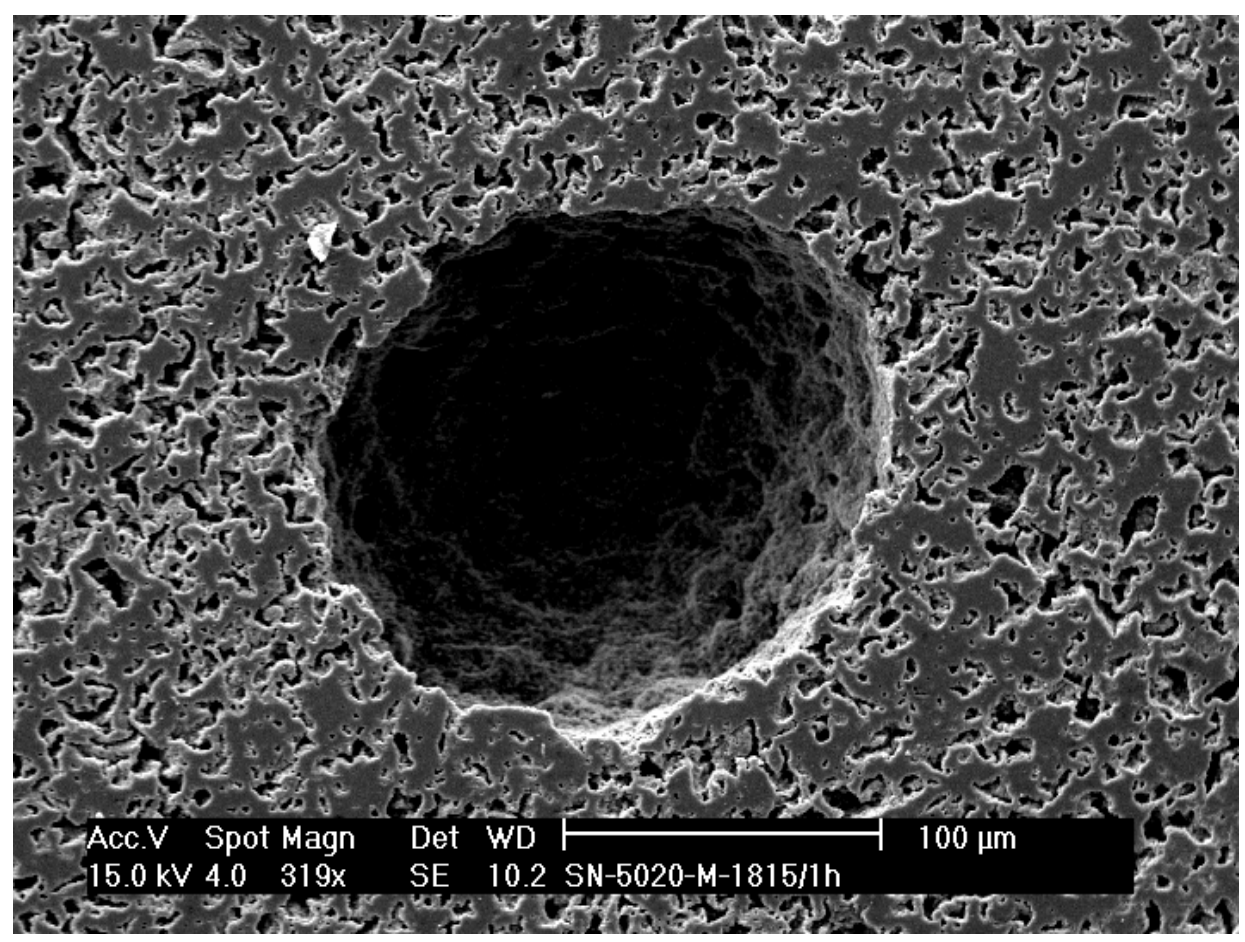

Figura 5.14: Defeito em amostra produzida via gel-casting com amido de milho; neste caso a suspensão continha $50 \%$ de sólidos e $20 \%$ de amido em volume.

Na tabela 5.3 são mostrados os dados referentes ao módulo de ruptura sob compressão das amostras produzidas por gel-casting com amido, sendo que para o caso da utilização do amido de arroz, apenas as amostras referentes a uma das composições foram ensaiadas. 
Tabela 5.3: Módulo de ruptura das amostras produzidas via gel-casting com amido.

\begin{tabular}{ccc}
\hline Amostra & Porosidade aparente (\%) & Módulo de ruptura $\sigma(\mathrm{MPa})$ \\
\hline $5520 \mathrm{~A}$ & $19,6 \pm 1,1$ & 540 \\
$5020 \mathrm{M}$ & $21,45 \pm 1,44$ & $618 \pm 126$ \\
$5030 \mathrm{M}$ & $26,92 \pm 4,14$ & $586 \pm 25$ \\
$5040 \mathrm{M}$ & $28,12 \pm 1,35$ & $519 \pm 73$ \\
$5520 \mathrm{M}$ & $18,86 \pm 6,83$ & $686 \pm 50$ \\
$5530 \mathrm{M}$ & $23,74 \pm 5,29$ & $556 \pm 47$ \\
$5020 \mathrm{~B}$ & $23,00 \pm 4,00$ & $321,28 \pm 7,83$ \\
$5030 \mathrm{~B}$ & $26,00 \pm 1,00$ & $336,9 \pm 28,09$ \\
$5520 \mathrm{~B}$ & $24,00 \pm 0,00$ & $469,46 \pm 9,82$ \\
$5530 \mathrm{~B}$ & $36,00 \pm 5,00$ & $246,1 \pm 97,84$ \\
\hline
\end{tabular}

Os dados da Tabela 5.3 são apresentados na Figura 5.15. Observa-se que o aumento da porosidade provoca a queda do módulo de ruptura, um comportamento já esperado, pois os poros funcionam como concentradores de tensão, facilitando assim a propagação de trincas. Constata-se também que as amostras produzidas a partir do amido de batata apresentam os menores valores de módulo de ruptura; estes valores reduzidos são reflexo dos defeitos microestruturais citados anteriormente, originados pelas dificuldades de processamento de suspensões contendo amido de batata. 


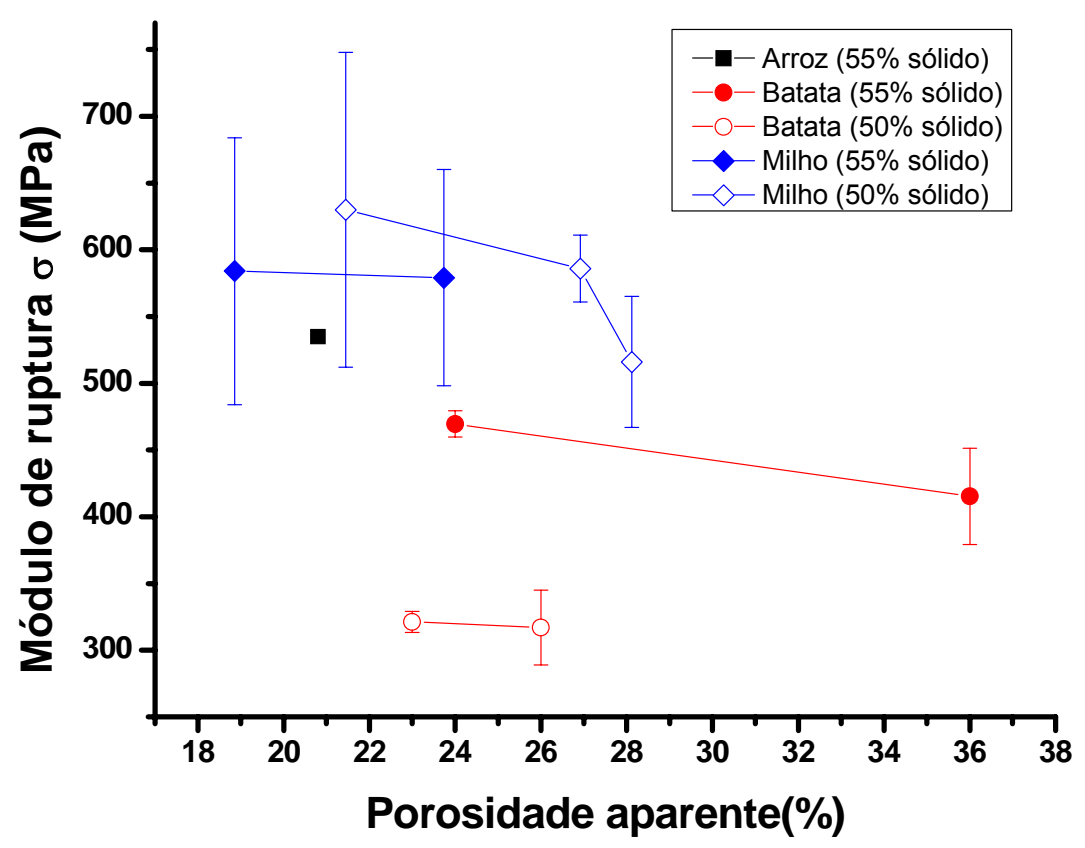

Figura 5.15: Relação do módulo de ruptura à compressão versus porosidade das amostras obtidas por gel-casting utilizando diferentes amidos e a partir de suspensões com diferentes percentuais de sólido.

\subsection{Amido como fase sacrificial}

$\mathrm{Na}$ Tabela 5.4 e Figura 5.16 são apresentados os dados referentes à retração volumétrica das amostras de nitreto de silício poroso, obtidas pela técnica da fase sacrificial, e sinterizadas sob diferentes condições. Os resultados obtidos mostram uma diferença significativa de retração entre 1600 e $1700{ }^{\circ} \mathrm{C}$, indicando que as amostras sinterizadas a $1600{ }^{\circ} \mathrm{C}$ apresentam uma considerável fração de porosidade referente ainda à sinterização parcial, ao passo que nas amostras sinterizadas em temperaturas superiores foi eliminada grande parte desta porosidade intrínseca à matriz cerâmica. Observa-se ainda que não há diferença quanto à retração para as amostras sinterizadas a $1700{ }^{\circ} \mathrm{C}$ por 30 minutos e 3 horas, indicando que, nesta temperatura, o tempo de patamar não afeta a densificação. No entanto o aumento da temperatura para $1800{ }^{\circ} \mathrm{C}$ e 1850 ${ }^{\circ} \mathrm{C}$ promoveu retração em todas as composições estudadas.

Na tabela 5.5 e figura 5.17 são apresentados os valores obtidos para a densidade a verde das amostras prensadas, com relação ao tipo e teor de amido adicionado. Com o aumento do teor de amido ocorre uma melhoria na 
compactação das misturas, indicando que o amido pode estar atuando como um lubrificante entre as partículas, reduzindo o atrito entre as mesmas. Na figura 5.17-a é apresentada a densidade relativa à densidade teórica das composições, calculada pela regra das misturas, considerando-se a densidade do amido como sendo $1,50 \mathrm{~g} / \mathrm{cm}^{3}$, e a densidade da matriz cerâmica como sendo $3,27 \mathrm{~g} / \mathrm{cm}^{3}$. Já na figura 5.17-b são apresentados os valores da densidade aparente, com o volume das amostras calculado geometricamente. Os diferentes amidos aparentemente proporcionaram comportamento muito similar às misturas em termos de densificação na prensagem, a menos das amostras contendo $30 \% \mathrm{em}$ volume de amido de batata, que estranhamente promoveram aumento da densidade a verde fora do padrão esperado. 
Tabela 5.4: Retração volumétrica das amostras obtidas pelo método da fase sacrificial.

\begin{tabular}{|c|c|c|c|c|}
\hline Amostra & $\begin{array}{c}\text { Amido } \\
\text { empregado }\end{array}$ & $\begin{array}{l}\% \text { de amido } \\
\text { adicionado }\end{array}$ & $\begin{array}{l}\text { Tratamento } \\
\text { térmico }\end{array}$ & $\begin{array}{c}\text { Retração } \\
\text { volumétrica (\%) }\end{array}$ \\
\hline A20 & & 20 & $\begin{array}{c}1850^{\circ} \mathrm{C} / 1 \mathrm{~h} \\
1800^{\circ} \mathrm{C} / 1 \mathrm{~h} \\
1700^{\circ} \mathrm{C} / 3 \mathrm{~h} \\
1700^{\circ} \mathrm{C} / 0,5 \mathrm{~h} \\
1600^{\circ} \mathrm{C} / 1 \mathrm{~h}\end{array}$ & $\begin{array}{l}44,0 \pm 0,3 \\
40,1 \pm 0,4 \\
38,1 \pm 0,2 \\
37,7 \pm 0,2 \\
23,2 \pm 0,9\end{array}$ \\
\hline A30 & $\begin{array}{l}\text { Amido de } \\
\text { arroz }\end{array}$ & 30 & $\begin{array}{c}1850^{\circ} \mathrm{C} / 1 \mathrm{~h} \\
1800^{\circ} \mathrm{C} / 1 \mathrm{~h} \\
1700^{\circ} \mathrm{C} / 3 \mathrm{~h} \\
1700^{\circ} \mathrm{C} / 0,5 \mathrm{~h} \\
1600^{\circ} \mathrm{C} / 1 \mathrm{~h}\end{array}$ & $\begin{array}{c}46,9 \pm 0,5 \\
42,8 \pm 2,2 \\
38,9 \pm 0,0 \\
38,6 \pm 0,3 \\
22,00 \pm 0,8\end{array}$ \\
\hline A40 & & 40 & $\begin{array}{c}1850^{\circ} \mathrm{C} / 1 \mathrm{~h} \\
1800^{\circ} \mathrm{C} / 1 \mathrm{~h} \\
1700^{\circ} \mathrm{C} / 3 \mathrm{~h} \\
1700^{\circ} \mathrm{C} / 0,5 \mathrm{~h} \\
1600^{\circ} \mathrm{C} / 1 \mathrm{~h}\end{array}$ & $\begin{array}{l}48,0 \pm 0,5 \\
44,3 \pm 1,2 \\
39,0 \pm 0,0 \\
39,6 \pm 0,6 \\
24,2 \pm 0,4\end{array}$ \\
\hline M20 & & 20 & $\begin{array}{c}1850^{\circ} \mathrm{C} / 1 \mathrm{~h} \\
1800^{\circ} \mathrm{C} / 1 \mathrm{~h} \\
1700^{\circ} \mathrm{C} / 3 \mathrm{~h} \\
1700^{\circ} \mathrm{C} / 0,5 \mathrm{~h} \\
1600^{\circ} \mathrm{C} / 1 \mathrm{~h}\end{array}$ & $\begin{array}{l}44,0 \pm 0,5 \\
40,2 \pm 0,6 \\
36,6 \pm 0,4 \\
35,8 \pm 2,3 \\
22,4 \pm 1,4\end{array}$ \\
\hline M30 & $\begin{array}{l}\text { Amido de } \\
\text { milho }\end{array}$ & 30 & $\begin{array}{c}1850^{\circ} \mathrm{C} / 1 \mathrm{~h} \\
1800^{\circ} \mathrm{C} / 1 \mathrm{~h} \\
1700^{\circ} \mathrm{C} / 3 \mathrm{~h} \\
1700^{\circ} \mathrm{C} / 0,5 \mathrm{~h} \\
1600^{\circ} \mathrm{C} / 1 \mathrm{~h}\end{array}$ & $\begin{array}{l}46,8 \pm 0,4 \\
42,4 \pm 0,9 \\
37,8 \pm 0,5 \\
38,1 \pm 0,4 \\
22,8 \pm 0,9\end{array}$ \\
\hline M40 & & 40 & $\begin{array}{c}1800^{\circ} \mathrm{C} / 1 \mathrm{~h} \\
1700^{\circ} \mathrm{C} / 0,5 \mathrm{~h}\end{array}$ & $\begin{array}{l}44,9 \pm 0,4 \\
40,1 \pm 0,5\end{array}$ \\
\hline B20 & & 20 & $\begin{array}{c}1850^{\circ} \mathrm{C} / 1 \mathrm{~h} \\
1800^{\circ} \mathrm{C} / 1 \mathrm{~h} \\
1700^{\circ} \mathrm{C} / 3 \mathrm{~h} \\
1700^{\circ} \mathrm{C} / 0,5 \mathrm{~h}\end{array}$ & $\begin{array}{l}44,4 \pm 0,2 \\
42,3 \pm 1,8 \\
36,3 \pm 0,5 \\
36,8 \pm 0,1\end{array}$ \\
\hline B30 & $\begin{array}{c}\text { Amido de } \\
\text { batata }\end{array}$ & 30 & $\begin{array}{c}1850^{\circ} \mathrm{C} / 1 \mathrm{~h} \\
1800^{\circ} \mathrm{C} / 1 \mathrm{~h} \\
1700^{\circ} \mathrm{C} / 3 \mathrm{~h} \\
1700^{\circ} \mathrm{C} / 0,5 \mathrm{~h} \\
1600^{\circ} \mathrm{C} / 1 \mathrm{~h}\end{array}$ & $\begin{array}{l}43,0 \pm 0,5 \\
40,9 \pm 1,9 \\
36,9 \pm 0,1 \\
36,6 \pm 0,3 \\
20,9 \pm 0,3\end{array}$ \\
\hline B40 & & 40 & $\begin{array}{c}1850^{\circ} \mathrm{C} / 1 \mathrm{~h} \\
1800^{\circ} \mathrm{C} / 1 \mathrm{~h} \\
1700^{\circ} \mathrm{C} / 3 \mathrm{~h} \\
1700^{\circ} \mathrm{C} / 0,5 \mathrm{~h} \\
1600^{\circ} \mathrm{C} / 1 \mathrm{~h}\end{array}$ & $\begin{array}{l}43,5 \pm 0,4 \\
41,0 \pm 2,4 \\
40,8 \pm 2,2 \\
37,4 \pm 0,2 \\
22,8 \pm 1,5\end{array}$ \\
\hline
\end{tabular}



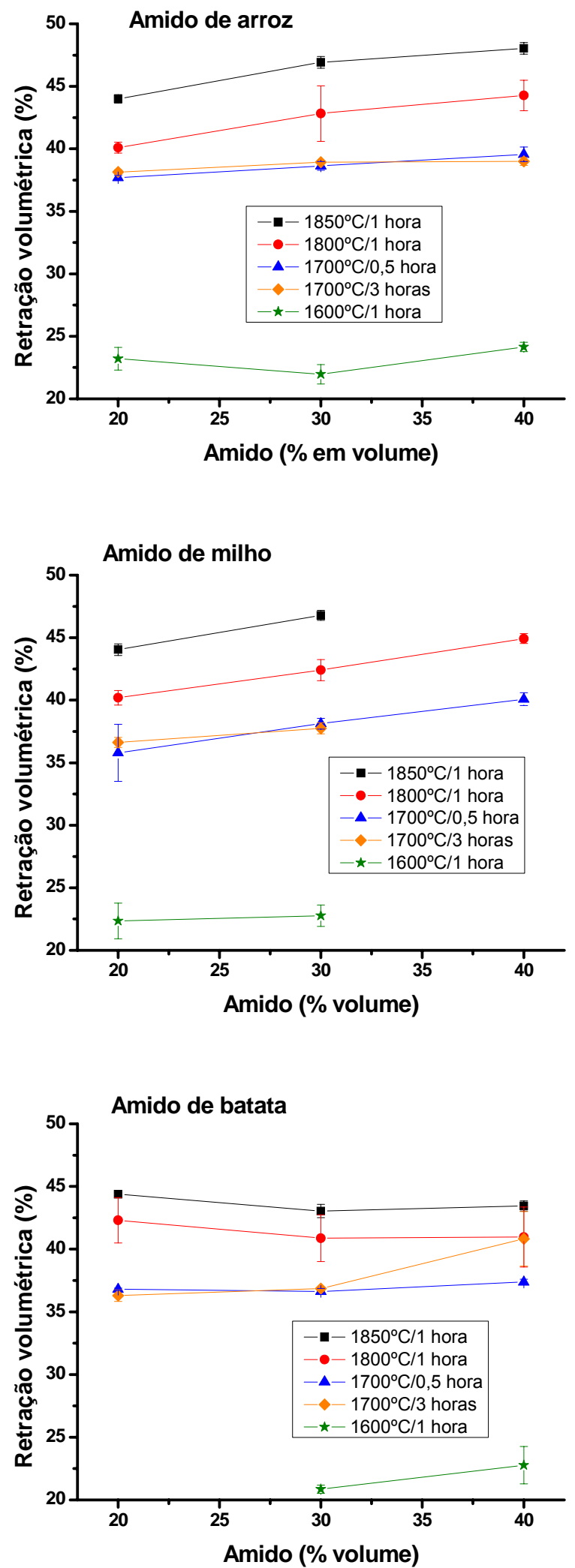

Figura 5.16: Relação entre a retração volumétrica e o percentual de amido adicionado a matriz cerâmica. 
Tabela 5.5: Densidade a verde relativa das amostras produzidas pelo método fase sacrificial com amido.

\begin{tabular}{cccc}
\hline Amido & $\begin{array}{c}\text { Teor de amido } \\
(\% \text { em volume })\end{array}$ & $\begin{array}{c}\text { Densidade a verde } \\
\text { relativa(\% de D.T })\end{array}$ & $\begin{array}{c}\text { Densidade a verde } \\
\text { aparente }\left(\mathrm{g} / \mathrm{cm}^{3}\right)\end{array}$ \\
\hline \multirow{2}{*}{ Amido de } & 20 & $55,9 \pm 0,1$ & 1,62 \\
Arroz & 30 & $57,3 \pm 0,1$ & 1,56 \\
\hline \multirow{2}{*}{ Amido de } & 40 & $59,9 \pm 0,1$ & 1,53 \\
Milho & 20 & $55,4 \pm 0,1$ & 1,60 \\
\hline \multirow{2}{*}{ Amido de } & 40 & $57,3 \pm 0,1$ & 1,56 \\
Batata & 20 & $59,9 \pm 0,1$ & 1,53 \\
\hline
\end{tabular}

Os resultados obtidos para a perda de massa das composições estudadas são apresentados na Tabela 5.6 e Figura 5.18. A linha tracejada mostrada nos gráficos da figura 5.18 indica o quanto deveria se esperar de perda de massa referente à eliminação do amido. Para todas as composições estudadas observou-se um comportamento bastante similar quanto à perda de massa, e como esperado, essa perda não sofreu interferência do tipo de amido adicionado. Observa-se que para quantidades maiores de amido, ocorre uma diferença mais acentuada entre o teor de amido adicionado e a perda total de massa. Parte da diferença entre a perda calculada e a medida, pode ser explicada pela redução de massa típica do nitreto de silício, quando sinterizado, que é em torno de $3 \%$. Além disso, pode-se considerar a perda de umidade adsorvida, defloculante e outros aditivos, o que pode representar algo em torno de 2 a $3 \%$. Outra possibilidade seria a decomposição parcial do nitreto de silício, mas esta só poderia ocorrer em temperaturas elevadas $\left(1850{ }^{\circ} \mathrm{C}\right.$ no caso deste trabalho), mas isso não foi observado já que a diferença de perda de massa entre as amostras sinterizadas nesta temperatura e as sinterizadas em temperaturas menores é pequena (1 a $2 \%$ ). No entanto, o aumento dessa diferença observado quando se tem a adição de maiores teores de amido não encontra uma explicação definitiva. 

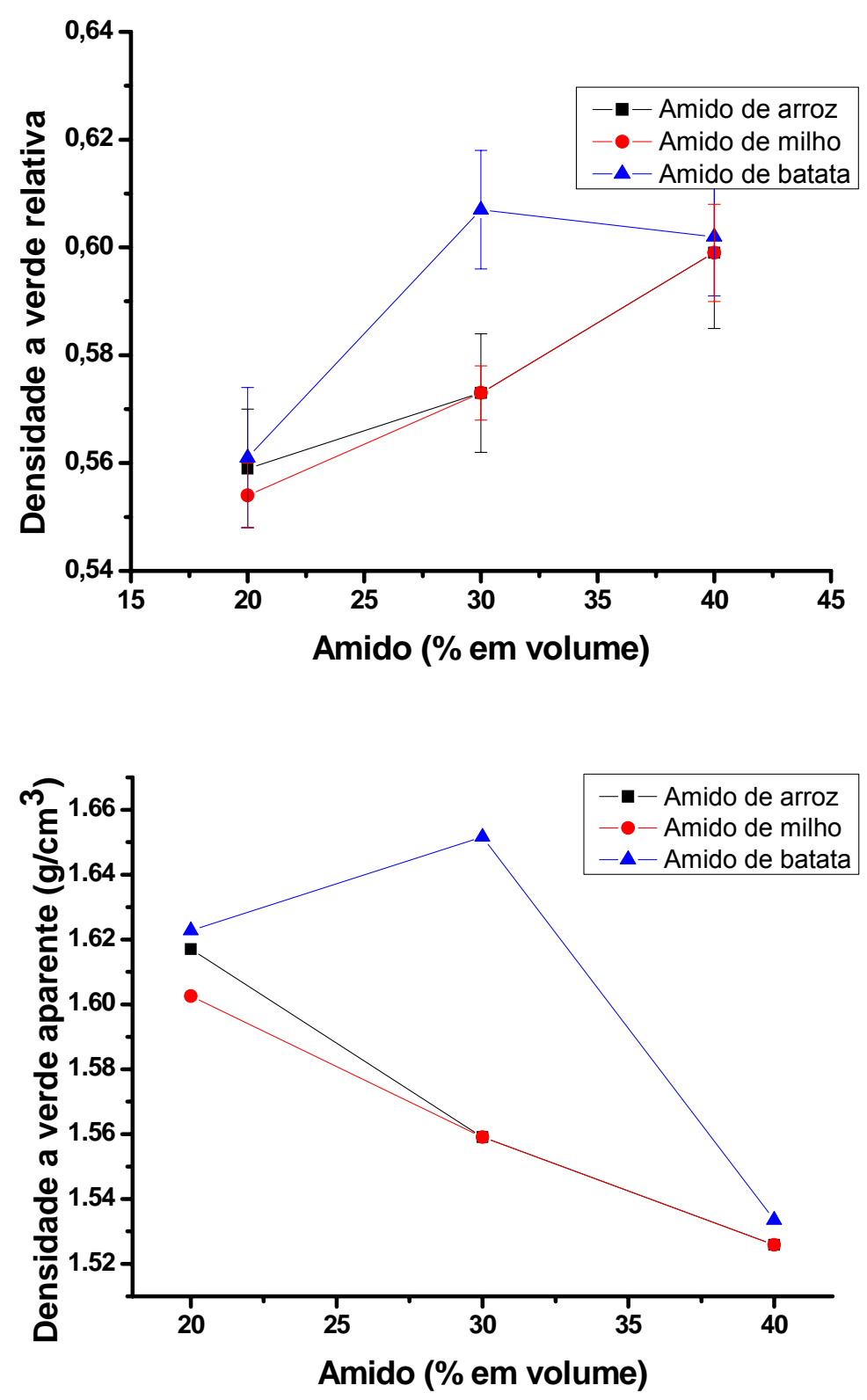

Figura 5.17: Relação entre densidade a verde e amido adicionado à matriz cerâmica. 
Tabela 5.6: Perda de massa das amostras obtidas pelo método da fase sacrificial.

\begin{tabular}{|c|c|c|c|c|}
\hline Amostra & $\begin{array}{c}\text { Amido } \\
\text { empregado }\end{array}$ & $\begin{array}{c}\% \text { de amido } \\
\text { adicionado } \\
(\% \text { em massa) }\end{array}$ & $\begin{array}{l}\text { Tratamento } \\
\text { térmico }\end{array}$ & $\begin{array}{l}\text { Perda de } \\
\text { Massa (\%) }\end{array}$ \\
\hline A20 & & $\begin{array}{l}10,3 \\
(20)\end{array}$ & $\begin{array}{c}1850^{\circ} \mathrm{C} / 1 \mathrm{~h} \\
1800^{\circ} \mathrm{C} / 1 \mathrm{~h} \\
1700^{\circ} \mathrm{C} / 3 \mathrm{~h} \\
1700^{\circ} \mathrm{C} / 0,5 \mathrm{~h} \\
1600^{\circ} \mathrm{C} / 1 \mathrm{~h}\end{array}$ & $\begin{array}{l}12,8 \pm 0,2 \\
12,3 \pm 0,2 \\
12,2 \pm 0,1 \\
12,2 \pm 0,1 \\
11,7 \pm 0,3\end{array}$ \\
\hline A30 & $\begin{array}{l}\text { Amido de } \\
\text { arroz }\end{array}$ & $\begin{array}{l}16,4 \\
(30)\end{array}$ & $\begin{array}{c}1850^{\circ} \mathrm{C} / 1 \mathrm{~h} \\
1800^{\circ} \mathrm{C} / 1 \mathrm{~h} \\
1700^{\circ} \mathrm{C} / 3 \mathrm{~h} \\
1700^{\circ} \mathrm{C} / 0,5 \mathrm{~h} \\
1600^{\circ} \mathrm{C} / 1 \mathrm{~h}\end{array}$ & $\begin{array}{l}21,4 \pm 0,1 \\
20,0 \pm 0,4 \\
20,3 \pm 0,3 \\
20,2 \pm 0,1 \\
19,9 \pm 0,1\end{array}$ \\
\hline A40 & & $\begin{array}{l}23,4 \\
(40)\end{array}$ & $\begin{array}{c}1850^{\circ} \mathrm{C} / 1 \mathrm{~h} \\
1800^{\circ} \mathrm{C} / 1 \mathrm{~h} \\
1700^{\circ} \mathrm{C} / 3 \mathrm{~h} \\
1700^{\circ} \mathrm{C} / 0,5 \mathrm{~h} \\
1600^{\circ} \mathrm{C} / 1 \mathrm{~h}\end{array}$ & $\begin{array}{l}33,6 \pm 2,7 \\
33,5 \pm 1,3 \\
31,7 \pm 0,0 \\
32,3 \pm 1,2 \\
30,8 \pm 0,5\end{array}$ \\
\hline M20 & & $\begin{array}{l}10,3 \\
(20)\end{array}$ & $\begin{array}{c}1850^{\circ} \mathrm{C} / 1 \mathrm{~h} \\
1800^{\circ} \mathrm{C} / 1 \mathrm{~h} \\
1700^{\circ} \mathrm{C} / 3 \mathrm{~h} \\
1700^{\circ} \mathrm{C} / 0,5 \mathrm{~h} \\
1600^{\circ} \mathrm{C} / 1 \mathrm{~h}\end{array}$ & $\begin{array}{l}13,6 \pm 0,1 \\
12,7 \pm 0,2 \\
12,8 \pm 0,9 \\
12,2 \pm 0,3 \\
12,0 \pm 0,3\end{array}$ \\
\hline M30 & $\begin{array}{l}\text { Amido de } \\
\text { milho }\end{array}$ & $\begin{array}{l}16,4 \\
(30)\end{array}$ & $\begin{array}{c}1850^{\circ} \mathrm{C} / 1 \mathrm{~h} \\
1800^{\circ} \mathrm{C} / 1 \mathrm{~h} \\
1700^{\circ} \mathrm{C} / 3 \mathrm{~h} \\
1700^{\circ} \mathrm{C} / 0,5 \mathrm{~h} \\
1600^{\circ} \mathrm{C} / 1 \mathrm{~h}\end{array}$ & $\begin{array}{l}21,7 \pm 0,4 \\
20,9 \pm 0,6 \\
20,5 \pm 0,4 \\
20,0 \pm 0,3 \\
19,8 \pm 0,3\end{array}$ \\
\hline M40 & & $\begin{array}{l}23,4 \\
(40) \\
\end{array}$ & $\begin{array}{c}1800^{\circ} \mathrm{C} / 1 \mathrm{~h} \\
1700^{\circ} \mathrm{C} / 0,5 \mathrm{~h}\end{array}$ & $\begin{array}{l}31,9 \pm 0,2 \\
31,3 \pm 0,2\end{array}$ \\
\hline B20 & & $\begin{array}{l}10,3 \\
(20)\end{array}$ & $\begin{array}{c}1850^{\circ} \mathrm{C} / 1 \mathrm{~h} \\
1800^{\circ} \mathrm{C} / 1 \mathrm{~h} \\
1700^{\circ} \mathrm{C} / 3 \mathrm{~h} \\
1700^{\circ} \mathrm{C} / 0,5 \mathrm{~h}\end{array}$ & $\begin{array}{l}14,1 \pm 0,0 \\
12,5 \pm 0,2 \\
13,2 \pm 0,6 \\
12,4 \pm 0,2\end{array}$ \\
\hline B30 & $\begin{array}{l}\text { Amido de } \\
\text { batata }\end{array}$ & $\begin{array}{l}16,4 \\
(30)\end{array}$ & $\begin{array}{c}1850^{\circ} \mathrm{C} / 1 \mathrm{~h} \\
1800^{\circ} \mathrm{C} / 1 \mathrm{~h} \\
1700^{\circ} \mathrm{C} / 3 \mathrm{~h} \\
1700^{\circ} \mathrm{C} / 0,5 \mathrm{~h} \\
1600^{\circ} \mathrm{C} / 1 \mathrm{~h}\end{array}$ & $\begin{array}{l}22,1 \pm 0,4 \\
20,5 \pm 0,1 \\
21,0 \pm 0,1 \\
20,8 \pm 0,2 \\
20,3 \pm 0,2\end{array}$ \\
\hline B40 & & $\begin{array}{l}23,4 \\
(40)\end{array}$ & $\begin{array}{c}1850^{\circ} \mathrm{C} / 1 \mathrm{~h} \\
1800^{\circ} \mathrm{C} / 1 \mathrm{~h} \\
1700^{\circ} \mathrm{C} / 3 \mathrm{~h} \\
1700^{\circ} \mathrm{C} / 0,5 \mathrm{~h} \\
1600^{\circ} \mathrm{C} / 1 \mathrm{~h}\end{array}$ & $\begin{array}{l}32,8 \pm 3,2 \\
31,0 \pm 1,6 \\
28,6 \pm 2,7 \\
32,7 \pm 1,3 \\
28,9 \pm 1,4\end{array}$ \\
\hline
\end{tabular}

$\left(^{*}\right)$ entre parênteses é apresentado o percentual em volume do amido adicionado. 


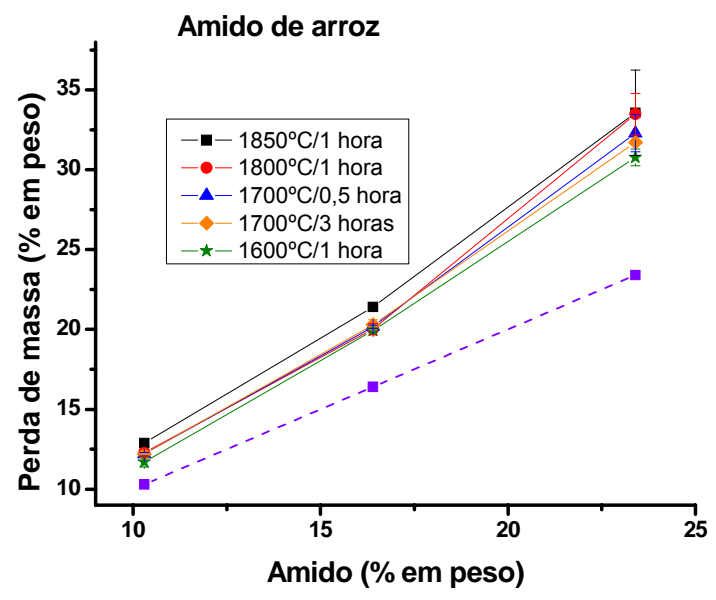

(a)

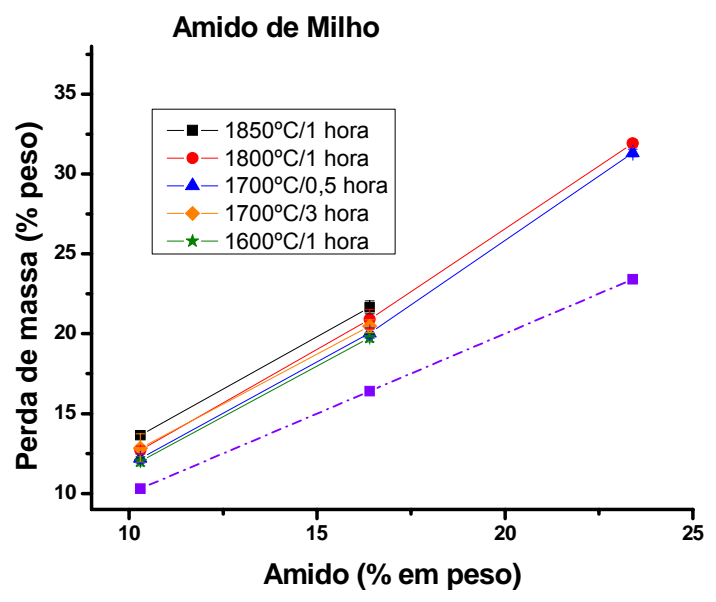

(b)

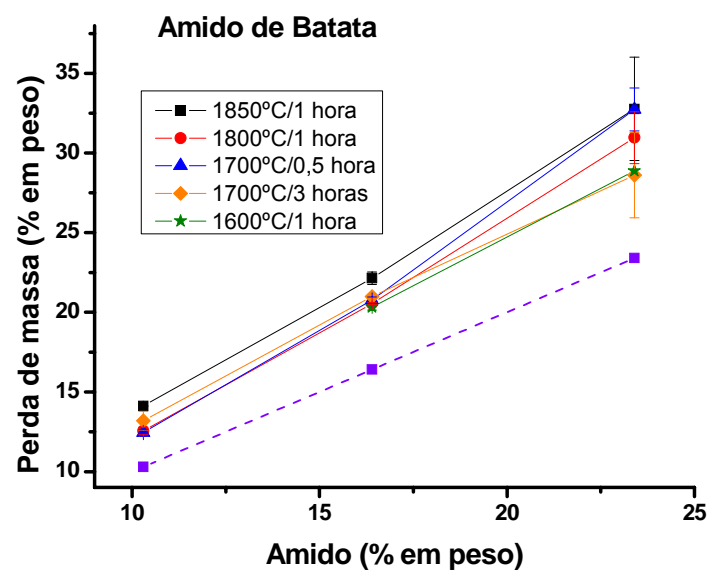

(c)

Figura 5.18: Relação entre perda de massa e adição de amido(\% em peso), para os amidos de arroz (a), milho (b) e batata (c). A linha tracejada nos gráficos indica qual a perda referente apenas ao amido adicionado. 
As amostras de $\mathrm{Si}_{3} \mathrm{~N}_{4}$ porosas, após a sinterização foram caracterizadas quanto à densidade aparente e porosidade aparente pelo método de Arquimedes, sendo os resultados obtidos apresentados na tabela 5.7 e figuras 5.19 e 5.20. De um modo geral, há uma consistência em todos os resultados obtidos para a porosidade e densidade aparente. Como era de se esperar, para todas as amostras, ocorreu um aumento na porosidade aparente (ou redução da densidade) com o aumento do percentual de amido adicionado à mistura inicial, confirmando que o mesmo atuou como a fase sacrificial para a formação de poros. Observa-se claramente uma tendência a uma relação linear entre teor de amido adicionado e porosidade aparente. Além disso, constata-se a clara redução da porosidade com o aumento da temperatura, o que já é esperado, e está completamente de acordo com os dados de retração volumétrica discutidos anteriormente. 
Tabela 5.7: Densidade relativa e porosidade aparente das amostras porosas de $\mathrm{Si}_{3} \mathrm{~N}_{4}$ obtidas pelo método da fase sacrificial .

\begin{tabular}{|c|c|c|c|c|c|}
\hline Amostra & $\begin{array}{c}\text { Amido } \\
\text { empregado }\end{array}$ & $\begin{array}{l}\% \text { de amido } \\
\text { adicionado }\end{array}$ & $\begin{array}{l}\text { Tratamento } \\
\text { térmico }\end{array}$ & $\begin{array}{c}\text { Densidade } \\
\text { relativa (\%) }\end{array}$ & $\begin{array}{c}\text { Porosidade } \\
\text { aparente (\%) }\end{array}$ \\
\hline A20 & & 20 & $\begin{array}{c}1850^{\circ} \mathrm{C} / 1 \mathrm{~h} \\
1800^{\circ} \mathrm{C} / 1 \mathrm{~h} \\
1700^{\circ} \mathrm{C} / 3 \mathrm{~h} \\
1700^{\circ} \mathrm{C} / 0,5 \mathrm{~h} \\
1600^{\circ} \mathrm{C} / 1 \mathrm{~h}\end{array}$ & $\begin{array}{l}80,3 \pm 0,3 \\
76,4 \pm 0,4 \\
72,6 \pm 0,1 \\
72,4 \pm 0,2 \\
58,5 \pm 0,7\end{array}$ & $\begin{array}{l}19,7 \pm 0,3 \\
23,6 \pm 0,4 \\
27,4 \pm 0,1 \\
27,6 \pm 0,2 \\
41,5 \pm 0,7\end{array}$ \\
\hline A30 & $\begin{array}{l}\text { Amido de } \\
\text { arroz }\end{array}$ & 30 & $\begin{array}{c}1850^{\circ} \mathrm{C} / 1 \mathrm{~h} \\
1800^{\circ} \mathrm{C} / 1 \mathrm{~h} \\
1700^{\circ} \mathrm{C} / 3 \mathrm{~h} \\
1700^{\circ} \mathrm{C} / 0,5 \mathrm{~h} \\
1600^{\circ} \mathrm{C} / 1 \mathrm{~h}\end{array}$ & $\begin{array}{l}76,4 \pm 0,5 \\
70,7 \pm 0,5 \\
68,1 \pm 2,4 \\
67,2 \pm 1,7 \\
52,1 \pm 0,2\end{array}$ & $\begin{array}{l}23,7 \pm 0,5 \\
29,3 \pm 0,5 \\
31,9 \pm 2,4 \\
32,8 \pm 1,7 \\
47,9 \pm 0,2\end{array}$ \\
\hline A40 & & 40 & $\begin{array}{c}1850^{\circ} \mathrm{C} / 1 \mathrm{~h} \\
1800^{\circ} \mathrm{C} / 1 \mathrm{~h} \\
1700^{\circ} \mathrm{C} / 3 \mathrm{~h} \\
1700^{\circ} \mathrm{C} / 0,5 \mathrm{~h} \\
1600^{\circ} \mathrm{C} / 1 \mathrm{~h}\end{array}$ & $\begin{array}{l}70,2 \pm 0,9 \\
66,4 \pm 1,2 \\
59,3 \pm 0,3 \\
59,5 \pm 2,7 \\
47,6 \pm 1,4\end{array}$ & $\begin{array}{l}29,8 \pm 0,9 \\
33,6 \pm 1,2 \\
40,7 \pm 0,3 \\
40,5 \pm 2,7 \\
52,4 \pm 1,4\end{array}$ \\
\hline M20 & & 20 & $\begin{array}{c}1850^{\circ} \mathrm{C} / 1 \mathrm{~h} \\
1800^{\circ} \mathrm{C} / 1 \mathrm{~h} \\
1700^{\circ} \mathrm{C} / 3 \mathrm{~h} \\
1700^{\circ} \mathrm{C} / 0,5 \mathrm{~h} \\
1600^{\circ} \mathrm{C} / 1 \mathrm{~h}\end{array}$ & $\begin{array}{l}78,7 \pm 0,3 \\
75,2 \pm 0,4 \\
69,6 \pm 0,6 \\
69,2 \pm 0,4 \\
57,7 \pm 1,2\end{array}$ & $\begin{array}{l}21,3 \pm 0,3 \\
24,8 \pm 0,4 \\
30,4 \pm 0,6 \\
30,8 \pm 0,4 \\
42,3 \pm 1,2\end{array}$ \\
\hline M30 & $\begin{array}{l}\text { Amido de } \\
\text { milho }\end{array}$ & 30 & $\begin{array}{c}1850^{\circ} \mathrm{C} / 1 \mathrm{~h} \\
1800^{\circ} \mathrm{C} / 1 \mathrm{~h} \\
1700^{\circ} \mathrm{C} / 3 \mathrm{~h} \\
1700^{\circ} \mathrm{C} / 0,5 \mathrm{~h} \\
1600^{\circ} \mathrm{C} / 1 \mathrm{~h} \\
\end{array}$ & $\begin{array}{l}75,8 \pm 0,3 \\
70,9 \pm 0,5 \\
65,4 \pm 0,3 \\
65,7 \pm 0,2 \\
52,9 \pm 0,2 \\
\end{array}$ & $\begin{array}{l}24,2 \pm 0,3 \\
29,1 \pm 0,5 \\
34,6 \pm 0,3 \\
34,3 \pm 0,2 \\
47,1 \pm 0,2 \\
\end{array}$ \\
\hline M40 & & 40 & $\begin{array}{c}1800^{\circ} \mathrm{C} / 1 \mathrm{~h} \\
1700^{\circ} \mathrm{C} / 0,5 \mathrm{~h}\end{array}$ & $\begin{array}{l}66,4 \pm 1,1 \\
60,1 \pm 0,3\end{array}$ & $\begin{array}{l}33,6 \pm 1,1 \\
39,9 \pm 0,3\end{array}$ \\
\hline B20 & & 20 & $\begin{array}{c}1850^{\circ} \mathrm{C} / 1 \mathrm{~h} \\
1800^{\circ} \mathrm{C} / 1 \mathrm{~h} \\
1700^{\circ} \mathrm{C} / 3 \mathrm{~h} \\
1700^{\circ} \mathrm{C} / 0,5 \mathrm{~h}\end{array}$ & $\begin{array}{l}81,0 \pm 0,2 \\
77,1 \pm 0,4 \\
71,2 \pm 0,3 \\
71,6 \pm 0,2\end{array}$ & $\begin{array}{l}19,0 \pm 0,2 \\
22,9 \pm 0,4 \\
28,8 \pm 0,3 \\
28,4 \pm 0,2\end{array}$ \\
\hline B30 & $\begin{array}{l}\text { Amido de } \\
\text { batata }\end{array}$ & 30 & $\begin{array}{c}1850^{\circ} \mathrm{C} / 1 \mathrm{~h} \\
1800^{\circ} \mathrm{C} / 1 \mathrm{~h} \\
1700^{\circ} \mathrm{C} / 3 \mathrm{~h} \\
1700^{\circ} \mathrm{C} / 0,5 \mathrm{~h} \\
1600^{\circ} \mathrm{C} / 1 \mathrm{~h}\end{array}$ & $\begin{array}{l}74,6 \pm 0,3 \\
71,8 \pm 0,5 \\
68,2 \pm 0,2 \\
67,1 \pm 0,4 \\
55,3 \pm 0,3\end{array}$ & $\begin{array}{l}25,4 \pm 0,3 \\
28,2 \pm 0,5 \\
31,8 \pm 0,2 \\
32,9 \pm 0,4 \\
44,8 \pm 0,3\end{array}$ \\
\hline B40 & & 40 & $\begin{array}{c}1850^{\circ} \mathrm{C} / 1 \mathrm{~h} \\
1800^{\circ} \mathrm{C} / 1 \mathrm{~h} \\
1700^{\circ} \mathrm{C} / 3 \mathrm{~h} \\
1700^{\circ} \mathrm{C} / 0,5 \mathrm{~h} \\
1600^{\circ} \mathrm{C} / 1 \mathrm{~h}\end{array}$ & $\begin{array}{l}66,2 \pm 2,1 \\
63,4 \pm 1,4 \\
58,3 \pm 2,1 \\
59,8 \pm 4,1 \\
49,8 \pm 0,3\end{array}$ & $\begin{array}{l}33,8 \pm 2,1 \\
36,6 \pm 1,4 \\
41,7 \pm 2,1 \\
40,2 \pm 4,1 \\
50,2 \pm 0,3\end{array}$ \\
\hline
\end{tabular}



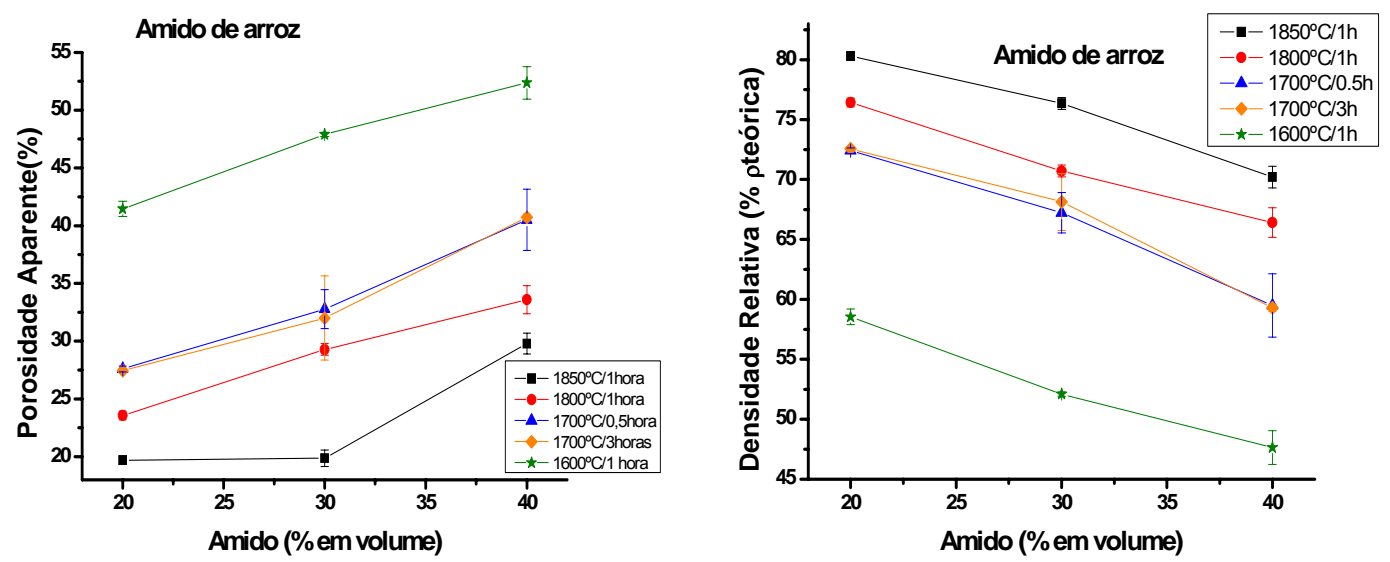

(a)
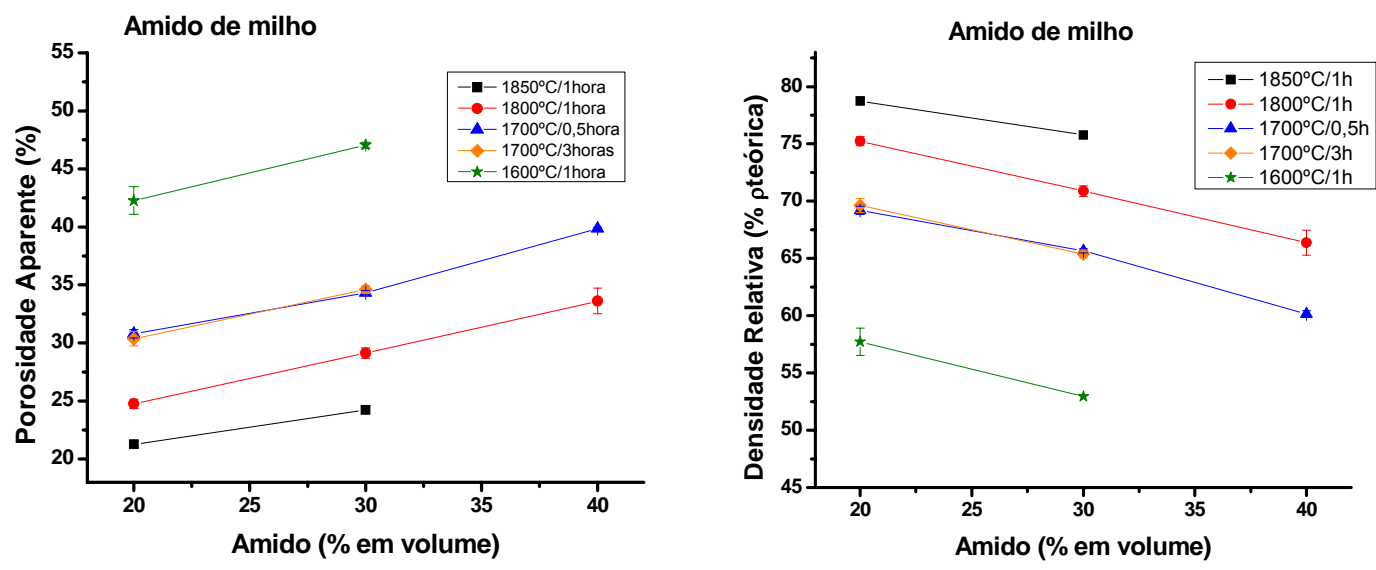

(b)
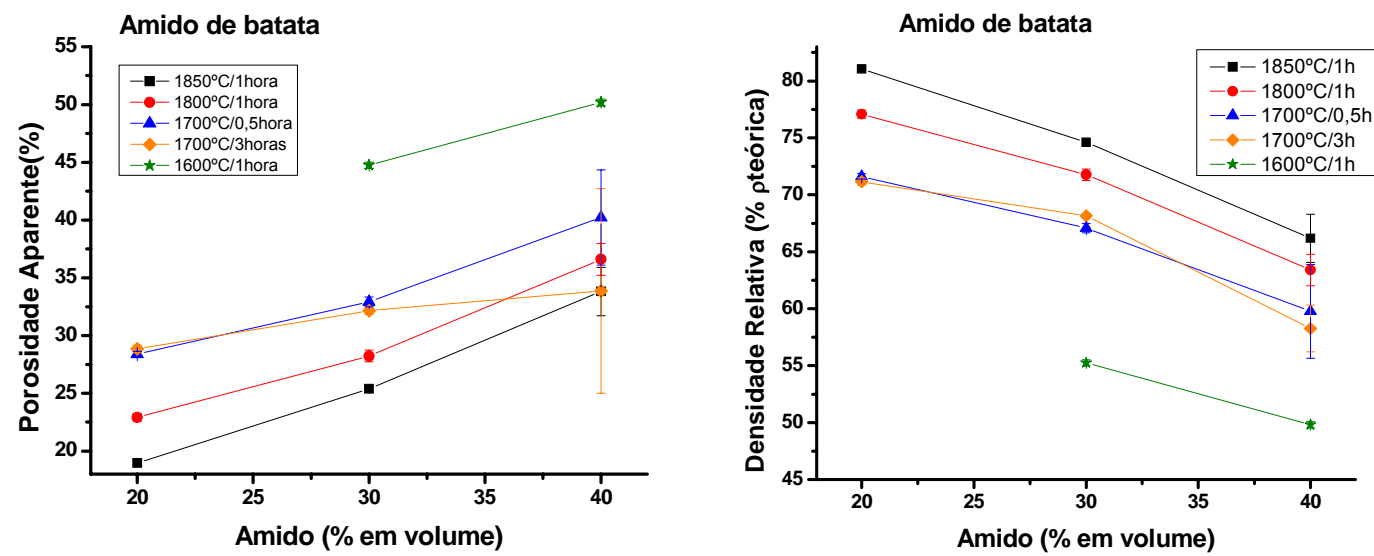

(c)

Figura 5.19: Porosidade aparente e densidade aparente versus percentual de amido para amostras porosas de $\mathrm{Si}_{3} \mathrm{~N}_{4}$ obtidas por fase sacrificial, e sinterizadas sob diferentes tratamentos térmicos. Em (a) amido de arroz, em (b) amido de milho e em (c) amido de batata. 


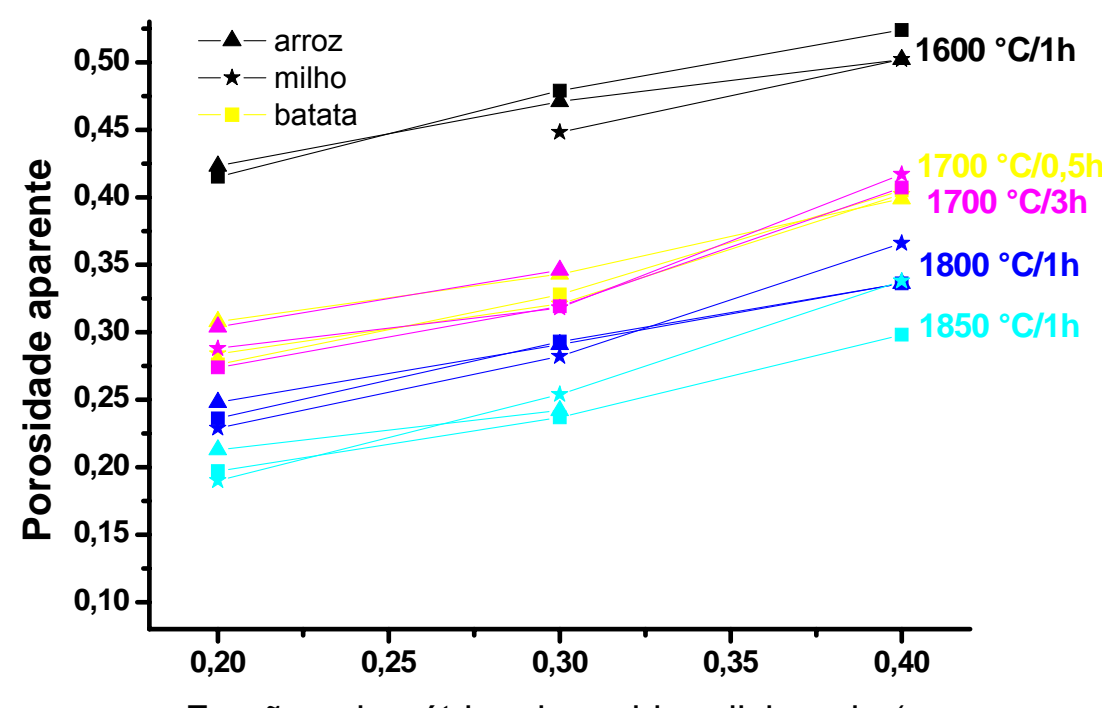

Fração volumétrica de amido adicionado $(\phi)$

Figura 5.20: Porosidade aparente versus fração volumétrica de amido adicionado para amostras porosas de $\mathrm{Si}_{3} \mathrm{~N}_{4}$ obtidas por fase sacrificial, e sinterizadas sob diferentes tratamentos térmicos.

$\mathrm{Na}$ figura 5.21 são mostradas micrografias das amostras porosas de $\mathrm{Si}_{3} \mathrm{~N}_{4}$ obtidas por fase sacrificial, a partir da adição de amido de arroz em diferentes percentagens.

Observa-se uma clara diferença entre as microestruturas, constatandose o aumento da porosidade com o teor de amido adicionado. Com a adição de $20 \%$ e $30 \%$ tem-se uma maior população de poros isolados, ao passo que a adição de $40 \%$ de amido levou a um aumento de poros interconectados.

$\mathrm{Na}$ figura 5.22 são apresentadas microestruturas de amostras porosas de $\mathrm{Si}_{3} \mathrm{~N}_{4}$ obtidas por fase sacrificial com a adição de $30 \%$ de amido de arroz, podendo-se observar detalhes da estrutura de poros. 


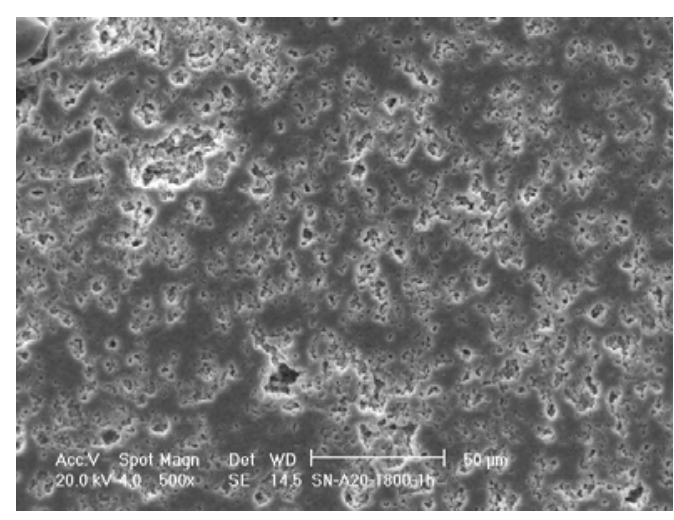

(a)

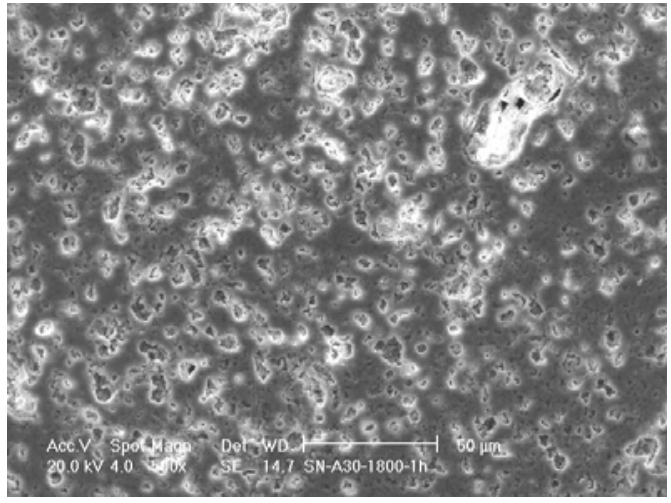

(b)

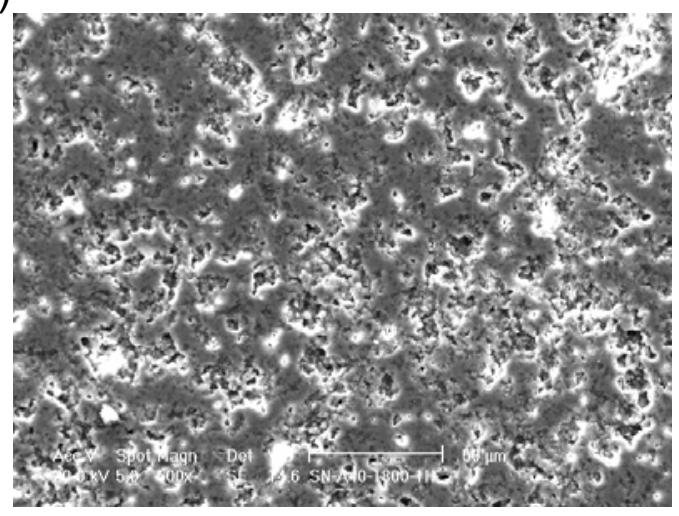

(c)

Figura 5.21: Amostras porosas de $\mathrm{Si}_{3} \mathrm{~N}_{4}$ obtidas com a adição de $20 \%$ (a), $30 \%$ (b) e $40 \%$ (c) de amido de arroz, sinterizadas a $1800^{\circ} \mathrm{C}$ por 1 hora.
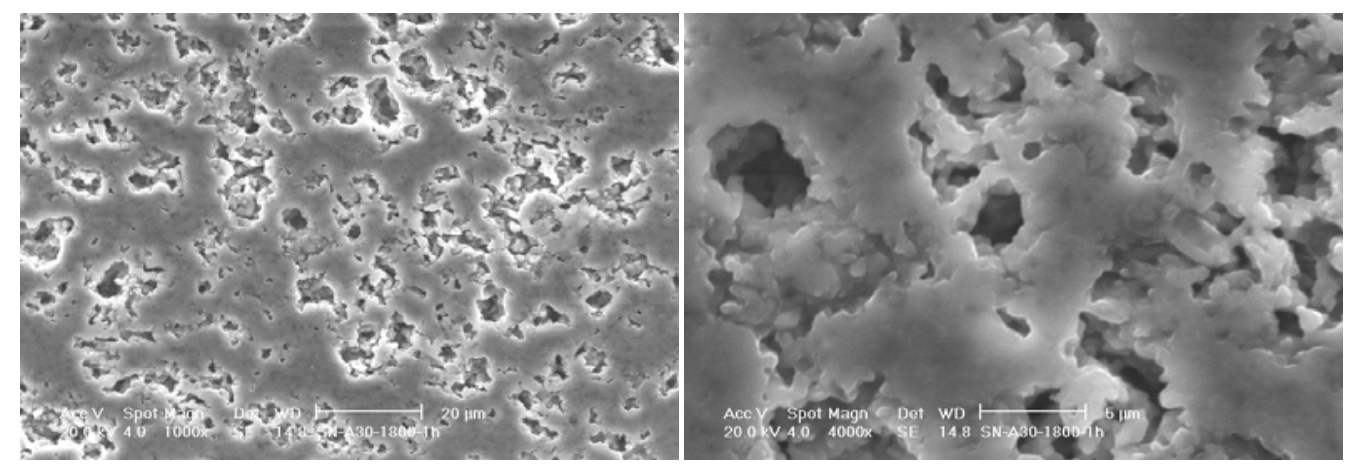

Figura 5.22: Detalhes da estrutura de poros de amostra obtida com a adição de $30 \%$ de amido de arroz, sinterizada a $1800^{\circ} \mathrm{C}$ por 1 hora.

As amostras, após a sinterização, foram submetidas à análise por difração por raio-x, para a verificação das fases cristalinas presentes, particularmente no que se refere á transformação de $\alpha-\mathrm{Si}_{3} \mathrm{~N}_{4}$ para $\beta-\mathrm{Si}_{3} \mathrm{~N}_{4}$. Os difratogramas para cada uma das temperaturas estudadas são apresentados na 
figura 5.23. Na Figura 5.24 é apresentada parte de um dos difratogramas (1700 ${ }^{\circ} \mathrm{C} / 0,5 \mathrm{~h}$ ) indicando-se os picos relacionados à equação de Yeheskel e Gefen.
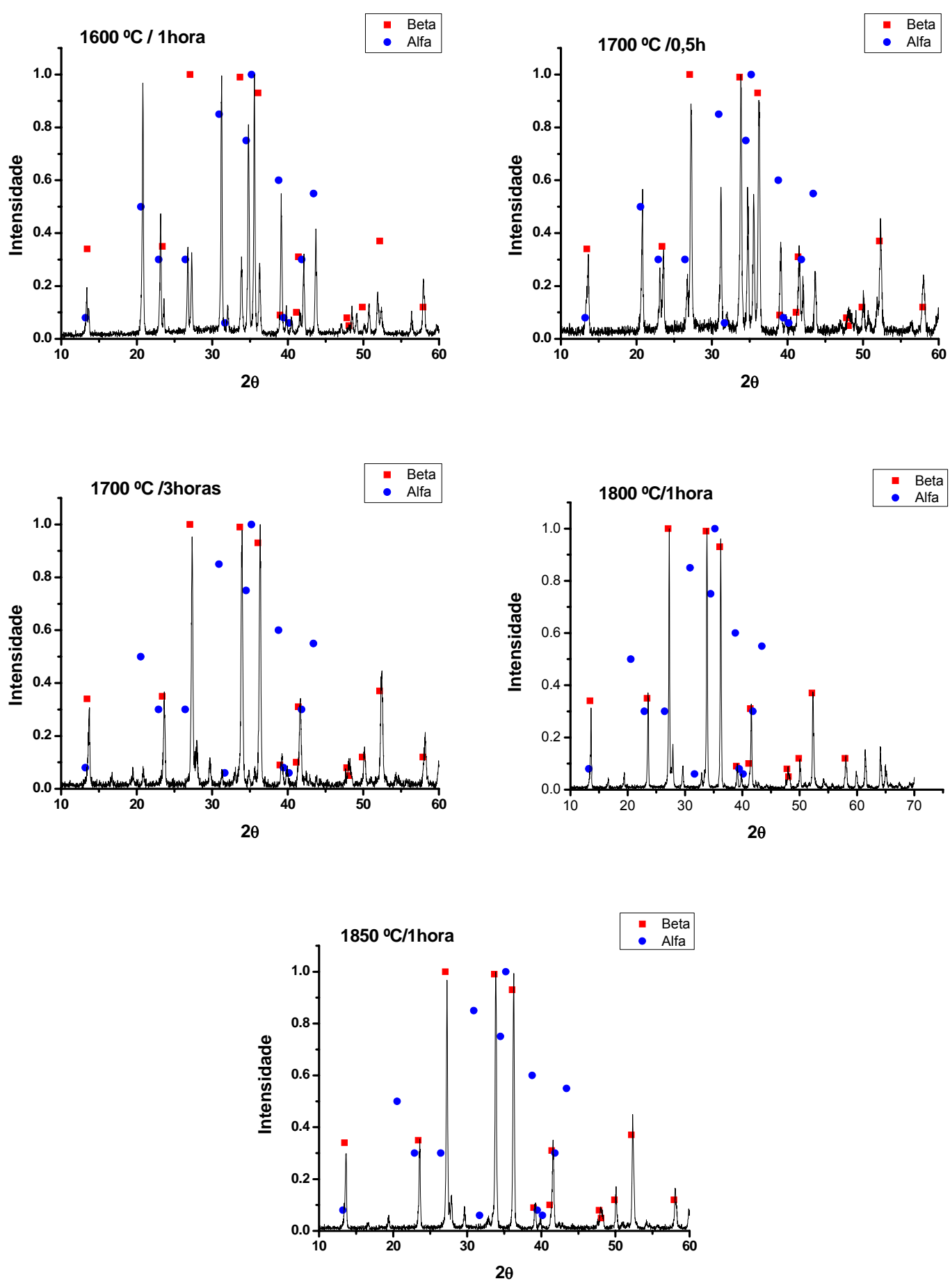

Figura 5.23: Difratogramas de raios- $x$ das amostras, porosas de $\mathrm{Si}_{3} \mathrm{~N}_{4}$ sinterizadas sob diferentes condições. 


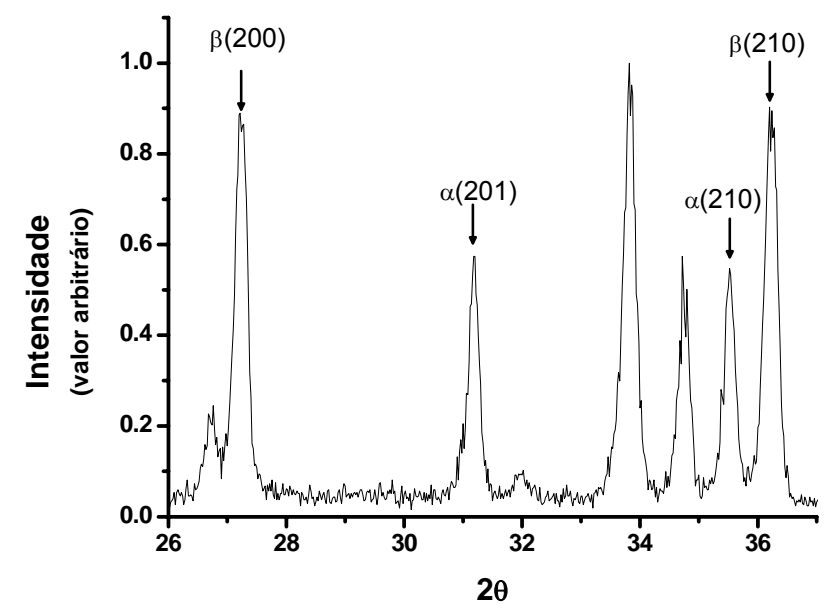

Figura 5.24: Parte do difratograma de raios $X$ indicando os picos relacionados à equação de Yeheskel e Gefen.

$\mathrm{Na}$ Tabela 5.8 são apresentados os percentuais das fases $\alpha-\mathrm{Si}_{3} \mathrm{~N}_{4}$ e $\beta$ $\mathrm{Si}_{3} \mathrm{~N}_{4}$ calculados a partir da equação proposta por Yeheskel e Gefen, para os diferentes tratamentos de sinterização empregados. Constata-se que com o aumento da temperatura (ou tempo de patamar) ocorre uma maior transformação de fases $\alpha-\mathrm{Si}_{3} \mathrm{~N}_{4}$ para $\beta-\mathrm{Si}_{3} \mathrm{~N}_{4}$.

Tabela 5.8: Percentual de $\alpha-\mathrm{Si}_{3} \mathrm{~N}_{4}$ e $\beta-\mathrm{Si}_{3} \mathrm{~N}_{4}$ presente nas amostras porosas de Si3N4, sinterizadas sob diferentes tratamentos térmico.

\begin{tabular}{ccc}
\hline Sinterização & $\alpha-\mathrm{Si}_{3} \mathrm{~N}_{4}(\%)$ & $\beta-\mathrm{Si}_{3} \mathrm{~N}_{4}(\%)$ \\
\hline $1850^{\circ} \mathrm{C} / 1 \mathrm{~h}$ & 1,0 & 99,0 \\
$1800^{\circ} \mathrm{C} / 1 \mathrm{~h}$ & 1,0 & 99,0 \\
$1700^{\circ} \mathrm{C} / 3 \mathrm{~h}$ & 7,1 & 92,9 \\
$1700^{\circ} \mathrm{C} / 0,5 \mathrm{~h}$ & 38,3 & 61,7 \\
$1600^{\circ} \mathrm{C} / 1 \mathrm{~h}$ & 76,6 & 23,4 \\
\hline
\end{tabular}

Amostras das composições estudadas neste tópico foram submetidas a ensaios de compressão, sendo os resultados apresentados na Tabela 5.9 e nas figuras de 5.25 a 5.27 . Na figura 5.28 estes dados são apresentados de modo separado para uma melhor visualização dos resultados. Na Figura 5.28-a são comparados os valores de resistência a compressão para as amostras obtidas a partir da adição de diferentes amidos, e sinterizadas a $1800{ }^{\circ} \mathrm{C}$ e $1600{ }^{\circ} \mathrm{C}$ por 
1hora. Já na Figura 5.28-b estão estes mesmos dados para as amostras sinterizadas a $1700{ }^{\circ} \mathrm{C}$ por 0,5 e 3 horas.

Tabela 5.9: Densidade relativa e porosidade aparente das amostras obtidas pelo método da fase sacrificial utilizando diferentes amidos.

\begin{tabular}{|c|c|c|c|c|c|}
\hline Amostra & $\begin{array}{c}\text { Amido } \\
\text { empregado }\end{array}$ & $\begin{array}{l}\% \text { de amido } \\
\text { adicionado }\end{array}$ & $\begin{array}{c}\text { Tratamento } \\
\text { térmico }\end{array}$ & $\begin{array}{l}\text { Porosidade } \\
\text { aparente (\%) }\end{array}$ & $\begin{array}{c}\text { Módulo de } \\
\text { ruptura } \sigma(\mathrm{MPa})\end{array}$ \\
\hline A20 & & 20 & $\begin{array}{c}1850^{\circ} \mathrm{C} / 1 \mathrm{~h} \\
1800^{\circ} \mathrm{C} / 1 \mathrm{~h} \\
1700^{\circ} \mathrm{C} / 3 \mathrm{~h} \\
1700^{\circ} \mathrm{C} / 0,5 \mathrm{~h} \\
1600^{\circ} \mathrm{C} / 1 \mathrm{~h}\end{array}$ & $\begin{array}{l}19,7 \pm 0,3 \\
23,6 \pm 0,4 \\
27,4 \pm 0,1 \\
27,6 \pm 0,2 \\
41,5 \pm 0,7\end{array}$ & $\begin{array}{c}399,4 \pm 249,2 \\
566,9 \pm 41,0 \\
339,0 \pm 149,1 \\
508,0 \pm 117,1 \\
227,1 \pm 55,3\end{array}$ \\
\hline A30 & $\begin{array}{l}\text { Amido de } \\
\text { arroz }\end{array}$ & 30 & $\begin{array}{c}1850^{\circ} \mathrm{C} / 1 \mathrm{~h} \\
1800^{\circ} \mathrm{C} / 1 \mathrm{~h} \\
1700^{\circ} \mathrm{C} / 3 \mathrm{~h} \\
1700^{\circ} \mathrm{C} / 0,5 \mathrm{~h} \\
1600^{\circ} \mathrm{C} / 1 \mathrm{~h}\end{array}$ & $\begin{array}{l}23,7 \pm 0,5 \\
29,3 \pm 0,5 \\
31,9 \pm 2,4 \\
32,8 \pm 1,7 \\
47,9 \pm 0,2\end{array}$ & $\begin{array}{c}367,9 \pm 183,0 \\
417,1 \pm 75,1 \\
438,8 \pm 39,5 \\
294,8 \pm 90,3 \\
135,6 \pm 10,6\end{array}$ \\
\hline A40 & & 40 & $\begin{array}{c}1850^{\circ} \mathrm{C} / 1 \mathrm{~h} \\
1800^{\circ} \mathrm{C} / 1 \mathrm{~h} \\
1700^{\circ} \mathrm{C} / 3 \mathrm{~h} \\
1700^{\circ} \mathrm{C} / 0,5 \mathrm{~h} \\
1600^{\circ} \mathrm{C} / 1 \mathrm{~h}\end{array}$ & $\begin{array}{l}29,8 \pm 0,9 \\
33,6 \pm 1,2 \\
40,7 \pm 0,3 \\
40,5 \pm 2,7 \\
52,4 \pm 1,4\end{array}$ & $\begin{array}{c}115,4 \pm 32,4 \\
219,8 \pm 40,0 \\
95,8 \pm 6,5 \\
132,4 \pm 38,9 \\
23,5 \pm 9,5\end{array}$ \\
\hline M20 & & 20 & $\begin{array}{c}1850^{\circ} \mathrm{C} / 1 \mathrm{~h} \\
1800^{\circ} \mathrm{C} / 1 \mathrm{~h} \\
1700^{\circ} \mathrm{C} / 3 \mathrm{~h} \\
1700^{\circ} \mathrm{C} / 0,5 \mathrm{~h} \\
1600^{\circ} \mathrm{C} / 1 \mathrm{~h}\end{array}$ & $\begin{array}{l}21,3 \pm 0,3 \\
24,8 \pm 0,4 \\
30,4 \pm 0,6 \\
30,8 \pm 0,4 \\
42,3 \pm 1,2\end{array}$ & $\begin{array}{c}423,6 \pm 159,9 \\
458,5 \pm 18,1 \\
328,7 \pm 68,2 \\
303,5 \pm 39,4 \\
144 \pm 21,2\end{array}$ \\
\hline M30 & $\begin{array}{l}\text { Amido de } \\
\text { milho }\end{array}$ & 30 & $\begin{array}{c}1850^{\circ} \mathrm{C} / 1 \mathrm{~h} \\
1800^{\circ} \mathrm{C} / 1 \mathrm{~h} \\
1700^{\circ} \mathrm{C} / 3 \mathrm{~h} \\
1700^{\circ} \mathrm{C} / 0,5 \mathrm{~h} \\
1600^{\circ} \mathrm{C} / 1 \mathrm{~h}\end{array}$ & $\begin{array}{l}24,2 \pm 0,3 \\
29,1 \pm 0,5 \\
34,6 \pm 0,3 \\
34,3 \pm 0,2 \\
47,1 \pm 0,2\end{array}$ & $\begin{array}{c}354,2 \pm 30,0 \\
334,3 \pm 70,5 \\
261,0 \pm 31,8 \\
235,8 \pm 22,3 \\
85,1 \pm 3,6\end{array}$ \\
\hline M40 & & 40 & $\begin{array}{c}1800^{\circ} \mathrm{C} / 1 \mathrm{~h} \\
1700^{\circ} \mathrm{C} / 0,5 \mathrm{~h}\end{array}$ & $\begin{array}{l}33,6 \pm 1,1 \\
39,9 \pm 0,3\end{array}$ & $\begin{array}{c}242,4 \pm 53,2 \\
60,1 \pm 0,3\end{array}$ \\
\hline B20 & & 20 & $\begin{array}{c}1850^{\circ} \mathrm{C} / 1 \mathrm{~h} \\
1800^{\circ} \mathrm{C} / 1 \mathrm{~h} \\
1700^{\circ} \mathrm{C} / 3 \mathrm{~h} \\
1700^{\circ} \mathrm{C} / 0,5 \mathrm{~h}\end{array}$ & $\begin{array}{l}19,0 \pm 0,2 \\
22,9 \pm 0,4 \\
28,8 \pm 0,3 \\
28,4 \pm 0,2\end{array}$ & $\begin{array}{c}390,7 \pm 105,2 \\
438,0 \pm 102,4 \\
358,3 \pm 0,8 \\
297,1 \pm 96,2\end{array}$ \\
\hline B30 & $\begin{array}{l}\text { Amido de } \\
\text { batata }\end{array}$ & 30 & $\begin{array}{c}1850^{\circ} \mathrm{C} / 1 \mathrm{~h} \\
1800^{\circ} \mathrm{C} / 1 \mathrm{~h} \\
1700^{\circ} \mathrm{C} / 3 \mathrm{~h} \\
1700^{\circ} \mathrm{C} / 0,5 \mathrm{~h} \\
1600^{\circ} \mathrm{C} / 1 \mathrm{~h}\end{array}$ & $\begin{array}{l}25,4 \pm 0,3 \\
28,2 \pm 0,5 \\
31,8 \pm 0,2 \\
32,9 \pm 0,4 \\
44,8 \pm 0,3\end{array}$ & $\begin{array}{c}260,4 \pm 52,8 \\
265,3 \pm 58,7 \\
204,5 \pm 29,5 \\
142,4 \pm 34,6 \\
88,0 \pm 4,3\end{array}$ \\
\hline B40 & & 40 & $\begin{array}{c}1850^{\circ} \mathrm{C} / 1 \mathrm{~h} \\
1800^{\circ} \mathrm{C} / 1 \mathrm{~h} \\
1700^{\circ} \mathrm{C} / 3 \mathrm{~h} \\
1700^{\circ} \mathrm{C} / 0,5 \mathrm{~h} \\
1600^{\circ} \mathrm{C} / 1 \mathrm{~h}\end{array}$ & $\begin{array}{l}33,8 \pm 2,1 \\
36,6 \pm 1,4 \\
41,7 \pm 2,1 \\
40,2 \pm 4,1 \\
50,2 \pm 0,3\end{array}$ & $\begin{array}{c}110,2 \pm 41,5 \\
97,7 \pm 43,7 \\
70,4 \pm 17,1 \\
40,3 \pm 32,9 \\
28,3 \pm 0,0\end{array}$ \\
\hline
\end{tabular}




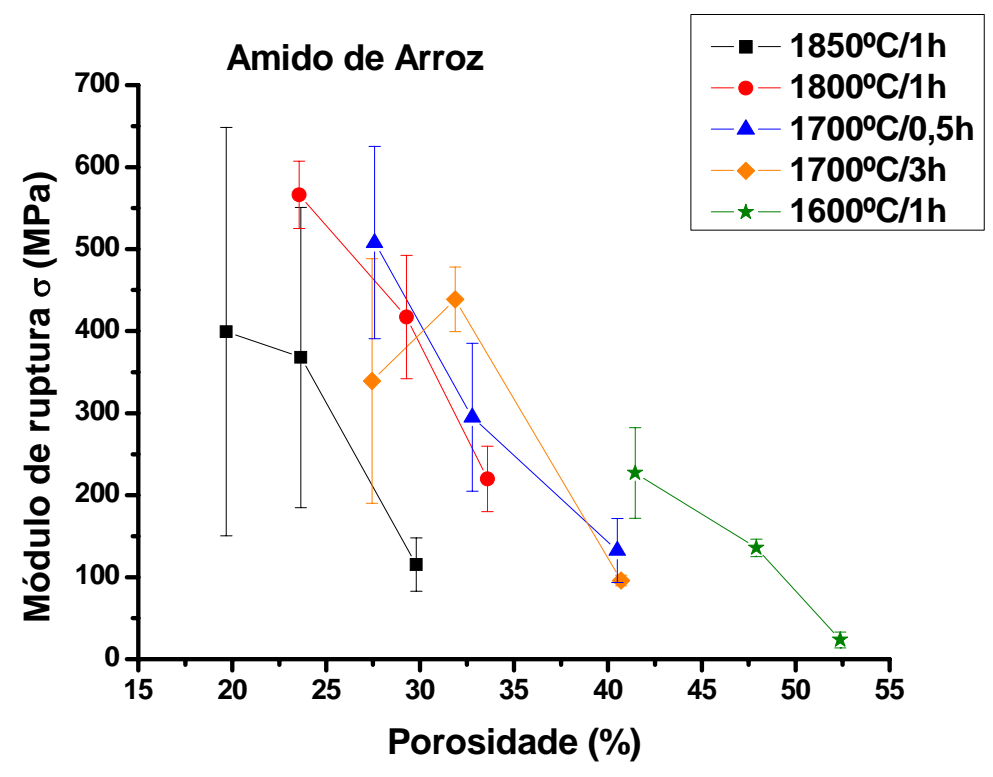

Figura 5.25: Módulo de ruptura versus porosidade aparente para amostras processadas com amido de arroz submetidas a diferentes tratamentos térmicos.

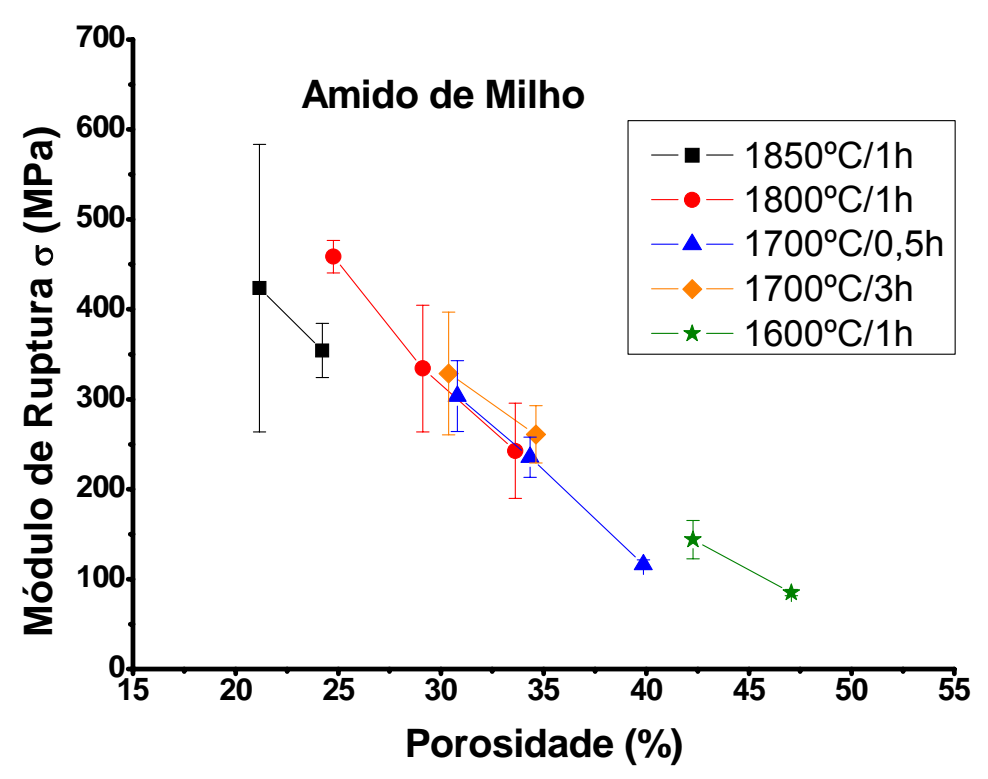

Figura 5.26: Módulo de ruptura versus porosidade aparente para amostras processadas com amido de milho submetidas a diferentes tratamentos térmicos. 


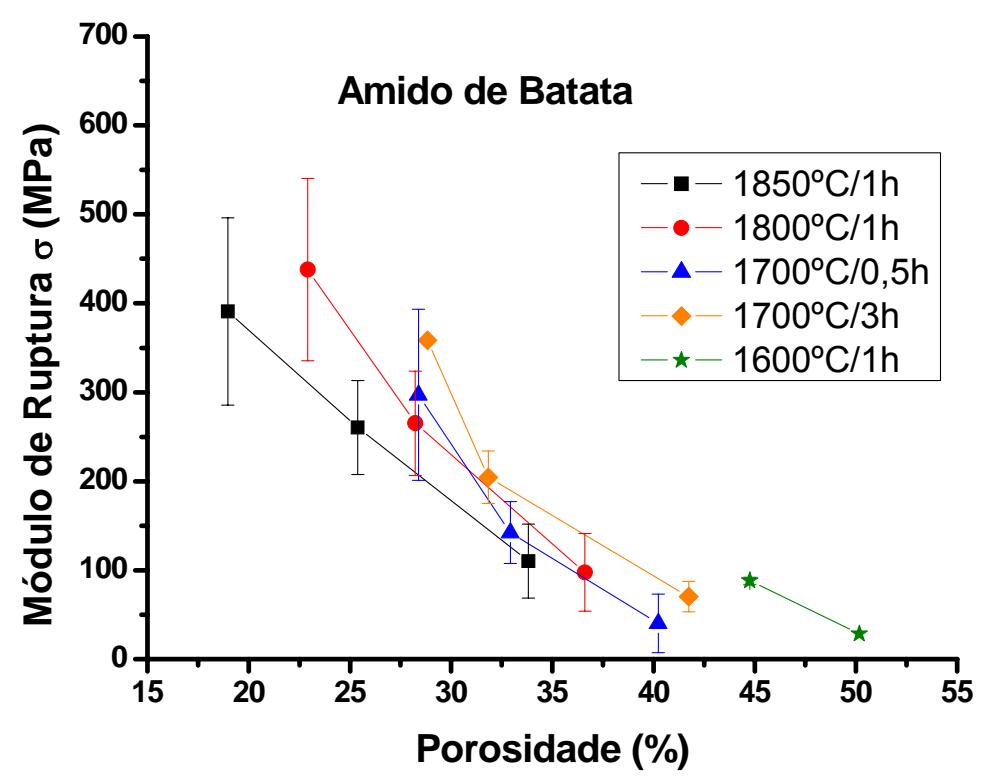

Figura 5.27: Módulo de ruptura versus porosidade aparente para amostras processadas com amido de batata submetidas a diferentes tratamentos térmicos.

Constata-se que o módulo de ruptura apresenta uma relação inversa com a porosidade, próximo a uma relação linear, independente do tipo de amido empregado e das condições de sinterização. Na Figura 5.28-a são apresentadas linhas tracejadas, a partir das quais é possível inferir o quão próximo da linearidade é esta relação entre o módulo de ruptura e a porosidade. Os valores de módulo de ruptura obtidos com o tratamento a $1850{ }^{\circ} \mathrm{C}$ se mostraram menores que os encontrados para as cerâmicas sinterizadas sob outras condições, mas com porosidade semelhante. Esta redução foi mais acentuada para as amostras obtidas a partir do amido de arroz (figura 5.25). Este comportamento das amostras sinterizadas a $1850{ }^{\circ} \mathrm{C}$ poderiam ser relacionados a uma possível decomposição do nitreto de silício, pois nas condições de temperatura e pressão de $\mathrm{N}_{2}$ utilizadas, esta decomposição está em uma condição limítrofe. No entanto caso esta decomposição ocorresse, a perda de massa das amostras seria consideravelmente maior que as detectadas (Tabela 5.6). 


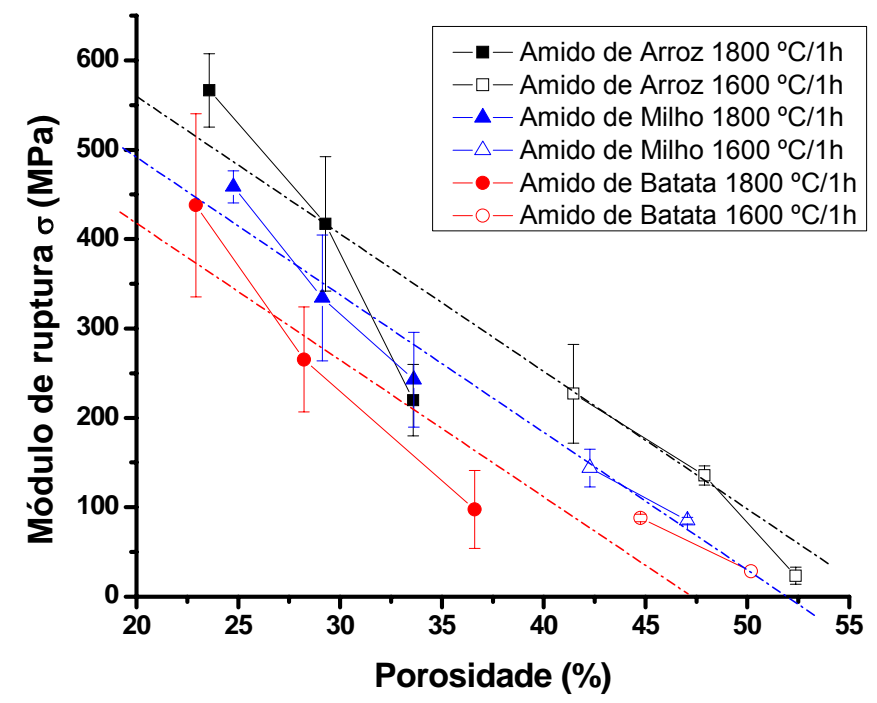

(a)

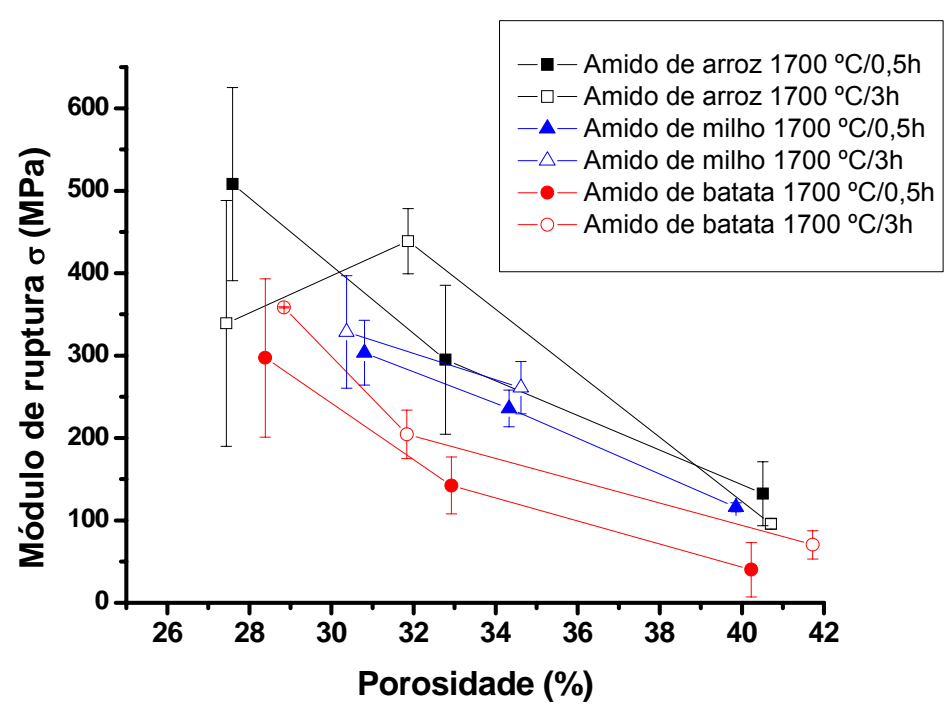

(b)

Figura 5.28: Relação do módulo de ruptura versus porosidade das amostras processadas com amidos de arroz, batata e milho e submetidas a diferentes tratamentos térmicos.

Podia-se esperar que ao compararem-se os tratamentos a $1700{ }^{\circ} \mathrm{C}$ (Figura 5.28-b), as amostras submetidas a tratamento mais longo ( 3 horas), tendo porosidade semelhante às sinterizadas por 0,5 horas, apresentassem valores de módulo de ruptura maiores, devido ao fenômeno do reforço in-situ, já que nestas condições há um maior percentual de fase $\beta-\mathrm{Si}_{3} \mathrm{~N}_{4}$. Os dados experimentais, no 
entanto, não mostraram esta tendência, como pode ser mais bem visualizado na Figura 5.28-b. Estes resultados indicam que a temperatura de $1700{ }^{\circ} \mathrm{C}$ ainda é insuficiente para que a fração dos grãos já transformados de $\beta-\mathrm{Si}_{3} \mathrm{~N}_{4 .}(92,8 \%$ conforme a Tabela 5.8) tenham experimentado um crescimento anisotrópico suficiente para este reforço ocorra.

A relação inversa e quase linear entre o módulo de ruptura e a porosidade permite afirmar, não apenas que a porosidade é o fator determinante para o comportamento mecânico, mas também que as características microestruturais do nitreto de silício pouco interferiram neste comportamento. Isto é surpreendente, já que as amostras sinterizadas a $1600{ }^{\circ} \mathrm{C}$ apresentam predominantemente a fase $\alpha-\mathrm{Si}_{3} \mathrm{~N}_{4}(76 \%$ da fase $\alpha)$, cujos grãos são caracteristicamente equiaxiais, enquanto as amostras sinterizadas a $1800{ }^{\circ} \mathrm{C}$ são compostas essencialmente de $\beta-\mathrm{Si}_{3} \mathrm{~N}_{4}(99 \%$ de fase $\beta)$, cujos grãos alongados são os responsáveis pelo fenômeno do reforço in-situ nas cerâmicas densas a base de nitreto de silício. Poder-se-ia, portanto esperar que a predominância dos grãos de $\beta-\mathrm{Si}_{3} \mathrm{~N}_{4}$ proporcionasse um deslocamento para cima das curvas de resistência mecânica versus porosidade. Como isso não se deu, conclui-se que a sinterização a $1800^{\circ} \mathrm{C} / 1$ hora também não proporcionou o suficiente crescimento anisotrópico dos grãos de $\beta-\mathrm{Si}_{3} \mathrm{~N}_{4}$ para a promoção do mecanismo de reforço insitu nas cerâmicas porosas.

As amostras produzidas a partir da adição de amido de arroz apresentaram maiores valores de módulo de ruptura, seguidas das obtidas com amido de milho e por fim das obtidas com amido de batata. Isto pode ser explicado pelo tamanho de poros obtidos: amostras com poros menores apresentam melhores propriedades mecânicas. Como o amido de arroz é o de menor tamanho, origina poros menores, e assim sucessivamente.

Na figura 5.29, são comparados os valores de resistência mecânica das amostras porosas obtidas pelas diferentes técnicas de fabricação empregadas: por gel-casting e por fase sacrificial. Em (a) são apresentados os resultados para amostras obtidas com amido de milho e em (b) para as obtidas com amido de batata. As amostras obtidas por gel-casting, de um modo geral, apresentaram melhores propriedades mecânicas, e menos sensíveis à 
porosidade, sendo que se comparando os tipos de amido, o de milho proporcionou corpos mais resistentes.

As análises e resultados obtidos neste estudo não permitem que se explique de forma convincente o motivo de as amostras obtidas por gel-casting apresentarem maiores valores de resistência mecânica que as obtidas por fase sacrificial. Estudos mais detalhados quanto à estrutura de poros deverão ser realizados posteriormente para que se encontre esta explicação.

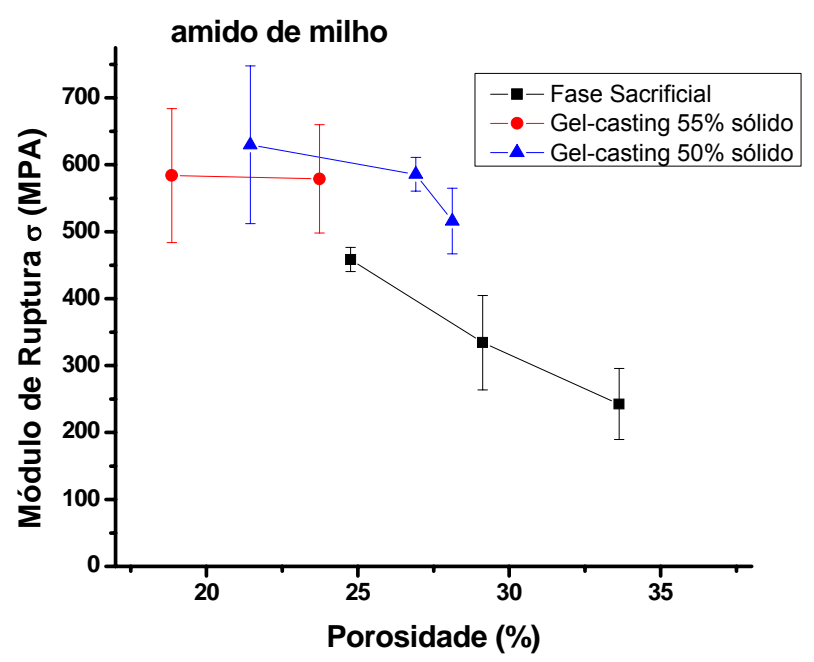

(a)

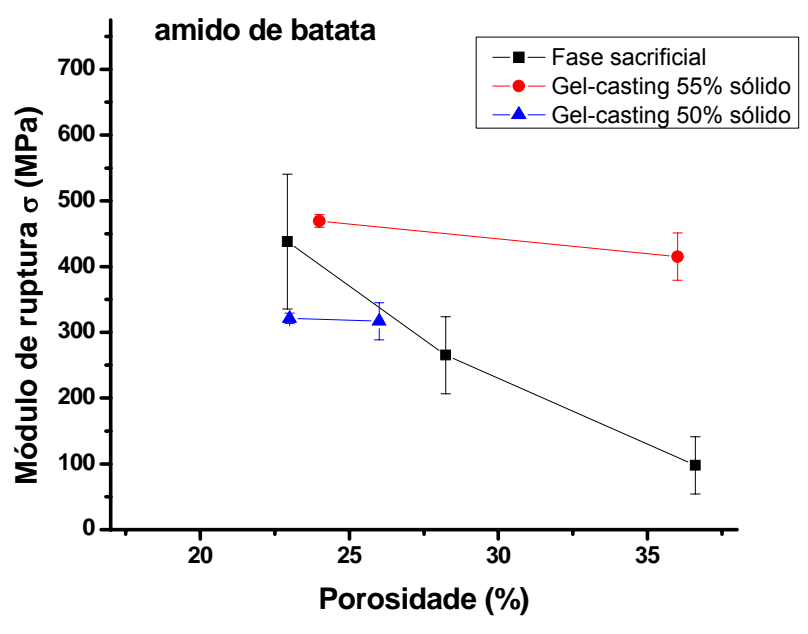

(b)

Figura 5.29: Módulo de ruptura versus porosidade aparente para amostras produzidas pelos métodos gel-casting e fase sacrifical, submetidas à sinterização a $1800^{\circ} \mathrm{C}$ por 1 hora. Em (a) amostras obtidas a partir do amido de milho e em (b) a partir do amido de batata. 


\section{Conclusões}

- Tratamentos de oxidação superficial de partículas de nitreto de silício permitem que se obtenha uma maior estabilização de suspensões aquosas com este material, reduzindo a viscosidade, e permitindo que se possa processar estas suspensões com uma maior faixa de teor de sólidos. Com isso pode-se, pelo método gel-casting, obter corpos porosos com uma maior flexibilidade na estrutura de poros.

- O método gel-casting de espuma utilizando como gelificantes ágar, albumina ou gelatina mostrou-se bastante versátil para a produção de cerâmicas porosas, permitindo que se possa obter uma ampla gama de estruturas de poros. No entanto, para o caso da produção de peças porosas de nitreto de silício, as dificuldades relacionadas à estabilização da suspensão aquosa (viscosidade, sedimentação, estabilização das bolhas formadas, etc.) não permitiram que se tivesse o processo sob controle e reprodutível, indicando a necessidade de mais estudos relacionados ao tema.

- O método de gel-casting com amido se mostrou eficiente para produção de corpos com diferentes estruturas de poros. O tipo de amido influencia na porosidade do corpo obtido, pois amidos com maior tamanho médio de grânulos geram maior porosidade, isto ocorre devido à eliminação da fração de poros menores originados pelo amido; assim as amostras obtidas a partir do amido de arroz (de menor tamanho) apresentam uma maior fração de poros suscetíveis de serem eliminados pela sinterização.

- O amido de batata não se mostrou adequado para ser utilizado como gelificante no método de gel-casting, pois a suspensão produzida com a adição do mesmo apresentou elevada viscosidade, a ponto de dificultar o preenchimento do molde, e causar o surgimento de uma maior população de defeitos nas amostras, o que foi constatado por microscopia e pelos menores valores de tensão de ruptura obtidos com estas amostras. 
- O método de obtenção de corpos porosos pela introdução de amido como fase sacrificial produziu amostras com uma relação praticamente linear entre percentual de amido adicionado e porosidade.

- Os valores de módulo de ruptura por compressão apresentaram uma relação inversa com a porosidade. $\mathrm{O}$ aumento do patamar de sinterização de 0,5 para 3 horas, a $1700{ }^{\circ} \mathrm{C}$ não promoveu melhoria significativa da resistência mecânica dos corpos ensaiados, indicando que estas condições utilizadas de temperatura e tempo não foram suficientes para promover o crescimento anisotrópico dos grãos já transformados em $\beta-\mathrm{Si}_{3} \mathrm{~N}_{4}$.

- Para as condições empregadas neste estudo, a porosidade foi o fator determinante para o comportamento mecânico,sendo que as características microestruturais do nitreto de silício pouco interferiram neste comportamento, já que as condições de sinterização não foram suficientes para proporcionar o adequado crescimento anisotrópico dos grãos de $\beta$ $\mathrm{Si}_{3} \mathrm{~N}_{4}$ de modo a ocorrer o fenômeno do reforço in-situ.

- As amostras produzidas a partir da adição de amido de arroz foram as que apresentaram, para a mesma porosidade aparente, os maiores valores de resistência à compressão, indicando que a presença de poros menores levam a melhorias nas propriedades mecânicas.

- As amostras obtidas por gel-casting, com amido como gelificante apresentaram, para mesma porosidade aparente, maiores valores de resistência à compressão que as amostras obtidas por fase sacrificial. 


\section{Trabalhos Futuros}

- Aprimorar o método gel-casting de espumas para o nitreto de silício.

- Estudar o efeito da mistura de diferentes amidos na estrutura de poros das amostras.

- Estudar o efeito dos aditivos de sinterização na resistência mecânica das amostras.

- Utilizar o amido para produção de amostras via gel-casting de espumas. 


\section{Publicações}

- MESQUITA, R.M.; BRESSIANI, A.H.A.; ALBANO, M.P.; PLUCKNETT, K.P.; GENOVA, L.A. Produção de Corpos Porosos de Nitreto de Silício Utilizando-se amido como Fase Sacrificial. In: $52^{\circ}$ Congresso Brasileiro de Cerâmica, 2008, Florianópolis, p. 1-10.

- MESQUITA, R.M.; BRESSIANI, A.H.A.; GENOVA, L.A. Produção de Nitreto de Silício Poroso pela técnica de "Gel-casting". In: $51^{\circ}$ Congresso Brasileiro de Cerâmica, 2007, Salvador, p. 1-08. 


\section{Referências Bibliográficas}

1. GUZMAN, I,Y. Certain principles of formation of porous ceramic structures: properties and applications (A Review). Glass and Ceramics, v. 60, n. 910 p. $280-283,2003$.

2. RICE, R.W. Porosity of Ceramics. Marcel Dekker, 1998. cap. 1, overview: porosity (and microcrack) dependence of properties. p. 1-17. cap. 10, sumary of porosity and microcracking effects, applications, special fabrication, and engineering. p. 475-526.

3. SHEPPARD, L. Porous ceramics: Processing and applications. In: INTERNATIONAL FORUM FOR MATERIALS ENGINEERING AT SANJO TSUBAME (IFMEST) `92, September 28-29, 1992, Niigata. p. 3-23.

4. KELLY, A. Why engineer porous materials? Phil. Trans. R. Soc. A, v. 364, n. 1838, p. 5-14, 2006.

5. NETTLESHIP, I. Applications of Porous Ceramics. Key Eng. Mater., v. 122 - 124, p. 305 - 324, 1996.

6. STUDART, A.R.; GONZENBACH, U.T.; TERVOORT, E.; GAUCKLER, L.J. Processing routes to macroporous ceramics: A Review. J. Am. Ceram. Soc., v. 89, n. 6, p. 1771-1789, 2006.

7. COLOMBO, P. Conventional and novel processing methods for cellular ceramics. Phil. Trans. R. Soc. A, v. 364, n. 1838, p. 109-124, 2006.

8. RÖDEL, J.; KOUNGA, A.B.N.; WEISSENBERGER-EIBL, M.; KOCH D.; BIERWISCH, A.; ROSSNER, W.; HOFFMANN, M.J.; DNAZER, R.; SCHNEIDER, G. Development of a road map for advanced ceramics: $2010-$ 2025. J. Eur. Ceram. Soc., 2008

9. VLACK, L.H.V.; Propriedades dos Materiais Cerâmicos. Tradução: SILVEIRA, C.; ONIKI, S.; p. 3 - 6, 211, 218-227,234 , 1973.

10. Jr., W.A.L.; Dry Pressing Technical Ceramics. Am. Soc. Bull. V. 75, n. 4, p.103-106, 1996.

11. MONTANARO, L.; JORAND, Y.; FANTOZZI, G.; NEGRO, A. Ceramics Foams by Power Processing. J. Eur. Ceram. Soc., v. 18, n.9, p. 13391350, 1998.

12. RAMBO, C.R; ANDRADE, T.; FEY, T.; SIEBER, H.; MARTINELLI, A.E.; GREIL, P. Microcellular $\mathrm{Al}_{2} \mathrm{O}_{3}$ Ceramics from Wood for Filter Applications.

J. Am. Ceram. Soc., v. 91, n.3, p. 852-859, 2008.

13.ZHU, X.; JIANG, D.; TAN, S.; Improvement in the strength of reticulated porous ceramics by vacuum degassing. Mater. Lett., v. 51, n.4, p. 363-367, 2001.

14.PU, X.P.; LIU, X.J.; QIU, F.G.; HUANG, L.P. Novel method to Optimize the Structure of Reticulated Porous Ceramics. J. Am. Ceram. Soc., v. 87, n.7, p. 1392-1394, 2004. 
15.ZHU, X.W.; JIANG, D.L.; TAN, S.H; ZHANG, Z.Q. Improvement in the Strut Thickness of Reticulated Porous Ceramics. J. Am. Ceram. Soc., v. 84, n.7, p. 1654-1656, 2001.

16. RICHARDSON, T.; PENG, Y.; REMUE, D. Properties of Ceramic Foam Catalyst Supports: Pressure Drop. Appl. Catal. A-General., v. 204, n.1, p. 19-32, 2000.

17.RAMBO, C.R.; SIEBER, H.; GENOVA, L. A. Synthesis of porous biomorfhic $\alpha / \beta-\mathrm{Si}_{3} \mathrm{~N}_{4}$ composite from sea sponge. J. Porous Mater., v. 15, n.4, p. 419 - 425, 2008.

18. INNOCENTINI, M.D.M; SEPULVEDA, P.; SALVINI, V.R.; PANDOLFELLI, V.C.; COURY, J.R. Permeability and Structure of Cellular Ceramics: A Comparison between Two Preparation Techniques. J. Am. Ceram. Soc., v. 81, n.12, p. 3349-3352, 1998.

19.DESCAMPS, M.; DUHOO, T.; MONCHAU, F.; LU, J.; HARDOUIN, P.; HORNEZ, J.C.; LERICHE, A. Manufacture of Macroporous $\beta$-tricalcium phosphate bioceramics. J. Eur. Ceram. Soc., v.28, p. 149-157, 2008.

20.HAN, Y.S.; LI, J.B.; CHEN, Y.J. Fabrication of bimodal porous alumina ceramics. Mater. Res. Bull., v. 38, n. 2, p. 373-379, 2003.

21.TANG, F.; FUDOUZI, H.; UCHIKOSHI, T.; SAKKA, Y. Preparation of porous materials with controlled pore size and porosity. J. Eur. Ceram. Soc., v.24, n. 2, p. 341-344, 2004.

22.WANG, H.; SUNG, I.Y.; LI, X.D.; Kim D. Fabrication of Porous SiC Ceramics with Special Morphologies by Sacrificing Template Method. J. Porous Mater., v. 11, n.4, p. 265 - 271, 2004.

23. KUMAR, B.P.; KUMAR, H.H.; KHARAT, D.K. Study on pore-forming agents in processing of porous piezoceramics. J. Mater. Sci. -Mater, Electronics, v. 16, n.10, p. 681-686, 2005.

24. LIU, D.M. Influence of porosity and pore size on the compressive strength of porous hydroxyapatite ceramic. Ceram. Int., v. 23, n.2, p. 135-139, 1997.

25. KOC, N.; TIMUCIN, M.; KORKUSUZ, F. Fabrication and characterization of porous tricalcium phosphate ceramics. Ceram. Int., v. 30, n.2, p. 205-211, 2004.

26. ZHANG, G.J.; YANG, H.F.; OHJI, T. Fabrication of Porous Ceramics with Unidirectionally Aligned Continuous Pores. J. Am. Ceram. Soc., v. 84, n.6, p. $1395-1397,2001$.

27. SEPULVEDA, P.A Porous Ceramics and the Gelcasting of Foams. Am. Ceram. Soc. Bull. v.76, n. 10, p. 61-65,1997.

28. YOUNG, A.C.; OMATETE, O.O.; JANNEY, M.A.; MENCHHOFER, P.A. Gelcasting of Alumina. J. Am. Ceram. Soc., v.74, n.3, p. 612-618, 1991.

29. ORTEGA, F.S; INOSTROZA, P.A.S.; PANDOLFELLI, V.C. Avaliação de sistemas gelificantes para produção de cerâmicas porosas através da técnica "gelcasting" de espumas. Cerâmica, v. 46, n. 300, p. 225-229, 2000. 
30. ORTEGA, F.S. Propriedades Mecânicas de espumas cerâmicas produzidas via "gelcasting". Cerâmica, v. 49, n. 309, p. 01-05, 2003.

31.DHARA, S.; BHARGAVA, P. A simple direct casting route to ceramic foams. J. Am. Ceram. Soc. v.86, n.10, p. 1645-1650, 2003.

32. RIBEIRO, C; BRESSIANI, J.C; BRESSIANI A.H.A. Characterization of the calcium phosphate porous ceramic obtained by foam consolidation using albumin. Key Eng. Mat. v.361-363, p. 971-974, 2007.

33. TUCK, C.; EVANS, J.R.G. Porous ceramics prepared from aqueous foams. J. of Mat. Sci. L., v. 18, n. 13, p.1003-1005, 1999.

34. RIBEIRO, C.; BRESSIANI, J.C.; BRESSIANI, A.H.A. Obtention of TCP porous ceramic using albumin. Mat. Sci. Forum, v. 530, p.587-592, 2006.

35. TULLIANI, J.M.; MONTANARO, L.; BELL, T.J.; SWAIN, M.V. SemiclosedCell Mullite foams: Preparation and Macro- and Micromechanical Characterization. J. Am. Ceram. Soc., v. 82, n.4, p. 961-968, 1999.

36. SEPULVEDA, P; BINNER, J.G.P. Processing of cellular ceramics by foaming and in situ polymerization of organic monomers. J. Eur. Ceram. Soc., v. 19, n.12, p. 2059 - 2066, 1999.

37.PENG, H. X.; FAN, Z.; EVANS, J. R. G.; BUSFIELD, J. J. C. Microstructure of ceramic foams. J. Eur. Ceram. Soc., v. 20, n.7, p. $807-813,2000$.

38. EBARETONBOFA, E.; EVANS, J. R. G. High Porosity Hydroxyapatite Foam Scaffolds for Bone Substitute. J. Porous. Mater., v. 9, n.4, p. 257 263, 2002.

39. ORTEGA, F. S.; SEPULVEDA, P.; PANDOFELLI, V. C. Monomer systems for the gelcasting of foams. J. Eur. Ceram. Soc., v. 22, n.9-10, p. 1395 1401, 2002.

40. GARRN, I.; REETZ,C.; BRANDES, N.; KROH, L. W.; SCHUBERT, H. Clotforming: the use of proteins as binders for producing ceramic foams. J. Eur. Ceram. Soc., v. 24, n.3, p. $579-587,2004$.

41.PRABHAKARAN, K.; GOKHALE, N. M.; SHARMA, S. C.; LAL, R. A Novel Process for Low-Density Alumina Foams. J. Am. Ceram. Soc., v. 88, n.9, p. 2600 - 2603, 2005.

42. ORTEGA, F. S.; VALENZUELA, F. A. O.; SCURACCHIO, C. H.; V. C. PANDOFELLI Alternative gelling agents for the gelcasting of ceramic foams. J. Eur. Ceram. Soc., v. 23, n.1, p. 75 - 80, 2003.

43. PARK, J.K.; LEE, J.S.; LEE, S.I. Preparation of porous cordierite using Gelcasting Method and its feasibility as a filter. J. Porous Mater., v. 9, n. 3, p. $203-210,2002$.

44.SALVINI, V.R.; GARCIA, J.R.; OLIVEIRA, I.R.; V. C. PANDOFELLI. Foaming agent and the effects on the physical properties of porous alumina. Cerâmica, v. 52, n.321, p. 57 - 62, 2006.

45. GREGOROVÁ, E.; PABST, W. Porosity and pore size control in starch consolidation casting of oxide ceramics - Achiments and problems. J. Eur. Ceram. Soc., v.27, n.2-3, p. 669-672, 2007. 
46. LYCKFELDT, O.; FERREIRA, J.M.F Processing of Porous Ceramics by 'Starch Consolidation'. J. Eur. Ceram. Soc., v.18, n.2, p. 131-140, 1998.

47. GREGOROVÁ, E.; ZIVCOVÁ, Z.; PABST, W. Porosity and pores space characteristics of starch-processed porous ceramics. J. Mater. Sci., v.41, n.18, p. 6119-6122, 2006.

48. LEMOS, A.F.; FERREIRA, J.M. Porous bioactive calcium carbonate implants processed by starch consolidation. Mater. Sci. Eng. C-

Biomimetic Supramolecular Systems, v. 11, n.1, p. 35 - 40, 2000.

49. ALVES, H.M.; TARI, G.; FERREIRA, J.M. Processing of porous cordierite bodies by starch consolidation. Mater. Res. Bull., v. 33, n.10, p. 1439 1448, 1998.

50.BAREA, R.; OSENDI, M.I.; MIRANZO, P.; FERREIRA, J.M.F. Fabrication of Highly Porous Mullite Materials. J. Am. Ceram. Soc., v. 88, n.3, p. 777 779, 2005.

51.BHATTACHARJEE, S.; BESRA, L.; SINGH, B.P. Effect of additives on the microstructure of porous alumina. J. Eur. Ceram. Soc., v.27, n.1, p. 47-52, 2007.

52.DÍAZ, A.; HAMPSHIRE, S. Characterization of porous silicon nitride materials produced with starch. J. Eur. Ceram. Soc., v. 24, n. 2, p. 413419, 2004.

53. GREGOROVÁ, E.; PABST, W.; BOHAČENKO, I. Characterization of different starch types for their application in ceramic processing. J. Eur. Ceram. Soc. v. 26, p. 1301-1309, 2006.

54.ALMEIDA, F.A.; BOTELHO, E.C.; MELO, F.C.L.; CAMPOS, T.M.B.; THIM, G.P. Influence of cassava starch and sintering temperature on the alumina consolidation technique. J. Eur. Ceram. Soc. 2008.

55.GIBSON, J.L.; ASHBY, M.F. Cellular solids Structure and propertiesSecond edition. Cambridge Solid State Science Series, 1997. Cap. 1, Introduction, p. 1-13. Cap. 2, The Structure of Cellular Solids. p. 15-50. Cap. 5, The Mechanics of Foams: Basic Results, p. 175-231. Cap. 6, the mechanics of Foams: Refinements. p. 235-281.

56.PABST, W.;GREGOROVÁ, E.; TICHÁ, G. Elasticity of porous ceramics-A critical study of modulus-porosity relations. J. Eur. Ceram. Soc., v. 26, p. 1085-1097, 2006.

57.NAGEL, A.; PETZOW, G.; GREIL, P.; Rheology of aqueous silicon nitride suspensions. J. Eur. Ceram. Soc. v. 5, p. 371-378, 1989.

58. SHIH, C-J.; HON, M-H. Stabilization of aqueous $\mathrm{Si}_{3} \mathrm{~N}_{4}$ suspensions with ammonium salt of poly(acrylic acid) at various pH. Mat. Chem. And Phy. v. 57, p. 125-133, 1998.

59.MORENO, R.; SALOMONI, A.; CASTANHO, S.M. Colloidal Filtration of Silicon Nitride Aqueous Slips. Part I: Optimization of the Slip parameters. J. Eur. Ceram. Soc. v. 18, p. 405-416, 1998. 
60.MORENO, R.; SALOMONI, A.; STAMENKOVIC, I.; CASTANHO, S.M. Colloidal Filtration of Silicon Nitride Aqueous Slips. Part I: Slip Casting and Pressure Casting Performance. J. Eur. Ceram. Soc. v. 19, p. 49-59, 1999.

61.ALBANO, M.P.; GARRIDO, L.B. Improvement of ammonium polyacrylate adsorption on $\mathrm{Si}_{3} \mathrm{~N}_{4}$ powders by an aluminum hydroxide coating. Mat. Lett. v. 38, p. 431-436, 1999.

62. OLIVEIRA, M.I.L.L.; CHEN, K.; FERREIRA, J.M.F. Influence of powder pretreatments of dispersion ability of aqueous silicon nitrided-based suspensions. J. Eur. Ceram. Soc. v. 21, p. 2413-2421, 2001.

63.ZHANG, J.; YE, F.; JIANG, D.; IWASA, M. Dispersion of $\mathrm{Si}_{3} \mathrm{~N}_{4}$ powders in aqueous media. Col. And Surf. A: Physicochem. Eng. Aspects. v. 259, p.117-123, 2005.

64. HUI, L.; XUEMAN, P.; MINGXIA, X.; TINGXIAN, X.; Dispersion mechanisms of aqueous silicon nitride suspensions at high solid loading. Mater. Sci. Eng. A, v. 465, p. 13 - 21, 2007.

65. INAGAKI, Y.; KONDO, N.; OHJI, T. High performance porous silicon nitrides. J. Eur. Ceram. Soc., v. 22, n. 14-15, p. 2489-2494, 2002.

66. YANG, J-F.; OHJI, T.; ZENG, Y-P.; KANZAKI, S.; ZHANG, G-J. Fabrication and mechanical properties of porous silicon nitride ceramics from low-purity powder. J. Ceram. Soc. Jap., v. 111, n. 10, p. 758-761, 2003.

67. YANG, H.F.; ZHANG, G.J.; KONDO, N.; OHJI, T.; KANZAKI, S. Synthesis of Porous $\mathrm{Si}_{3} \mathrm{~N}_{4}$ Ceramics with Rod-Shaped Pore Structure. J. Am. Ceram. Soc. , v. 88, n.4, p. 1030-1032, 2005.

68. FUKASAWA, T.; DENG, Z.Y.; ANDO, M.; OHJI, T.; KANZAKI, S. Synthesis of Porous Silicon Nitride with Unidirectionally Aligned Channels Using Freeze-Drying Process. J. Am. Ceram. Soc., v. 85, n.9, p. 2151 - 2159, 2002.

69. KONDO, N.; INAGAKI, Y.; SUZUKI, Y.; OHJI, T. Fabrication of porous anisotrophic silicon nitride by using partial sinter-forging technique. Mater. Sci. Eng. A, v. 335, p. 26 - 31, 2002.

70.DÍAZ, A.; HAMPSHIRE, S.; YANG, J-F.; OHJI, T.; KANZAKI, S. Comparison of Mechanical Properties of Silicon Nitrides with Controlled Porosities Produced by Different Fabrication Routes. J. Am. Ceram. Soc., v. 88, n.3, p. 698 - 706, 2005.

71. GENOVA, L.A. Efeito das variáveis de processamento nas características microestruturais e mecânicas do nitreto de silício, Tese de doutorado em Ciências na Área de Tecnologia Nuclear-Materiais, Instituto de Pesquisas Energéticas e Nucleares, São Paulo, 2003.

72. TONELLO, K.P.S. Compósitos à base de $\mathrm{Al}_{2} \mathrm{O}_{3}$, com adições de $\mathrm{NbC}$ e de $\mathrm{MgO}$, Dissertação de mestrado em Ciências na Área de Tecnologia Nuclear - Materiais, São Paulo, 2009.

73. YEHESKEL, O.; GEFEN, Y. The Effect of the a Phase on the Elastic Properties of $\mathrm{Si}_{3} \mathrm{~N}_{4}$. Mater. Sci. Eng., v. 71, p. 95 - 99, 1985. 